\title{
MATÉRIA SECA, CONCENTRAÇÃO E CONTEÚDO DE MACRONUTRIENTES EM MUDAS DE CLONES DE EUCALÍPTO, EM FUNÇÃO DA IDADE
}

MARCOS ANTONIO FABIANO DE CAMARGO

Engenheiro Florestal

Orientador: Prof. Dr. RONALDO IVAN SILVEIRA

Dissertação apresentada à Escola Superior de Agricultura "Luiz de Queiroz", Universidade de São" Paulo, para obtenção do título de Mestre, Área de Concentração: Solos e Nutrição de Plantas.

PIRACICABA

Estado de São Paulo - Brasil

Outubro - 1997 
Dados Internacionais de Catalogação na Publicação (CIP) DIVISÃO DE BIBLIOTECA E DOCUMENTAÇÃO - Campus "Luiz de Queiroz"/USP

Camargo, Marcos Antonio Fabiano de

Matéria seca, concentração e conteúdo de macronutrientes em mudas de clones de eucalipto, em função da idade / Marcos Antonio Fabiano de Camargo. - Piracicaba, 1997.

$94 \mathrm{p}$.

Dissertação (mestrado) - Escola Superior de Agricultura Luiz de Queiroz, 1997. Bibliografia.

1. Clone de eucalipto 2. Idade de planta 3. Macronutriente 4. Matéria seca 5. Muda de eucalipto 6 . Nutrição vegetal 1 . Titulo 


\title{
MATÉRIA SECA, CONCENTRAÇÃO E CONTEÚDO DE MACRONUTRIENTES EM MUDAS DE CLONES DE EUCALÍPTO, EM FUNÇÃO DA IDADE
}

\author{
MARCOS ANTONIO FABIANO DE CAMARGO
}

Aprovada em: 28.11.1997

Comissão julgadora:

Prof. Dr. Ronaldo Ivan Silveira

Prof. Dr. José Leonardo de Moraes Gonçalves

Prof. Dr. Helio Grassi Filho
ESALQ/USP

ESALQ/USP

FCAVUNESP

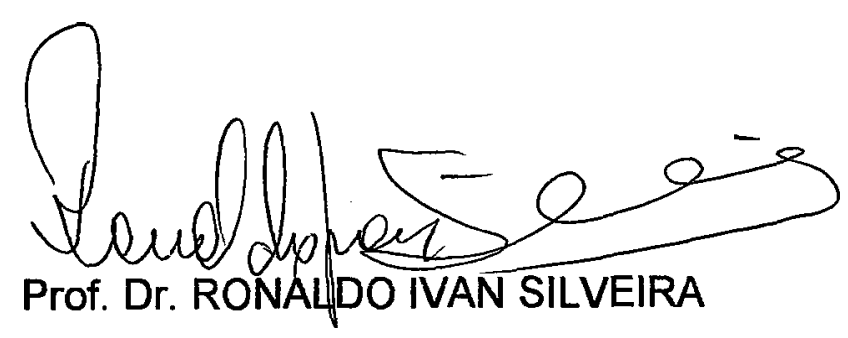

Orientador 
Aos meus pais, pelo que sou

Aos meus irmãos, pela amizade

A minha tia, pelo carinho,

OFEREÇO

A MARISA e aos nossos filhos MARCOS VINÍCIUS e VICTOR, 


\section{AGRADECIMENTOS}

Ao Prof. Dr. Ronaldo Ivan Silveira pela orientação deste trabalho e amizade sincera;

Ao Prof. Dr. Salim Simão pelo apoio na minha vida acadêmica;

A Companhia Suzano de Papel e Celulose pela doação do material e apoio financeiro para a realização das coletas e analises químicas;

Ao amigo Ronaldo Luiz Vaz de Arruda Silveira pelo apoio e companheirismo prestados na realização deste trabalho;

A Prof ${ }^{a}$. Liciana de Arruda Silveira Chalitta pela ajuda na realização das análises estatísticas;

A Denise Aparecida Gonçalves Oliveira pelas sugestões e digitação final deste trabalho;

Aos colegas e professores do Departamento de Ciência do Solo, pelo apoio e incentivo;

Aos Professores do Curso de Solos e Nutrição de Plantas, pelos ensinamentos e demais colegas e pessoas que direta ou indiretamente colaboraram na realização desse trabalho;

Ao Conselho Nacional de Desenvolvimento Científico e Tecnológico (CNPq) pela concessão da bolsa de estudo. 


\section{SUMÁRIO}

Página

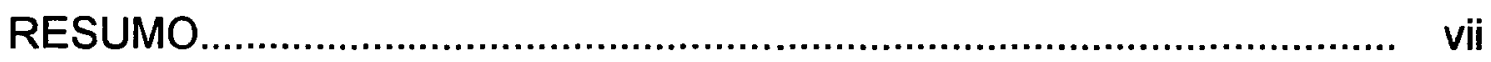

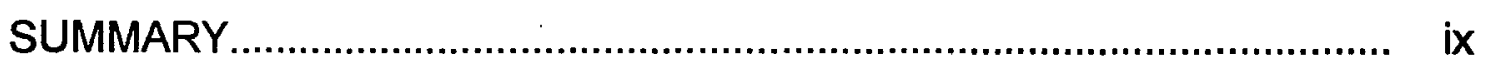

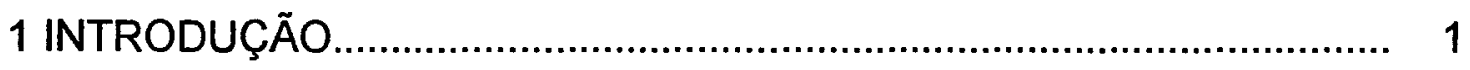

2 REVISÃO DE LITERATURA......................................................... 3

2.1 Estado nutricional......................................................................... 3

2.2 Adubação................................................................................ 3

3 MATERIAL E MÉTODOS............................................................. 10

3.1 Localização do Experimento............................................................. 10

3.2 Espécies estudadas, tratamento e manejo utilizado........................... 10

3.3 Delineamento experimental......................................................... 12

3.4 Determinações no material vegetal.................................................. 12

4 RESULTADOS E DISCUSSÃO....................................................... 14

4.1 Produção de matéria-seca............................................................ 14

4.2 Macronutrientes..................................................................... 21

4.2.1 Nitrogênio........................................................................... 21

4.2.1.1 Concentração........................................................................ 21

4.2.1.2 Acúmulo......................................................................... 24

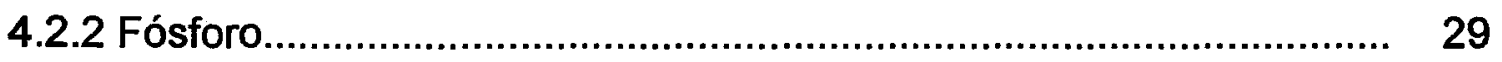

4.2.2.1 Concentração........................................................................ 29

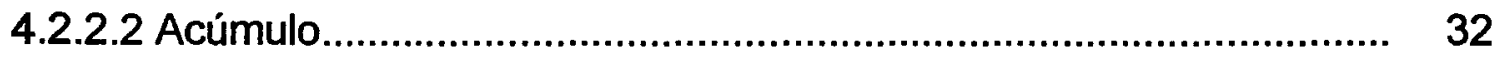

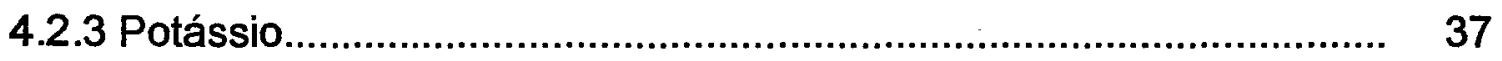

4.2.3.1 Concentração....................................................................... 37

4.2.3.2 Acúmulo.................................................................... 40

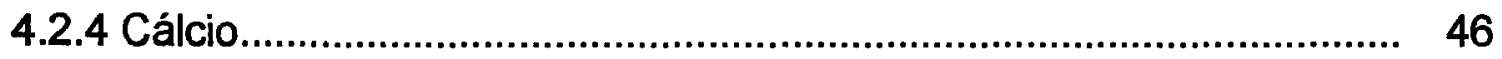


Página

4.2.4.1 Concentração....................................................................... 46

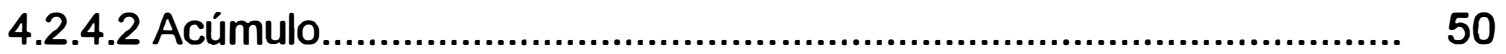

4.2.5 Magnésio.............................................................................. 54

4.2.5.1 Concentração....................................................................... 54

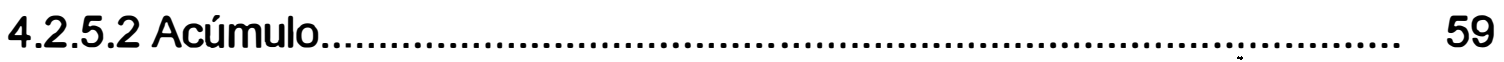

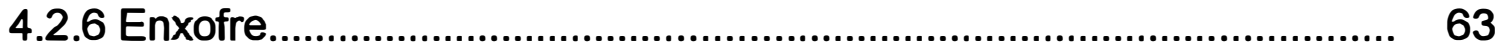

4.2.6.1 Concentração........................................................................ 63

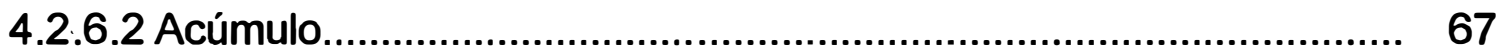

4.2.7 Considerações gerais................................................................... 71

5 CONCLUSÕES............................................................................ 78

REFERÊNCIAS BIBLIOGRÁFICAS............................................... 80

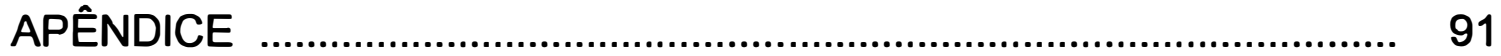




\title{
MATÉRIA SECA, CONCENTRAÇÃO E CONTEÚDO DE MACRONUTRIENTES EM MUDAS DE CLONES DE EUCALÍPTO, EM FUNÇÃO DA IDADE
}

\author{
Autor: MARCOS ANTONIO FABIANO DE CAMARGO \\ Orientador: Prof. Dr. RONALDO IVAN SILVEIRA
}

RESUMO

Mudas de quatro clones de Eucalyptus (Três E. grandis e um híbrido de E. grandis $x$ E. urophylla), cultivadas no viveiro da Cia Suzano de Papel e Celulose, SP, foram coletadas nas idades de 0 (estaca), 15, 30, 45, 60, 75 e 90 dias, seus componentes (folhas, caule e raizes) foram separados, pesados e analisados quimicamente com o objetivo de quantificar a produção da matéria seca, conteúdo e as concentrações totais de $\mathrm{N}, \mathrm{P}, \mathrm{K}, \mathrm{Ca}, \mathrm{Mg}$ e $\mathrm{S}$ nas mudas.

A produção de matéria seca aumentou com a idade das mudas. A distribuição das quantidades na planta obedeceu a seguinte ordem: caule >. folhas > raízes, nos quatro clones estudados.

A concentração dos macronutrientes nos tecidos dos vários componentes das mudas tenderam a decrescer com a idade.

As maiores concentrações dos nutrientes foram observados nas folhas, exceto para o magnésio, que apresentou teores elevados nas raízes. 
O nitrogênio foi o nutriente com as maiores concentrações em todas as partes da planta.

A ordem relativa das concentrações de nutrientes nas folhas foi: $N>$ $\mathrm{K}>\mathrm{Ca}>\mathrm{Mg}>\mathrm{P}>\mathrm{S}$, para os clones de $\mathrm{E}$. grandis $\mathrm{e}: \mathrm{N}>\mathrm{K}>\mathrm{Ca}=\mathrm{Mg}>\mathrm{P}>$ $S$, para o clone hibrido de $E$. grandis $x E$. urophylla. Para o caule a ordem foi: $\mathrm{K}>\mathrm{N}>\mathrm{Ca}>\mathrm{Mg}>\mathrm{P}>\mathrm{S}$, para todos os clones estudados. As raízes apresentaram a seguinte ordem: $\mathrm{Mg}>\mathrm{K}>\mathrm{N}>\mathrm{Ca}>\mathrm{P}=\mathrm{S}$, para dois dos clones de $\mathrm{E}$. grandis, $\mathrm{Mg}>\mathrm{N}>\mathrm{K}>\mathrm{Ca}>\mathrm{S}>\mathrm{P}$ e $\mathrm{Mg}>\mathrm{K}>\mathrm{N}>\mathrm{Ca}>\mathrm{S}>\mathrm{P}$ para um dos clones de $E$. grandis e $E$. grandis $\times E$. urophylla respectivamente.

Considerando o maior acúmulo, aos 90 dias de idade, $0 \mathrm{~N}$ foi 0 nutriente mais extraído, seguido em ordem decrescente pelo $\mathrm{K}, \mathrm{Mg}, \mathrm{Ca}, \mathrm{Pe}$ $S$, com exceção de um dos clones de $E$. grandis, cuja sequência foi a seguinte: $\mathrm{N}, \mathrm{K}, \mathrm{Ca}, \mathrm{Mg}, \mathrm{P}$ e $\mathrm{S}$. 


\title{
DRY MATTER, MACRONUTRIENTS \\ CONCENTRATION AND CONTENT IN EUCALYPTUS CLONE SEEDLINGS, ACCORDING TO THE AGE
}

\author{
Author: MARCOS ANTONIO FABIANO DE CAMARGO \\ Adviser: Prof. Dr. RONALDO IVAN SILVEIRA
}

\section{SUMMARY}

Seedling of four Eucalyptus clone (Three E. grandis and one hybrid $E$. grandis $\times$ E. urophylla), were cultivated on nursery. The material was collected in the ages of 0 (stake), 15, 30, 45, 60, 75 and 90 days, Leaves, stem and roots were weighted and chemically analyzed in order to obtain the yield, dry matter and total concentration of $\mathrm{N}, \mathrm{P}, \mathrm{K}, \mathrm{Ca}, \mathrm{Mg}$ and $\mathrm{S}$.

The dry matter yield increased according the age of the seedlings. The distribution of the amounts along the plant obeyed the following pattern: stem $>$ leaves $>$ roots.

The macronutrients concentration in the tissues of the several components on the seedlings trended to decreased with the age. The highest concentrations of the nutrients were observed in the leaves, except for $\mathrm{Mg}$ which showed high contents in the roots. Nitrogen was the nutrient with the highest concentrations in all parts of the plant.

The relative order of nutrient concentrations in the leaves was: $N>K>$ $\mathrm{Ca}>\mathrm{Mg}>\mathrm{P}>\mathrm{S}$, for the $\mathrm{E}$. grandis clone and: $\mathrm{N}>\mathrm{K}>\mathrm{Ca}=\mathrm{Mg}>\mathrm{P}>\mathrm{S}$, for 
E. grandis $\times$ E. urophylla hibrid clone. For the stem the order was: $\mathrm{K}>\mathrm{N}>\mathrm{Ca}$ $>\mathrm{Mg}>\mathrm{P}>\mathrm{S}$, for all the clone. In the roots the order was: $\mathrm{Mg}>\mathrm{K}>\mathrm{N}>\mathrm{Ca}>$ $\mathrm{P}=\mathrm{S}$, for two clones of $\mathrm{E}$. grandis, $\mathrm{Mg}>\mathrm{N}>\mathrm{K}>\mathrm{Ca}>\mathrm{S}>\mathrm{P}$ and $\mathrm{Mg}>\mathrm{K}>\mathrm{N}$ $>\mathrm{Ca}>\mathrm{S}>\mathrm{P}$ for one of the $E$. grandis clone and $E$. grandis $\times E$. urophylla, respectively.

Considering the higher accumulation, at the 90 days, the $\mathrm{N}$ was the most extracted nutrient, followed by the $\mathrm{K}, \mathrm{Mg}, \mathrm{Ca}, \mathrm{P}$ and $\mathrm{S}$. The sequence for $E$. grandis clones was the following: $\mathrm{N}, \mathrm{K}, \mathrm{Ca}, \mathrm{Mg}, \mathrm{P}$ and $\mathrm{S}$. 


\section{INTRODUÇÃO}

Pertencente à família das mirtáceas, o gênero Eucalyptus possui cerca de quinhentas espécies. Originário da Austrália, foi introduzido no Brasil em meados do século dezenove, a princípio com o objetivo de garantir abastecimento de lenha, dormentes e postes, para a Companhia Paulista de Estradas de Ferro.

Os incentivos fiscais concedidos pelo governo a área agrícola e extendida ao setor florestal, tornaram o plantio do Eucalyptus economicamente viável e de grande importância para o Brasil, em virtude do seu rápido crescimento, da sua produtividade e das suas várias aplicações; Dentre elas: a utilização da madeira na produção de carvão para fornos siderúrgicos, indústrias de celulose e papel, construção civil, dormentes, chapas e aglomerados, etc.

A expansão e reformas das áreas reflorestadas com Eucalyptus promove crescente demanda de mudas. Aumentar a produção de mudas, melhorar sua qualidade, produzindo-as no menor tempo possivel, são valores fundamentais para o êxito de um programa de reflorestamento.

A utilização de técnicas inadequađlas para se produzir mudas de Eucalyptus, pode prejudicar todo um programa de reflorestamento. A muda, como produto final do trabalho do viveiro, traz consigo caracteristicas distintas, uma vez que, a manutenção e melhoria do sistema de produção determina todo o dinamismo do viveiro florestal, justificando uma busca constante de novas técnicas para obtenção de melhor qualidade das mudas. 
A importância econômica da cultura do Eucalyptus no Brasil, tem proporcionado estudos detalhados sobre extração e exportação de nutrientes pelas espécies, fornecendo subsídios para se estabelecer programas de adubação adequados.

O presente trabalho teve como objetivo, determinar em mudas de Eucalyptus, a produção de matéria seca, a concentração e o acúmulo de macronutrientes nas diversas partes da planta, em função da idade. 


\section{REVISÃo DE LITERATURA}

\subsection{Estado nutricional}

O equilibrio nutricional de uma planta é um dos fatores necessários para que ocorra o seu desenvolvimento. Kramer \& Koslowski (1960) citaram o estado nutricional como um fator importante na fisiologia das plantas, uma vez que o suprimento adequado dos minerais é essencial para o sucesso do crescimento. Jacob \& Uexkull (1961) consideraram nutrientes para as plantas todos os elementos necessários ao crescimento e à produção de substâncias orgânicas.

Segundo Balloni (1984), a integração entre a experimentação, análise do solo ou substrato e análise foliar, podem fornecer os subsídios para uma orientação segura das necessidades nutricionais das espécies florestais.

\subsection{Adubação}

A necessidade cada vez maior de mudas e suas características para resistir às condições adversas das áreas utilizadas para os reflorestamentos, tem crescido, exigindo mais pesquisas, preocupadas com um maior controle na qualidade das mesmas (Ferreira, 1984).

A obtenção de mudas de espécies florestais, de boa qualidade e a baixo custo, é um dos fatores importantes para o sucesso do futuro povoamento florestal, refletindo na produtividade e qualidade da madeira. Estudos relativos a recipientes, substratos e à sua fertilização têm sido feitos, principalmente, para espécies como as do gênero Eucalyptus (Simões, 1970; Brasil \& Simões, 1973; Gomes et al., 1978; Campinhos Júnior \& Ikemori, 1983; Campinhos Júnior et al., 1984; Locatelli, 1984a, 1984b; Machado et al., 1988; Gomes et al., 1991). 
A resposta das mudas de eucalipto, a adubação de NPK, tem sido estudada por muitos pesquisadores (Karschon, 1961; Mello et al., 1961; Brandi et al., 1971, 1977a, 1977b; Barros et al., 1975, 1981a; Novais et al., 1979; Gomes \& Couto, 1984). Barros et al. (1982) afirmaram que as exigências nutricionais do eucalipto, na fase de mudas, são inferiores às estabelecidas para outras culturas agrícolas.

A fertilização nitrogenada, geralmente promove ganhos no crescimento de mudas de eucalipto, controlando ainda, o ritmo de crescimento, o tamanho e o vigor das mudas (Neves et al., 1990).

Respostas positivas à adubação fosfatada em mudas de eucalipto tem sido generalizados. Na maioria das vezes, quando o fósforo não é aplicado ao substrato, as mudas não se desenvolvem (Neves et al., 1990). Brandi et al., (1977a), avaliando os efeitos de NPK no crescimento de mudas de Eucalyptus citriodora, observaram que o fósforo foi o nutriente que mais contribuiu para o crescimento das mudas, indicando que bons resultados poderiam ser obtidos somente com a aplicação do mesmo.

A utilização de fertilizantes nitrogenados e fosfatados, que contém enxofre, como o sulfato de amônio e o superfosfato simples e o uso de substratos com elevados teores de matéria orgânica, considerada como um reservatório de enxofre, explicam a freqüente ausência de respostas à aplicação de enxofre (Neves et al., 1990).

Segundo Novais et al. (1980), o nível crítico de $\mathrm{K}$ no solo, para mudas de Eucalyptus grandis, situou-se abaixo de $9 \mathrm{mg} \mathrm{kg}^{-1}$ para solos pobres em $\mathrm{Ca}^{2+}$ e $\mathrm{Mg}^{2+}$, para Eucalyptus cloeziana, após a calagem, entre 11 e $31 \mathrm{mg} \mathrm{kg}^{-1}$ de K. De acordo com Barros et al. (1981b), o teor de $\mathrm{K}$ no solo deverá ser igual, ou superior a $30 \mathrm{mg} \mathrm{kg}^{-1}$, quando $\left(\mathrm{Ca}^{2+}+\mathrm{Mg}^{2+}\right)$ for superior a $8 \mathrm{mmol}_{\mathrm{c}} \mathrm{kg}^{-1} \mathrm{e}$, ou, a relação Ca:Mg for próxima de um. Prezotti (1985) observou que o nivel crítico de $\mathrm{K}$ no solo, para mudas de eucalipto, varia com o volume de solo utilizado. Quando se utilizam pequenos volumes de solo, as mudas crescem normaimente até um determinado estádio, quando então o potássio tornou-se 
fator limitante, em virtude do pequeno volume de solo explorado pelas raízes, havendo resposta da muda a qualquer adição de potássio que se faça nestas condições.

Neves et al. (1982) constataram elevada tolerância do eucalipto aos teores de $\mathrm{Al}, \mathrm{Mn}$ e $\mathrm{Fe}$, propondo a calagem para a cultura do eucalipto, corrigindo a acidez dos solos, não seja necessária para a maioria deles. Novais et al. (1979) recomendaram a calagem para o eucalipto, apenas para solos com teores menores a 2,5 $\mathrm{mmol}_{\mathrm{c}} \mathrm{kg}^{-1}\left(\mathrm{Ca}^{2+}+\mathrm{Mg}^{2+}\right)$.

Vários trabalhos têm sido conduzidos com o objetivo de avaliar a produção, distribuição da biomassa e nutrientes, em diversas espécies de Eucalyptus, conforme revisto por Reis \& Barros (1990). Esses estudos, na sua maioria, foram realizados em povoamentos de idade única (Haag et al., 1961b, 1976 e 1977; Rocha Filho et al., 1978; Silva, 1983; Poggiani \& Couto, 1983; Poggiani et al., 1983; Pereira, 1990; Morais et al., 1990; Santana, 1994) ou dentro da dinâmica seqüencial do crescimento dos povoamentos (Bellote, 1979; Reis et al., 1985; Reis et al., 1987; Teixeira et al., 1989).

Nesses trabalhos realizados em povoamentos de eucaliptos, pode-se destacar alguns para efeito de comparação aos teores dos nutrientes em mudas, como veremos nas próximas páginas. Haag et al. (1961b) estudaram plantas de Eucalyptus alba e Eucalyptus grandis, com dois anos de idade, situados em solo de cerrado. As análises quimicas mostraram as seguintes concentrações $\left(\mathrm{g} \mathrm{kg}^{-1}\right)$ nas diferentes partes da planta para $E$. alba: Folhas 20,7 de $\mathrm{N} ; 1,9$ de $\mathrm{P} ; 10,4$ de $\mathrm{K} ; 12,8$ de $\mathrm{Ca}$ e 4,3 de $\mathrm{Mg}$. Galhos ou ramos - 6,7 de $\mathrm{N} ; 1,3$ de $\mathrm{P} ; 8,3$ de $\mathrm{K} ; 11,4$ de Ca e 2,4 de Mg. Caule - 4,1 de N; 0,6 de P; 3,5 de K; 9,1 de Ca e 1,9 de Mg. Raiz - 5,4 de N; 0,7 de P; 4,3 de K; 9,2 de Ca e 2,1 de $\mathrm{Mg}$. Os teores encontrados para o E. grandis foram : Folhas - 22,2 de $\mathrm{N} ; 1,7$ de $\mathrm{P} ; 11,4$ de $\mathrm{K} ; 11,5$ de Ca e 4,4 de Mg. Galhos ou ramos - 5,5 de N; 0,9 de P; 5,7 de K; 10,6 de Ca e 2,1 de Mg. Caule - 3,9 de N; 0,6 de P; 4,8 de K; 9,2 de Ca e 2,0 de Mg. Raiz - 6,0 de N; 1,0 de $P ; 4,2$ de $K ; 10,1$ de Ca e 2,3 de 
$M g$. Através dos resultados obtidos, os autores observaram que o $E$. alba e o $E$. grandis são mais exigentes em $\mathrm{Ca}, \mathrm{N}$ e $\mathrm{K}$ e menos em $\mathrm{Mg}$ e $\mathrm{P}$.

Em dois povoamentos de Eucalyptus grandis com 7 anos de idade, cultivados em solos do município de Mogi-Guaçu, Estado de São Paulo, Haag et al. (1976), encontraram através de análise química, os seguintes teores foliares, respectivamente em função dos tipos de solo : 22,6 e $19,7 \mathrm{~g} \mathrm{~kg}^{-1}$ de $\mathrm{N}$; 1,2 e $1,1 \mathrm{~g} \mathrm{~kg}^{-1}$ de $\mathrm{P} ; 5,8$ e $3,8 \mathrm{~g} \mathrm{~kg}^{-1}$ de $\mathrm{K} ; 3,8$ e $4,1 \mathrm{~g} \mathrm{~kg}^{-1}$ de Ca; 1,5 e $1,5 \mathrm{~g}$ $\mathrm{kg}^{-1}$ de $\mathrm{Mg}$ e 2,4 e $2,6 \mathrm{~g} \mathrm{~kg}^{-1}$ de S.

A concentração dos nutrientes nas diferentes partes da planta, obedece a seguinte ordem decrescente : folhas, casca, ramos, lenho e raízes (Curlin, 1970).

Com relação às mudas de eucalipto, experimentos foram realizados visando o estabelecimento de métodos para o desenvolvimento e produção. Entre eles foi realizado um ensaio por Will (1961) o qual utilizou as espécies Eucalypus pilularis, Eucalypus botryoides e Eucalypus saligna em condições de viveiro e em solução nutritiva com a finalidade de verificar a concentração de $N$, $\mathrm{P}$ e $\mathrm{K}$ nas folhas dessas espécies na ausência e presença dos respectivos elementos, obtendo os seguintes resultados: $E$. pilulares $-12,4$ e $16,6 \mathrm{~g} \mathrm{~kg}^{-1}$ de $\mathrm{N} ; 0,8$ e $2,4 \mathrm{~g} \mathrm{~kg}^{-1}$ de $\mathrm{P}$ e 3,5 e $19,0 \mathrm{~g} \mathrm{~kg}^{-1}$ de $\mathrm{K}$. E. botryoides $-14,0$ e $18.1 \mathrm{~g}$ $\mathrm{kg}^{-1}$ de $\mathrm{N} ; 0,8$ e 1,6 $\mathrm{g} \mathrm{kg}^{-1}$ de $\mathrm{P}$ e 3,6 e 16,0 $\mathrm{g} \mathrm{kg}^{-1}$ de $\mathrm{K}$. E. saligna - 17,0 e 19,0 $\mathrm{g} \mathrm{kg}^{-1}$ de $\mathrm{N} ; 0,9$ e $2,2 \mathrm{~g} \mathrm{~kg}^{-1}$ de $P$ e 3,7 e $19,0 \mathrm{~g} \mathrm{~kg}^{-1}$ de $\mathrm{K}$. Concluiu que o $E$. saligna apresentou uma maior concentração de $\mathrm{N}$ quando comparado com as outras espécies estudadas, enquanto que para $P$ e $K$ as concentrações se eqüivaleram.

Haag et al. (1961a) realizaram estudos sobre a nutrição mineral do Eucalyptus alba desenvolvendo ensaio em vasos com areia lavada e solução nutritiva com o objetivo de estudar os efeitos das deficiências de macronutrientes no aspecto crescimento e composição química. Os resultados mostraram diferentes niveis do elemento nos tratamentos com omissão e 


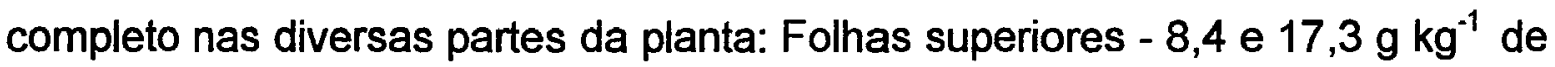
$\mathrm{N} ; 0,9$ e $1,2 \mathrm{~g} \mathrm{~kg}^{-1}$ de $\mathrm{P} ; 7,0$ e $11,3 \mathrm{~g} \mathrm{~kg}^{-1}$ de $\mathrm{K} ; 1,6$ e $3,0 \mathrm{~g} \mathrm{~kg}^{-1}$ de Ca; 2,1 e 5,2 $\mathrm{g} \mathrm{kg}^{-1}$ de $\mathrm{Mg}$ e 1,6 e $2,6 \mathrm{~g} \mathrm{~kg}^{-1}$ de S. Folhas inferiores $-8,9$ e $12,3 \mathrm{~g} \mathrm{~kg}^{-1}$ de $\mathrm{N}$; 0,5 e $1,0 \mathrm{~g} \mathrm{~kg}^{-1}$ de $\mathrm{P} ; 5,5$ e $9,5 \mathrm{~g} \mathrm{~kg}^{-1}$ de $\mathrm{K} ; 3,2$ e $3,4 \mathrm{~g} \mathrm{~kg}^{-1}$ de Ca; 2,1 e $5,1 \mathrm{~g}$ $\mathrm{kg}^{-1}$ de $\mathrm{Mg}$ e 0,9 e 2,6 $\mathrm{g} \mathrm{kg}^{-1}$ de S. Ramos $-6,1$ e $6,7 \mathrm{~g} \mathrm{~kg}^{-1}$ de $\mathrm{N} ; 0,5$ e 2,2 g $\mathrm{kg}^{-1}$ de $\mathrm{P} ; 4,0$ e $8,4 \mathrm{~g} \mathrm{~kg}^{-1}$ de $\mathrm{K} ; 3,8$ e $6,2 \mathrm{~g} \mathrm{~kg}^{-1}$ de Ca; 1,1 e $3,6 \mathrm{~g} \mathrm{~kg}^{-1}$ de $\mathrm{Mg} \mathrm{e}$ 1,6 e $1,9 \mathrm{~g} \mathrm{~kg}^{-1}$ de S. Caule- 5,0 e $5,6 \mathrm{~g} \mathrm{~kg}^{-1}$ de $\mathrm{N} ; 0,4$ e $1,3 \mathrm{~g} \mathrm{~kg}^{-1}$ de $\mathrm{P} ; 2,0 \mathrm{e}$ $7,5 \mathrm{~g} \mathrm{~kg}^{-1}$ de $\mathrm{K} ; 1,4$ e $2,4 \mathrm{~g} \mathrm{~kg}^{-1}$ de Ca; 1,4 e $2,7 \mathrm{~g} \mathrm{~kg}^{-1}$ de $\mathrm{Mg}$ e 0,1 e $1,5 \mathrm{~g}$ $\mathrm{kg}^{-1}$ de S. Raiz - 5,6 e $6,1 \mathrm{~g} \mathrm{~kg}^{-1}$ de N; 0,5 e $1,8 \mathrm{~g} \mathrm{~kg}^{-1}$ de $\mathrm{P} ; 2,5$ e $5,5 \mathrm{~g} \mathrm{~kg}^{-1}$ de $\mathrm{K} ; 0,8$ e 2,2 $\mathrm{g} \mathrm{kg}^{-1}$ de Ca; 1,3 e 2,8 $\mathrm{g} \mathrm{kg}^{-1}$ de $\mathrm{Mg}$ e 0,4 e $1,8 \mathrm{~g} \mathrm{~kg}^{-1}$ de S. Os autores concluíram que comparando com os resultados analíticos obtidos no presente experimento com os provenientes de material cultivado em condições de campo (Haag et al.,1961b) os primeiros podem ser utilizados para o reconhecimento de deficiências minerais nas plantações de eucaliptos.

Objetivando avaliar a composição química de um eucalipto híbrido na fase inicial de desenvolvimento e cultivado em solução nutritiva com omissão de $\mathrm{N}, \mathrm{P}, \mathrm{K}, \mathrm{Ca}, \mathrm{Mg}$ e S e na presença de todos os nutrientes, Kaul et al. (1966) encontraram os seguintes resultados, respectivamente : 12,0 e $19,7 \mathrm{~g} \mathrm{~kg}^{-1}$ de $\mathrm{N}$; 2,0 e 3,4 $\mathrm{g} \mathrm{kg}^{-1}$ de $\mathrm{P} ; 11,8$ e 22,9 $\mathrm{g} \mathrm{kg}^{-1}$ de $\mathrm{K} ; 6,6$ e $14,8 \mathrm{~g} \mathrm{~kg}^{-1}$ de Ca; 1,3 e 2,6 $\mathrm{g} \mathrm{kg}^{-1}$ de $\mathrm{Mg}$ e 14,0 e $14,8 \mathrm{~g} \mathrm{~kg}^{-1}$ de S. Em 1968, Kaul et al. desenvolveram o mesmo tipo de ensaio, entretanto, utilizando como espécie Eucalyptus grandis e obtiveram os seguintes resultados para os teores :11,5 e $23,8 \mathrm{~g} \mathrm{~kg}^{-1}$ de $\mathrm{N} ; 0,8$ e $2,1 \mathrm{~g} \mathrm{~kg}^{-1}$ de $\mathrm{P} ; 4,0$ e $8,0 \mathrm{~g} \mathrm{~kg}^{-1}$ de $\mathrm{K} ; 5,6$ e $8,4 \mathrm{~g} \mathrm{~kg}^{-1}$ de Ca; 1,2 e $2,9 \mathrm{~g} \mathrm{~kg}^{-1}$ de $\mathrm{Mg}$ e 1,7 e $3,3 \mathrm{~g} \mathrm{~kg}^{-1}$ de $\mathrm{S}$, respectivamente.

Rocha Filho et al. (1978) realizaram estudos com mudas de Eucalyptus urophylla, cultivadas em soluções nutritivas carente nos macronutrientes, com o objetivo de observar a influência da omissão e presença dos nutrientes sobre 0 crescimento e composição química das folhas superiores, medianas e inferiores, assim como do caule e raízes. Os resultados observados mostraram diferentes niveis do elemento nos tratamentos com omissão e presença nas 
diversas partes da planta, respectivamente: Folhas superiores - 7,2 e $26,7 \mathrm{~g}$ $\mathrm{kg}^{-1}$ de $\mathrm{N} ; 0,4$ e $2,2 \mathrm{~g} \mathrm{~kg}^{-1}$ de P; 0,9 e $17,8 \mathrm{~g} \mathrm{~kg}^{-1}$ de $\mathrm{K} ; 0,4$ e $6,4 \mathrm{~g} \mathrm{~kg}^{-1}$ de Ca; 0,4 e $1,7 \mathrm{~g} \mathrm{~kg}^{-1}$ de $\mathrm{Mg}$ e 0,5 e $1,1 \mathrm{~g} \mathrm{~kg}^{-1}$ de $\mathrm{S}$. Folhas medianas $-6,0$ e $31,6 \mathrm{~g} \mathrm{~kg}^{-1} \mathrm{de}$ $\mathrm{N} ; 0,3$ e 1,9 $\mathrm{g} \mathrm{kg}^{-1}$ de $\mathrm{P} ; 1,3$ e $18,8 \mathrm{~g} \mathrm{~kg}^{-1}$ de $\mathrm{K} ; 1,0$ e $8,0 \mathrm{~g} \mathrm{~kg}^{-1}$ de Ca; 0,4 e $1,3 \mathrm{~g}$ $\mathrm{kg}^{-1}$ de $\mathrm{Mg}$ e 0,6 e $1,0 \mathrm{~g} \mathrm{~kg}^{-1}$ de $\mathrm{S}$. Folhas inferiores $-6,9$ e $21,0 \mathrm{~g} \mathrm{~kg}^{-1} \mathrm{de} \mathrm{N} ; 0,4 \mathrm{e}$ $2,2 \mathrm{~g} \mathrm{~kg}^{-1}$ de P; 1,4 e $21,0 \mathrm{~g} \mathrm{~kg}^{-1}$ de $\mathrm{K} ; 2,2$ e $13,0 \mathrm{~g} \mathrm{~kg}^{-1}$ de Ca; 0,5 e $1,9 \mathrm{~g} \mathrm{~kg}^{-1}$ de $\mathrm{Mg}$ e 0,7 e 0,8 $\mathrm{g} \mathrm{kg}^{-1}$ de S. Caule - 3,2 e 12,3 $\mathrm{g} \mathrm{kg}^{-1}$ de $\mathrm{N} ; 0,4$ e $1,7 \mathrm{~g} \mathrm{~kg}^{-1}$ de $\mathrm{P}$; 0,8 e $12,8 \mathrm{~g} \mathrm{~kg}^{-1}$ de $\mathrm{K} ; 0,8$ e $9,4 \mathrm{~g} \mathrm{~kg}^{-1}$ de Ca; 0,1 e $1,1 \mathrm{~g} \mathrm{~kg}^{-1}$ de $\mathrm{Mg}$ e 0,2 e 0,4 g $\mathrm{kg}^{-1}$ de S. Raiz - 6,5 e 25,0 $\mathrm{g} \mathrm{kg}^{-1}$ de $\mathrm{N} ; 0,4$ e $6,8 \mathrm{~g} \mathrm{~kg}^{-1}$ de $P ; 0,8$ e $11,0 \mathrm{~g} \mathrm{~kg}^{-1}$ de $\mathrm{K} ; 0,1$ e $16,4 \mathrm{~g} \mathrm{~kg}^{-1}$ de $\mathrm{Ca} ; 0,1$ e $1,5 \mathrm{~g} \mathrm{~kg}^{-1}$ de $\mathrm{Mg}$ e 0,9 e $1,8 \mathrm{~g} \mathrm{~kg}^{-1}$ de $\mathrm{S}$. Verificaram que a omissão de nutrientes afetou sensivelmente o crescimento das plantas, exceção para o enxofre, que apresentou uma produção de matéria seca maior que a produzida pelas plantas cultivadas no tratamento completo. $O$ tratamento com omissão de nitrogênio foi o que mostrou maior efeito depressivo no crescimento. As plantas apresentaram sintomas de carência quando os niveis dos elementos nas folhas acusaram os seguintes valores em $\mathrm{g} \mathrm{kg}^{-1}: \mathrm{N}$ $(6,9) ; \mathrm{P}(0,4) ; \mathrm{K}(1,4)$; Ca $(0,4) ; \mathrm{Mg}(0,5)$ e $S(<0,5)$.

Silveira et al. (1995), trabalhando com mudas de Eucalyptus grandis, produzidas via sementes, aos 97 dias de idade, apresentaram a seguinte ordem para os teores de macronutrientes: folha $\left(9,7 \mathrm{~g} \mathrm{~kg}^{-1}\right)>$ raiz $\left(6,9 \mathrm{~g} \mathrm{~kg}^{-1}\right)>$ caule $\left(4,6 \mathrm{~g} \mathrm{~kg}^{-1}\right)$, para o elemento nitrogênio ; raiz $\left(2,9 \mathrm{~g} \mathrm{~kg}^{-1}\right)>$ caule $\left(2,7 \mathrm{~g} \mathrm{~kg}^{-1}\right)>$ folha $\left(1,5 \mathrm{~g} \mathrm{~kg}^{-1}\right)$, para o fósforo; folha = caule = raiz, $\left(12,0 \mathrm{~g} \mathrm{~kg}^{-1}\right)$ para 0 potássio; caule $\left(12,6 \mathrm{~g} \mathrm{~kg}^{-1}\right)>$ folha $\left(8,5 \mathrm{~g} \mathrm{~kg}^{-1}\right)>$ raiz $\left(7,3 \mathrm{~g} \mathrm{~kg}^{-1}\right)$, para o cálcio; raiz $\left(7,4 \mathrm{~g} \mathrm{~kg}^{-1}\right)>$ folha $\left(3,0 \mathrm{~g} \mathrm{~kg}^{-1}\right)>$ caule $\left(1,0 \mathrm{~g} \mathrm{~kg}^{-1}\right)$, para o magnésio; raiz $\left(1,1 \mathrm{~g} \mathrm{~kg}^{-1}\right)>$ folha $\left(0,6 \mathrm{~g} \mathrm{~kg}^{-1}\right)>$ caule $\left(0,5 \mathrm{~g} \mathrm{~kg}^{-1}\right)$ para 0 enxofre. 0 estudo também apresentou a seguinte ordem para 0 acúmulo total dos macronutrientes ( mg planta $\left.^{-1}\right): \mathrm{K}(15,0)>\mathrm{Ca}(12,0)>\mathrm{N}(9,6)>\mathrm{Mg}(3,5)>\mathrm{P}(3,4)>\mathrm{S}(1,7)$. 
As concentrações de macro e micronutrientes em folhas de Eucalyptus, aos noventa dias de idade, foram citadas por Dell et al. (1995), conforme pode ser observado na Tabela 1.

Tabela 1. Teor de nutrientes encontrados em folhas de Eucalyptus, aos 90 dias.

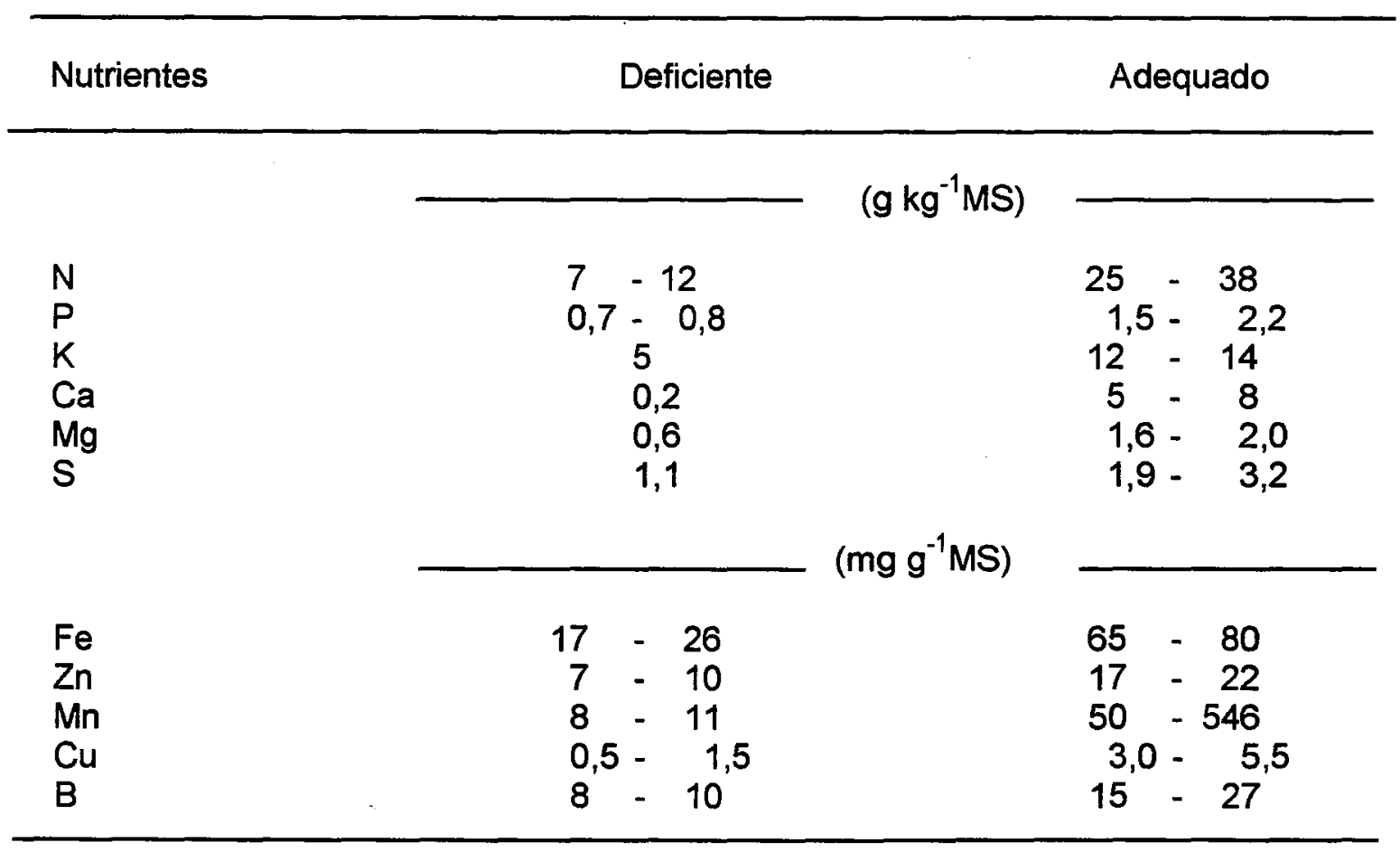

Fonte: Dell et al. (1995). 


\section{MATERIAL E MÉTODOS}

\subsection{Localização do experimento}

O experimento foi conduzido no viveiro da Companhia Suzano de Papel e Celulose, localizado no município de Alambari, região de Itapetininga, Estado de São Paulo, situado nas seguintes coordenadas geográficas: latitude $23^{\circ} 35^{\prime} \mathrm{S}$, longitude $48^{\circ} 03^{\prime} \mathrm{W}$.

\subsection{Espécies estudadas, tratamento e manejo utilizado}

Foram estudados quatro clones comerciais de eucaliptos, selecionados pela alta produtividade apresentada nos diferentes tipos de solos, ao longo do programa de melhoramento na empresa, sendo três Eucalyptus grandis (clones A7, C4 e D19) e um clone híbrido de Eucalyptus grandis x Eucalyptus urophylla (clone F40). As idades de avaliação foram: zero (0) (plantio da estaca); quinze (15); trinta (30); quarenta e cinco (45); sessenta (60); setenta e cinco (75) e noventa (90) dias, sendo que o plantio das estacas foi realizado no dia 06 de fevereiro e a última coleta realizada em 07/05/1996.

Os clones foram cultivados em tubetes de polipropileno com capacidade de $50 \mathrm{~cm}^{3}$, contendo substrato $(70 \%$ de vermiculita $+30 \%$ de palha de arroz cardonizada) cujas características químicas, segundo metodologia descrita por Kiehl (1985), são mostradas na Tabela 2. 
Tabela 2. Resultados da análise química do substrato utilizado no plantio das estacas dos clones de Eucalyptus estudados.

\begin{tabular}{lc|lc}
\hline & & & \\
Componentes analíticos & & \multicolumn{2}{l}{ Componentes analíticos } \\
\hline pH em CaCl $0,01 \mathrm{M}$ & 5,1 & M.O. compostada & \\
Umidade perdida a $60-65^{\circ} \mathrm{C}$ & $610,6 \mathrm{~g} \mathrm{~kg}^{-1}$ & M.O. resistente & $2,5 \mathrm{~g} \mathrm{~kg}^{-1}$ \\
Umid. perdida entre $65-110^{\circ} \mathrm{C}$ & $17,6 \mathrm{~g} \mathrm{~kg}^{-1}$ & Nitrogênio & $64,3 \mathrm{~g} \mathrm{~kg}^{-1}$ \\
Umid. total (natural) a $100-110^{\circ} \mathrm{C}$ & $628,2 \mathrm{~g} \mathrm{~kg}^{-1}$ & Fósforo (P) total & $0,5 \mathrm{~g} \mathrm{~kg}^{-1}$ \\
Mat. orgânica total (combustão) & $69,0 \mathrm{~g} \mathrm{~kg}^{-1}$ & Potássio (K) & $0,4 \mathrm{~g} \mathrm{~kg}^{-1}$ \\
Carbono total ( org. e mineral) & $38,2 \mathrm{~g} \mathrm{~kg}^{-1}$ & Cálcio (Ca) & $2,5 \mathrm{~g} \mathrm{~kg}^{-1}$ \\
Resíduo mineral e total & $303,0 \mathrm{~g} \mathrm{~kg}^{-1}$ & Magnésio (Mg) & $2,7 \mathrm{~g} \mathrm{~kg}^{-1}$ \\
Resíduo mineral insolúvel & $169,0 \mathrm{~g} \mathrm{~kg}^{-1}$ & Enxofre (S) & $31,4 \mathrm{~g} \mathrm{~kg}^{-1}$ \\
Resíduo mineral solúvel & $134,0 \mathrm{~g} \mathrm{~kg}^{-1}$ & Relação C/N (C total e N total) & $76 / 1$ \\
Carbono orgânico & $4,5 \mathrm{~g} \mathrm{~kg} \mathrm{~kg}^{-1}$ & Relação C/N (C org. e N total) & $9 / 1$ \\
\hline
\end{tabular}

Durante os primeiros trinta dias, as bandejas de suporte dos tubos contendo as mudas permaneceram em estufa, com luminosidade a $60 \%$ controlada por sombrites, com umidade e temperaturas constantes a $70-75 \%$ e $25-30^{\circ} \mathrm{C}$, respectivamente. Posteriormente, as mudas foram colocadas em bancadas fora da estufa, permanecendo com cobertura a $50 \%$ de luminosidade por mais dez dias e irrigadas diariamente, de acordo com a necessidade das mesmas. Durante o período de noventa dias, tempo utilizado para a produção das mudas, foram realizadas dezessete adubações, as quais totalizaram as seguintes quantidades de nutrientes (mg planta-1 $^{-1}$ ) : 17,81 de N; 2,46 de P; 9,34 de K; 17,00 de Ca; 3,38 de Mg; 2,13 de S; 1,00 de $\mathrm{Na}_{2} \mathrm{~B}_{4} \mathrm{O}_{7} .10 \mathrm{H}_{2} \mathrm{O} ; 0,48$ de $\mathrm{CuSO}_{4} .5 \mathrm{H}_{2} \mathrm{O} ; 0,80$ de $\mathrm{FeSO}_{4} .7 \mathrm{H}_{2} \mathrm{O}$; 0,25 de $\mathrm{MnSO}_{4} \cdot \mathrm{H}_{2} \mathrm{O}$ e 0,34 de $\mathrm{ZnSO}_{4} \cdot 5 \mathrm{H}_{2} \mathrm{O}$. 
Como prática convencional na empresa, aos 75 dias de idade, realizou-se uma limpeza (corte dos ramos laterais) nas mudas, com a finalidade de propiciar o desenvolvimento da brotação dominante.

\subsection{Delineamento experimental}

O delineamento experimental foi inteiramente casualizado, com quatro repetições, sendo considerado como parcela, a bandeja de suporte das mudas. Foram avaliadas noventa e seis (96) mudas de cada clone por parcela, em cada idade.

\subsection{Determinações no material vegetal}

O material coletado foi lavado em água desmineralizada, separado em folhas, caule e raizes, acondicionado em saco de papel e colocado em estufa com circulação de ar forçada $\left(T=60^{\circ}-65^{\circ} \mathrm{C}\right.$ ) até atingir peso constante. Após a determinação do peso da matéria seca, procedeu-se a moagem do material vegetal em moinho tipo Wiley, sendo submetidas às digestões nitro-perclórica e sulfúrica, segundo metodologia descrita por Sarruge \& Haag (1974), onde nos extratos, foram determinadas as concentrações totais dos elementos.

As determinações de nitrogênio foram realizadas pelo método analítico Kjeldahl (volumetria). O fósforo foi determinado por colorimetria pelo método vanadato-molibdato de amônia. Os teores de potássio, cálcio, magnésio foram determinados por espectrofotometria de absorção atômica. 
Para as determinações de enxofre, foi utilizado o método de turbidimetria da suspensão de sulfato de bário, após a adição de cloreto de bário (Tabatabai \& Bremer, 1970).

As variáveis utilizadas para avaliar os efeitos dos tratamentos foram a produção de matéria seca, concentração e acúmulo de macronutrientes $(\mathrm{N}$, $\mathrm{P}, \mathrm{K}, \mathrm{Ca}, \mathrm{Mg}$ e S) nos diferentes órgãos da planta. 


\section{RESULTADOS E DISCUSSÃO}

\subsection{Produção de material seco}

A diferença na produção de material seco nas diferentes partes e na planta inteira em função das idades, para os quatro clones de Eucalyptus estudados, estão na Tabela 3. Aos noventa dias, não houve variação significativa entre os clones para a produção de matéria seca das folhas. Verifica-se que o clone F40 apresentou menor produção de matéria seca para o caule $(71,43 ; 73,96$ e $76,69 \%)$ e total $(77,10 ; 75,31$ e $76,90 \%)$ quando comparado aos clones A7, C4 e D19, os quais não mostraram diferenças significativas entre si. A raiz foi o órgão da planta que apresentou maior variabilidade na produção de material seco entre os clones. A ordem de produção de matéria seca das raizes entre os clones foi: clone $\mathrm{C} 4=$ clone D19 > clone A7 > clone F40. Valores semelhantes para matéria seca das raízes, foram encontrados por Locatelli (1984) (119,0 $\mathrm{mg}$ planta $\left.^{-1}\right)$ em mudas de $E$. grandis aos 90 dias e superiores por Neves (1983) (291,0 mg planta-1) em mudas de E. grandis aos 100 dias de idade.

As médias dos dados mostraram ainda que ocorreu aumento na matéria seca das folhas, caule e raízes, sendo que as folhas e raízes apresentaram acréscimos percentuais a partir de sessenta dias, conforme pode ser observado na Tabela 4. 
Tabela 3. Produção de matéria seca, nas diversas partes da planta, nos clones de Eucalyptus estudados, em função da idade.

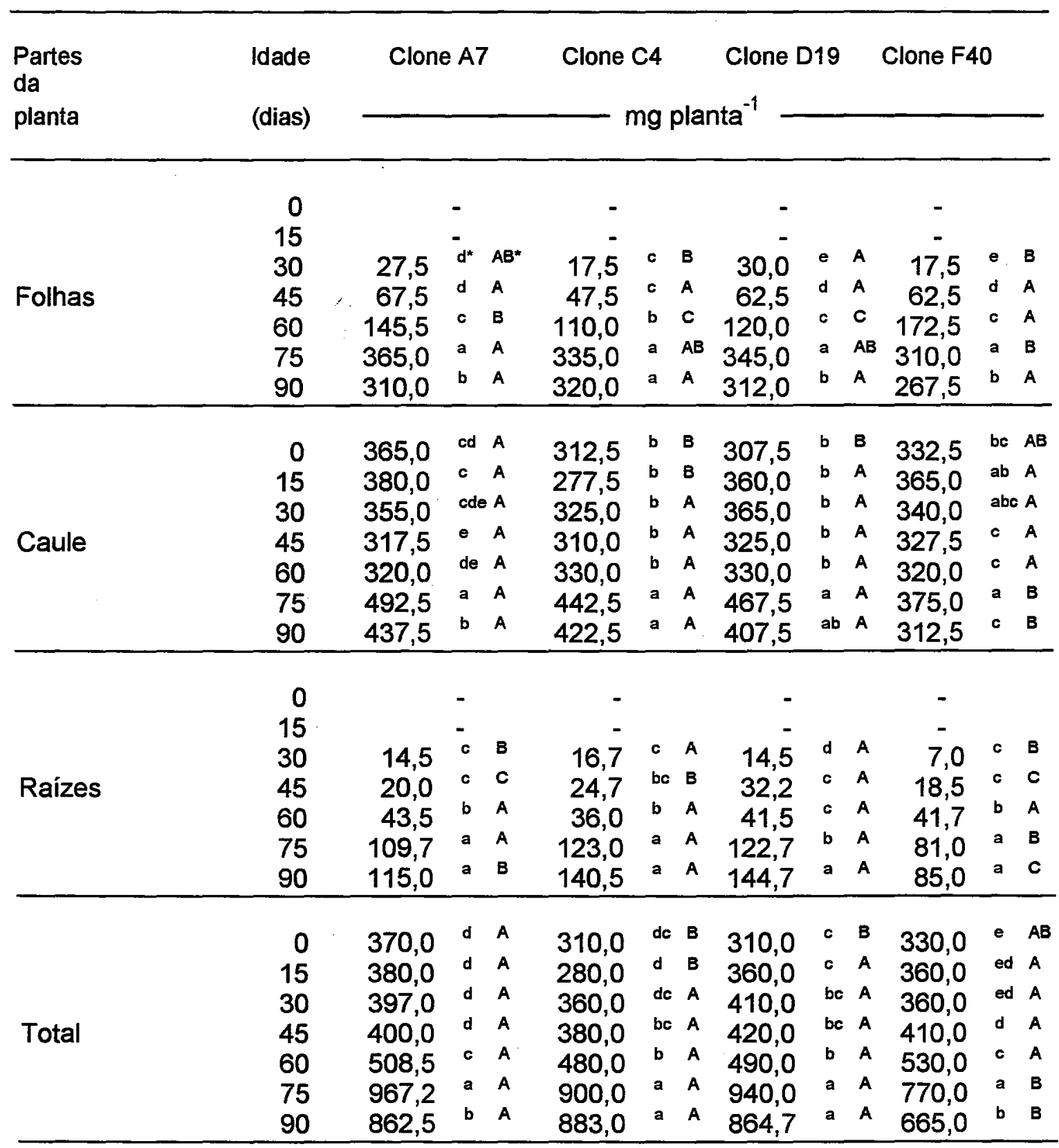

(*) OBS: Letras maiúsculas diferentes em cada linha e letras minúsculas diferentes em cada coluna, indicam diferença significativa ao nivel de $5 \%$ de probabilidade, entre clones e entre idades, respectivamente. 
O caule foi o órgão da planta que apresentou menores acréscimos de matéria seca durante o desenvolvimento da muda, no período de 90 dias, independente do clone estudado, sendo o clone F40, dentre os estudados, o que apresentou o menor acréscimo. Considerando a época de maior acúmulo de matéria seca no caule, observou-se que os aumentos percentuais ocorreu entre 0 e 75 dias, cujos valores foram de 35; 42; 52 e 13, para os clones A7, C4, D19 e F40, respectivamente (Tabela 4).

A diminuição da matéria seca das folhas $(15,07 ; 4,48 ; 9,56$ e 13,71\%) e do caule $(11,17 ; 4,52 ; 12,83$ e $16,67 \%)$, nos clones A7, C4, D19 e F40, respectivamente, nas datas entre setenta e cinco e noventa dias, foi conseqüência do manejo realizado nas mudas (poda) no qual retirou-se os ramos laterais, deixando apenas o ramo dominante. Entretanto a diminuição da matéria seca do caule, nas idades entre 15 e 60 dias (Tabela 4), ocorreram, no inicio, pela queda das duas meias folhas que fazem parte da estaca, no momento do plantio, com o decorrer dos dias; e pela variação dos diâmetros das estacas, uma vez que há variações no diâmetro dos ramos do eucalipto de onde foram retirados as estacas.

A folha foi o órgão que mais acumulou matéria seca durante o desenvolvimento da estaca (Figura 1). Os acréscimos percentuais de biomassa entre as idades de 30 e 75 dias (idade de maior acúmulo) foram elevados quando comparado ao caule, variando de $1.050 \%$ para o clone D19 a 1.914 \% para o clone C4. Para as raízes, os aumentos percentuais no período de 30 a 90 dias de idade foram elevadas, porém menores que as folhas, chegando a ser de 693, 741, 898 e 1.114 para os clones A7, C4, D19 e F40, respectivamente (Tabela 4). 
Tabela 4. Percentuais na produção de matéria seca nos clones de Eucalyptus estudados, em função da idade.

\begin{tabular}{|c|c|c|c|c|c|}
\hline \multirow{2}{*}{$\begin{array}{l}\text { Partes } \\
\text { da } \\
\text { planta }\end{array}$} & \multirow{2}{*}{$\begin{array}{l}\text { Idade } \\
\text { (dias) }\end{array}$} & Clone A7 & Clone C4 & \multirow{2}{*}{$\begin{array}{r}\text { Clone D19 } \\
\%\end{array}$} & \multirow[t]{2}{*}{ Clone F40 } \\
\hline & & & $\%$ & & \\
\hline Folhas & $\begin{array}{r}0 \\
15 \\
30 \\
45 \\
60 \\
75 \\
90 \\
\end{array}$ & $\begin{array}{r}- \\
- \\
100 \\
245 \\
527 \\
1327 \\
1127 \\
\end{array}$ & $\begin{array}{r}- \\
- \\
100 \\
271 \\
628 \\
1914 \\
1828 \\
\end{array}$ & $\begin{array}{c}- \\
- \\
100 \\
208 \\
400 \\
1150 \\
1042 \\
\end{array}$ & $\begin{array}{r}- \\
- \\
100 \\
357 \\
986 \\
1771 \\
1528 \\
\end{array}$ \\
\hline Caule & $\begin{array}{r}0 \\
15 \\
30 \\
45 \\
60 \\
75 \\
90 \\
\end{array}$ & $\begin{array}{r}100 \\
104 \\
97 \\
87 \\
88 \\
135 \\
120 \\
\end{array}$ & $\begin{array}{r}100 \\
89 \\
104 \\
99 \\
106 \\
142 \\
135 \\
\end{array}$ & $\begin{array}{l}100 \\
117 \\
119 \\
106 \\
107 \\
152 \\
132 \\
\end{array}$ & $\begin{array}{r}100 \\
110 \\
102 \\
98 \\
96 \\
113 \\
94 \\
\end{array}$ \\
\hline Raizes & $\begin{array}{r}0 \\
15 \\
30 \\
45 \\
60 \\
75 \\
90 \\
\end{array}$ & $\begin{array}{c}- \\
- \\
100 \\
138 \\
300 \\
756 \\
793 \\
\end{array}$ & $\begin{array}{c}- \\
- \\
100 \\
148 \\
215 \\
736 \\
841 \\
\end{array}$ & $\begin{array}{c}- \\
- \\
100 \\
222 \\
286 \\
846 \\
998 \\
\end{array}$ & $\begin{array}{r}- \\
100 \\
264 \\
596 \\
1157 \\
1214 \\
\end{array}$ \\
\hline Total & $\begin{array}{r}0 \\
15 \\
30 \\
45 \\
60 \\
75 \\
90\end{array}$ & $\begin{array}{l}100 \\
103 \\
107 \\
108 \\
137 \\
261 \\
233\end{array}$ & $\begin{array}{r}100 \\
90 \\
116 \\
122 \\
155 \\
290 \\
284 \\
\end{array}$ & $\begin{array}{l}100 \\
116 \\
132 \\
135 \\
158 \\
303 \\
277 \\
\end{array}$ & $\begin{array}{l}100 \\
109 \\
109 . \\
124 \\
161 \\
233 \\
203 \\
\end{array}$ \\
\hline
\end{tabular}

Considerando as médias dos clones estudados, calculou-se a produção de matéria seca das folhas, caules e raízes em relação a biomassa total. Aos 90 dias de idade, a variação percentual da matéria seca dos órgãos 
em relação ao total foi de 36,$9 ; 36,2 ; 36,1$ e 40,2 para as folhas, 50,$7 ; 47,8$; 47,1 e 47,0 para o caule e de 13,3; 15,9; 16,7 e 12,8 para as raízes, para os clones A7, C4, D19 e F40, respectivamente. Os resultados do presente trabalho são menores para as folhas e raízes e maiores para o caule, quando comparados com os obtidos por Silveira et al. (1995), que estudando a biomassa de folhas, caule e raízes, em mudas produzidas via sementes de Eucalyptus grandis, na idade de 97 dias, encontraram os valores de $47,0 \%$ para as folhas, $33,0 \%$ para o caule e de $20,0 \%$ para as raizes. Os resultados obtidos no presente estudo foram inferiores às médias encontradas por Araújo (1994) e Dantas (1992), para as produção de matéria seca da parte aérea (folhas + caule) e raízes, em mudas de $E$. grandis.

A tendência observada em povoamentos puros de eucalipto, como relatado por Pereira et al. (1984), com o passar dos anos, foi de apenas a biomassa do caule aumentar, em oposição as folhas que diminuem proporcionalmente, sem que tenha sido avaliado o sistema radicular. Entretanto, aos dezoito meses de idade, a produção de matéria seca da parte aérea de eucaliptos, cultivados em solos de cerrado, não apresentaram diferenças percentuais significativas nos diversos componentes avaliados (folhas, caule e ramos), segundo estudos realizados pelos mesmos autores.

Através da Tabela 5 e Figura 1, observa-se que a produção de matéria seca foliar, para os clones A7, C4, D19 e F40, das raízes nos clones A7 e F40 e para a produção de matéria seca total no clone F40 , ajustaramse a equações lineares. Para a produção de biomassa do caule nos clones A7 e C4, das raízes nos clones C4 e D19 ajustaram-se a equações do segundo grau, enquanto que para o caule, nos clones D19 e F40, não houve ajuste. 
Tabela 5. Equação de regressão para acúmulo de matéria seca (g planta ${ }^{-1}$ ), nas diversas partes da planta, para os clones de Eucalyptus estudados, em função da idade (dias).

Partes da planta Equação

R2 Prob.

C.V.

CLONE A7

Folhas

Caule

Raízes

$$
y=-0,1620+0,0057^{*} x
$$

$0,82<1 \%$

$0,48<1 \%$

$y=0,3780-0,0022^{*} X+0,00004^{*} X^{2}$

0,88

$y=-0,0686+0,0021^{*} x$

Total $y=0,3621-0,0019^{*} x+0,0001^{*} X^{2}$

0,81

$<1 \% \quad 19,48$

\section{CLONE C4}

\begin{tabular}{|c|c|c|c|c|}
\hline $\begin{array}{l}\text { Folhas } \\
\text { Caule } \\
\text { Raizes }\end{array}$ & $\begin{array}{l}y=-0,1910+0,0059^{*} X \\
y=0,3024-0,0006^{*} X+0,00003^{*} X^{2} \\
y=0,0246-0,0013^{*} X+0,00003^{*} X^{2}\end{array}$ & $\begin{array}{l}0,86 \\
0,68 \\
0,89\end{array}$ & $\begin{array}{l}<1 \% \\
<1 \% \\
<1 \%\end{array}$ & $\begin{array}{l}32,39 \\
10,85 \\
27,43\end{array}$ \\
\hline Total & $y=0,2993-0,0019^{*} x+0,0001^{*} x^{2}$ & 0,88 & $<1 \%$ & 17,73 \\
\hline \multicolumn{5}{|c|}{ CLONE D19 } \\
\hline $\begin{array}{l}\text { Folhas } \\
\text { Caule } \\
\text { Raízes }\end{array}$ & $\begin{array}{l}y=-0,1650+0,0056^{*} X \\
\text { não significativo } \\
y=0,0112-0,0007^{*} x+0,00003^{*} X^{2}\end{array}$ & $\begin{array}{l}0,85 \\
0,92\end{array}$ & $\begin{array}{l}<1 \% \\
<1 \%\end{array}$ & $\begin{array}{l}30,94 \\
21,93\end{array}$ \\
\hline Total & $y=0,3181-0,0001^{*} X+0,0001^{*} X^{2}$ & 0,83 & $<1 \%$ & 19,40 \\
\hline \multicolumn{5}{|c|}{ CLONE F40 } \\
\hline $\begin{array}{l}\text { Folhas } \\
\text { Caule } \\
\text { Raízes }\end{array}$ & $\begin{array}{l}y=-0,1330+0,0050^{*} X \\
\text { não significativo } \\
y=-0,0407+0,0015^{*} X\end{array}$ & $\begin{array}{l}0,86 \\
0,93\end{array}$ & $\begin{array}{l}<1 \% \\
<1 \%\end{array}$ & $\begin{array}{l}27,45 \\
19,51\end{array}$ \\
\hline Total & $y=0,2798+0,0047^{*} x$ & 0,79 & $<1 \%$ & 15,36 \\
\hline
\end{tabular}




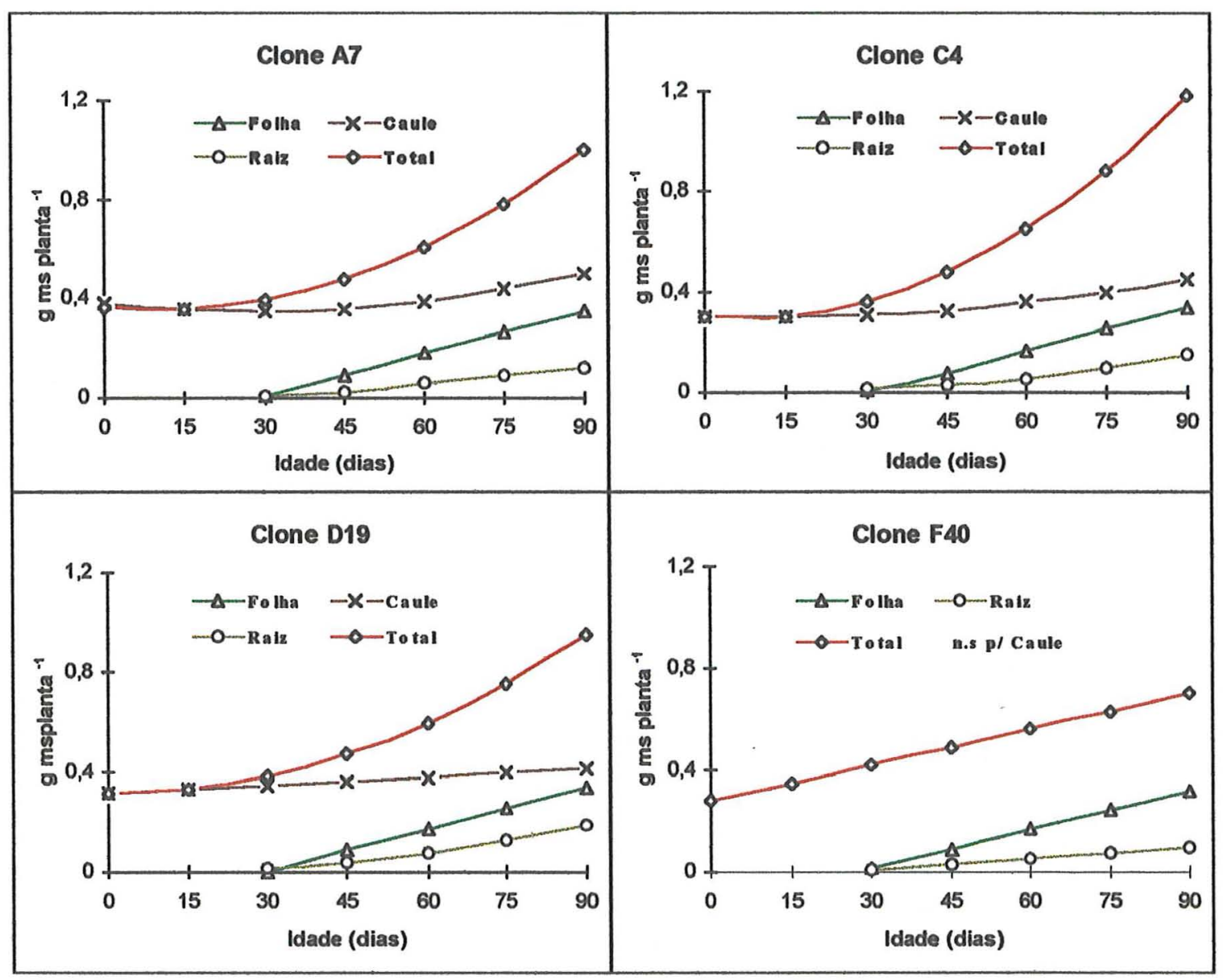

Figura 1 - Produção de matéria seca (g planta-1 ${ }^{-1}$ nas diversas partes e planta inteira, nos clones de Eucalyptus estudados, em função da idade (dias). 


\subsection{Macronutrientes}

\subsubsection{Nitrogênio}

\subsubsection{Concentração}

Aos noventa dias de idade, o clone A7 apresentou menores concentrações de nitrogênio nas folhas $(8,02 ; 5,80$ e $10,55 \%)$ quando comparado aos clones C4, D19 e F40, respectivamente, enquanto os mesmos não mostraram diferenças entre si, como podemos observar na Tabela 6. As concentrações de nitrogênio diminuíram com a idade das plantas, para todos os órgãos, com exceção das raízes nos clones C4 e D19. A mesma tendência de decréscimo do teor de nitrogênio em eucalipto, com a idade das mudas, foi verificado por Silveira et al., (1995), e também em plantios, em Minas Gerais, por Morais (1988) e Pereira (1990) e em São Paulo por Bellote (1979).

As diferenças de teor são mais acentuadas quando compara-se os tratamentos zero (estacas) e noventa dias para o caule, entre trinta e noventa dias para as folhas e raízes. Durante todo o desenvolvimento das mudas, as maiores concentrações de nitrogênio foram encontradas nas folhas e as menores nos caules. Aos noventa dias de idade observou-se que ocorreu variação significativa para o teor de nitrogênio nas folhas, para os clones A7 e F40 e para o caule no clone A7, em relação aos demais. Nas raízes, as variações ocorreram nos clones A7 e F40, em relação aos clones C4 e D19.

Nessa mesma idade, as concentrações de nitrogênio nos clones estudados variaram de 19,5 a $21,8 \mathrm{~g} \mathrm{~kg}^{-1}$ nas folhas; 8,7 a $12,6 \mathrm{~g} \mathrm{~kg}^{-1}$ nas raizes de 5,1 a $8,1 \mathrm{~g} \mathrm{~kg}^{-1}$ nos caules. 
Tabela 6. Concentração de nitrogênio, nas diversas partes da planta, nos clones de Eucalyptus estudados, em função da idade.

\begin{tabular}{|c|c|c|c|c|c|c|c|c|c|}
\hline \multirow{2}{*}{$\begin{array}{l}\begin{array}{l}\text { Partes } \\
\text { da } \\
\text { planta }\end{array} \\
\text { Folhas }\end{array}$} & \multirow{2}{*}{$\begin{array}{l}\text { Idade } \\
\text { (dias) } \\
0 \\
15 \\
30 \\
45 \\
60 \\
75 \\
90 \\
\end{array}$} & \multicolumn{2}{|c|}{ Clone A7 } & Clone C & \multicolumn{2}{|c|}{$\begin{array}{l}\mathrm{g} \mathrm{kg}^{-1} \\
-\end{array}$} & ne D19 & \multicolumn{2}{|c|}{ Clone F40 } \\
\hline & & $\begin{array}{c}- \\
- \\
21,6 \\
21,5 \text { a } \\
20,4 \text { a } \\
21,3 \text { a } \\
19,5 \text { a }\end{array}$ & $\begin{array}{l}B^{*} \\
B C \\
B \\
A \\
B\end{array}$ & $\begin{array}{ccc}- & & \\
- & & \\
26,2 & \text { a } & \text { A } \\
23,2 & \text { ab } & \text { A } \\
22,8 & \text { b } & \text { A } \\
14,7 & \text { c } & \text { B } \\
21,2 & \text { b } & \text { A } \\
\end{array}$ & $\begin{array}{l}A \\
A B \\
A B \\
B \\
A B\end{array}$ & $\begin{array}{l}- \\
- \\
22,6 \\
20,5 \\
24,5 \\
16,0 \\
20,7 \\
\end{array}$ & $\begin{array}{ll}a b & A B \\
b & C \\
a & A \\
c & B \\
b & A B \\
\end{array}$ & $\begin{array}{c}- \\
- \\
23,7 \text { ab } \\
24,3^{\text {a }} \\
24,0^{\text {ab }} \\
22,4 \text { ab } \\
21,8^{\text {b }} \\
\end{array}$ & $\begin{array}{l}A B \\
A \\
A \\
A \\
A\end{array}$ \\
\hline Caule & $\begin{array}{r}0 \\
15 \\
30 \\
45 \\
60 \\
75 \\
90 \\
\end{array}$ & $\begin{array}{r}12,2 \text { a } \\
11,4 \text { a } \\
7,9 \text { b } \\
7,7 \text { b } \\
6,2^{\text {bc }} \\
5,7 \text { c } \\
5,1^{c} \\
\end{array}$ & $\begin{array}{l}B \\
B \\
B \\
A \\
B \\
B \\
B\end{array}$ & $\begin{array}{r}15,0^{\text {a }} \\
11,5^{\text {b }} \\
7,6^{\circ} \\
8,1^{\circ} \\
9,4^{\circ} \\
5,2^{\text {d }} \\
8,1^{\circ} \\
\end{array}$ & $\begin{array}{l}\text { A } \\
B \\
B \\
A \\
A \\
B \\
A\end{array}$ & $\begin{array}{r}13,1 \\
11,7 \\
8,8 \\
8,3 \\
10,2 \\
5,5 \\
7,2 \\
\end{array}$ & $\begin{array}{ll}a & A \\
\text { ab } & B \\
\text { bcd } & B \\
\text { cd } & A \\
\text { abc } & A \\
\text { d } & B \\
\text { cd } & A \\
\end{array}$ & $\begin{array}{r}15,2^{\mathrm{a}} \\
14,5^{\mathrm{a}} \\
11,0^{\mathrm{b}} \\
8,6^{\mathrm{c}} \\
7,9^{\mathrm{cd}} \\
9,0^{\mathrm{c}} \\
6,8^{\mathrm{d}} \\
\end{array}$ & $\begin{array}{l}A \\
A \\
A \\
A \\
A B \\
A \\
A\end{array}$ \\
\hline Raízes & $\begin{array}{r}0 \\
15 \\
30 \\
45 \\
60 \\
75 \\
90 \\
\end{array}$ & $\begin{array}{c}- \\
- \\
14,1 \text { ab } \\
15,2 \text { a } \\
10,1 \text { cd } \\
11,9 \text { bc } \\
8,7 \text { d }\end{array}$ & $\begin{array}{l}\text { B } \\
\text { A } \\
\text { B } \\
\text { A } \\
\text { B }\end{array}$ & $\begin{aligned}- & \\
- & \\
11,0 & \text { bc } \\
12,1 & \text { b } \\
14,8 & \text { a } \\
9,4 & \text { c } \\
12,6 & \text { ab }\end{aligned}$ & $\begin{array}{l}\text { C } \\
B \\
A \\
B \\
A\end{array}$ & $\begin{array}{r}- \\
- \\
12,5 \\
12,3 \\
14,2 \\
9,2 \\
12,1\end{array}$ & $\begin{array}{ll}\text { a } & B C \\
\text { a } & B \\
\text { a } & A \\
\text { b } & B \\
\text { a } & A\end{array}$ & $\begin{array}{c}- \\
- \\
17,6 \text { a } \\
15,1^{\text {ab }} \\
12,44^{\text {d }} \\
13,0^{\text {bc }} \\
10,0^{d}\end{array}$ & $\begin{array}{l}A \\
A \\
A B \\
A \\
B\end{array}$ \\
\hline
\end{tabular}

(*) OBS: Letras maiúsculas diferentes em cada linha e letras minúsculas diferentes em cada coluna, indicam diferença significativa ao nivel de $5 \%$ de probabilidade, entre clones e entre idades, respectivamente.

As concentrações de nitrogênio encontradas nas folhas, dos clones de Eucalyptus, aos noventa dias de idade, são maiores que os teores observados por Will (1961); Haag et al. (1961a), semelhantes aos observados por Kaul et al. (1966) e inferiores aos encontrados por Rocha Filho et al. (1978) em mudas e por Bellote (1979), em plantios de Eucalyptus grandis com doze 
meses. Porém, os teores para todos os clones estudados, estão abaixo da faixa citada como adequada, por Dell et al. (1995), de 25 a $38 \mathrm{~g} \mathrm{~kg}^{-1}$.

$O$ teor de nitrogênio não foi significativo para folhas, nos clones $A 7$ e D19, e raizes, clones C4 e D19. Para as folhas, clones C4 e F40 e raizes, nos clones A7 e F40, ajustaram-se equações lineares, enquanto que para o caule, em todos os clones estudados, foram ajustadas equações do segundo grau, conforme mostra a Tabela 7 e Figura 2.

Tabela 7. Equação de regressão para teor de nitrogênio $\left(\mathrm{g} \mathrm{kg}^{-1}\right)$, nas diversas partes da planta, nos clones de Eucalyptus estudados, em função da idade (dias).

\begin{tabular}{|c|c|c|c|c|}
\hline Clones & Partes da planta & Equação & $\mathrm{R}^{2}$ & Prob. C.V \\
\hline $\begin{array}{l}\text { A7 } \\
\text { C4 } \\
\text { D19 } \\
\text { F40 }\end{array}$ & $\begin{array}{l}\text { Folhas } \\
\text { Folhas } \\
\text { Folhas } \\
\text { Folhas }\end{array}$ & $\begin{array}{l}\text { não significativo } \\
y=29,0450-0,1233^{*} X \\
\text { não significativo } \\
y=25,4750-0,0373^{*} X\end{array}$ & $\begin{array}{l}0,43 \\
0,36\end{array}$ & $\begin{array}{l}<1 \% 14,69 \\
<1 \% \quad 4,76\end{array}$ \\
\hline $\begin{array}{l}\text { A7 } \\
\text { C4 } \\
\text { D19 } \\
\text { F40 }\end{array}$ & $\begin{array}{l}\text { Caule } \\
\text { Caule } \\
\text { Caule } \\
\text { Caule }\end{array}$ & $\begin{array}{l}y=12,8399-0,1506^{*} X+0,0007^{*} X^{2} \\
y=14,5607-0,2268^{*} X+0,0017^{*} X^{2} \\
y=14,0363-0,1688^{*} X+0,0010^{*} X^{2} \\
y=15,7411-0,1810^{*} X+0,0010^{*} X^{2}\end{array}$ & $\begin{array}{l}0,87 \\
0,76 \\
0,77 \\
0,89\end{array}$ & $\begin{array}{ll}<1 \% & 13,30 \\
<1 \% & 16,81 \\
<1 \% & 15,28 \\
<1 \% & 10,47\end{array}$ \\
\hline $\begin{array}{l}\text { A7 } \\
\text { C4 } \\
\text { D19 } \\
\text { F40 }\end{array}$ & $\begin{array}{l}\text { Raízes } \\
\text { Raízes } \\
\text { Raízes } \\
\text { Raízes }\end{array}$ & $\begin{array}{l}y=17,7100-0,0947^{*} X \\
\text { não significativo } \\
\text { não significativo } \\
y=20,5300-0,1152^{*} X\end{array}$ & 0,59 & $<1 \% \quad 14,56$ \\
\hline
\end{tabular}




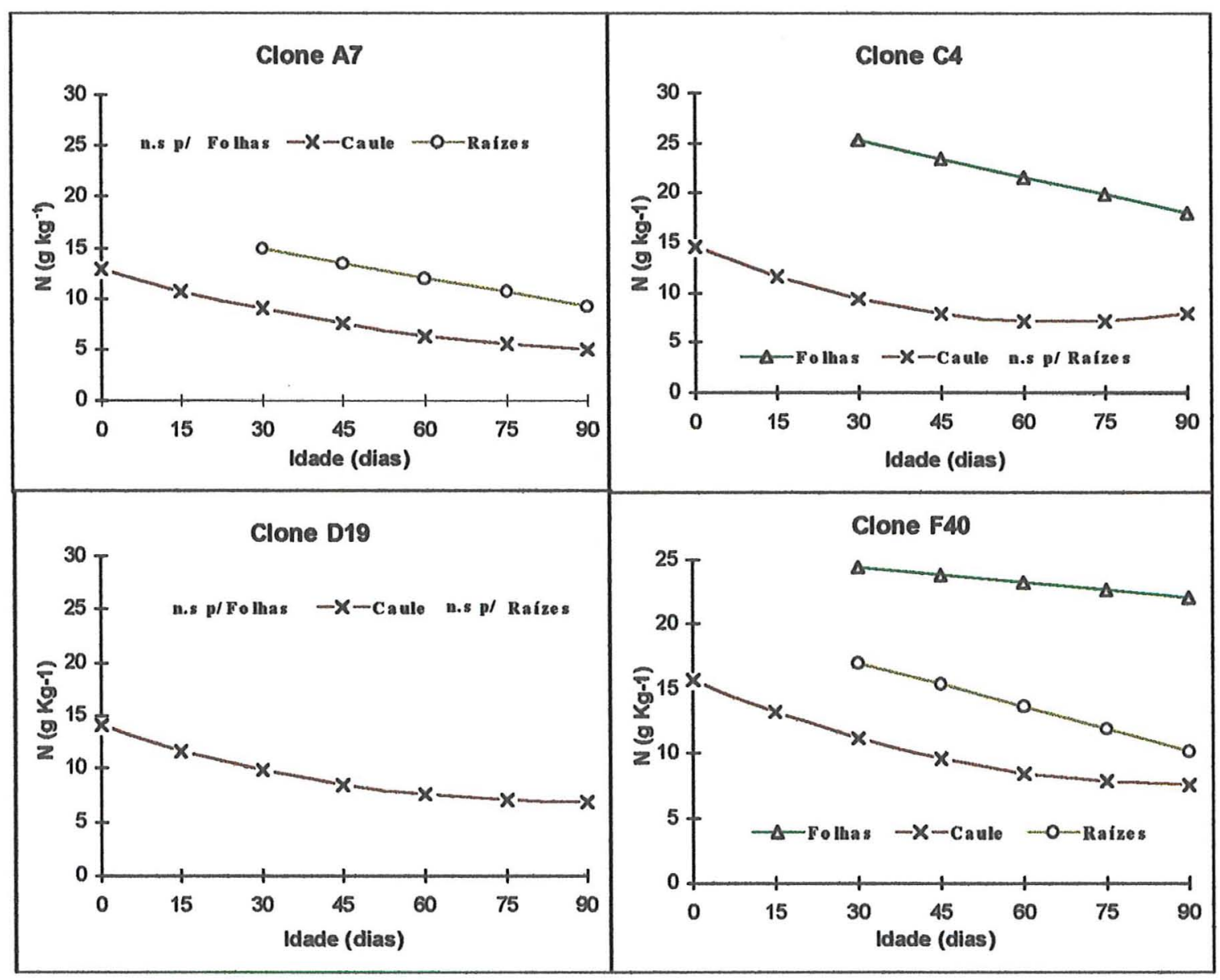

Figura 2 - Teores de nitrogênio $\left(\mathrm{g} \mathrm{kg}^{-1}\right)$, nas diferentes partes da planta, nos clones de Eucalyptus estudados, em função da idade (dias). 


\subsubsection{Acúmulo}

O conteúdo de nitrogênio acumulado pelas diversas partes e na planta inteira, em função das idades, nos clones estudados, é mostrado na Tabela 8, onde se verifica que houve diferenças no acumulo de nitrogênio, sendo esse, um efeito crescente para as folhas, raízes e total e decrescente para o caule. Entre os clones, não houve variação significativa para acúmulo nas folhas aos noventa dias de idade. Observou-se variações nas quantidades de $\mathrm{N}$ entre os clones $\mathrm{A} 7$ e $\mathrm{F} 40$ para o caule e raízes, em relação aos clones C4 e D19. Para o total de nitrogênio acumulado, apenas o clone C4 diferiu dos clones A7 e F40.

Quantidades de nitrogênio no caule, para todos os clones estudados e total, para os clones C4 e D19 ajustaram-se equaçōes do segundo grau, enquanto que as folhas e raízes, para todos os clones e total, para os clones A7 e F40, foram representados por equações do primeiro grau, conforme podemos observar na Tabela 9 e Figura 3.

O acúmulo de nitrogênio nas folhas, aos noventa dias de idade, foram de 6,$04 ; 6,80 ; 6,48$ e 5,40 mg planta $^{-1}$, no caule de 2,$23 ; 3,40 ; 2,95$ e $2,11 \mathrm{mg}$ planta $^{-1}$ e nas raizes de 1,$00 ; 1,78 ; 1,75$ e $0,85 \mathrm{mg}_{\text {planta }}{ }^{-1}$, para os clones A7, C4, D19 e F40, respectivamente. Esses valores, com exceção das raízes nos clones C4 e D19, são maiores quando comparados com os obtidos por Silveira et al.(1995), em mudas de E. grandis, com 97 dias de idade, para folhas $\left(5,80 \mathrm{mg} \mathrm{planta}^{-1}\right)$, caule $\left(1,80 \mathrm{mg}\right.$ planta $\left.^{-1}\right)$ e raízes $\left(1,60 \mathrm{mg}\right.$ planta $\left.{ }^{-1}\right)$. 
Tabela 8. Acúmulo de nitrogênio, nas diversas partes da planta, nos clones de Eucalyptus estudados, em função da idade.

\begin{tabular}{|c|c|c|c|c|c|c|c|c|c|c|c|c|c|}
\hline \multirow{2}{*}{$\begin{array}{l}\begin{array}{l}\text { Partes } \\
\text { da } \\
\text { planta }\end{array} \\
\text { Folhas }\end{array}$} & \multirow{2}{*}{$\begin{array}{c}\text { Idade } \\
\text { (dias) } \\
0 \\
15 \\
30 \\
45 \\
60 \\
75 \\
90\end{array}$} & \multicolumn{3}{|c|}{ Clone A7 } & \multicolumn{3}{|c|}{ Clone C4 } & \multicolumn{3}{|c|}{ Clone D19 } & \multicolumn{3}{|c|}{ Clone F40 } \\
\hline & & $\begin{array}{l}0,60 \\
1,45 \\
2,96 \\
7,78 \\
6,04\end{array}$ & $\begin{array}{l}- \\
- \\
d^{*} \\
d \\
c \\
a \\
b\end{array}$ & $\begin{array}{l}A^{*} \\
A \\
B \\
A \\
A\end{array}$ & $\begin{array}{l}0,46 \\
1,10 \\
2,50 \\
4,94 \\
6,80\end{array}$ & $\begin{array}{l}d \\
d \\
c \\
b \\
a\end{array}$ & $\begin{array}{l}\text { A } \\
A \\
B \\
B \\
A\end{array}$ & $\begin{array}{l}0,64 \\
1,28 \\
2,93 \\
5,53 \\
6,48\end{array}$ & $\begin{array}{l}\text { e } \\
d \\
c \\
b \\
a\end{array}$ & $\begin{array}{l}\text { A } \\
A \\
B \\
B \\
A\end{array}$ & $\begin{array}{r}- \\
0,41 \\
1,51 \\
4,13 \\
6,92 \\
5,40\end{array}$ & $\begin{array}{l}c \\
c \\
b \\
a \\
b\end{array}$ & $\begin{array}{l}\text { A } \\
\text { A } \\
\text { A } \\
\text { A } \\
\text { A }\end{array}$ \\
\hline Caule & $\begin{array}{r}0 \\
15 \\
30 \\
45 \\
60 \\
75 \\
90\end{array}$ & $\begin{array}{l}4,48 \\
4,32 \\
2,79 \\
2,47 \\
2,07 \\
2,79 \\
2,23\end{array}$ & $\begin{array}{l}a \\
a \\
b \\
b \\
b \\
b \\
b\end{array}$ & $\begin{array}{l}\text { A } \\
\text { A } \\
\text { A } \\
\text { A } \\
\text { B } \\
\text { B } \\
\text { B }\end{array}$ & $\begin{array}{l}4,69 \\
3,18 \\
2,82 \\
2,52 \\
3,10 \\
2,32 \\
3,40\end{array}$ & $\begin{array}{l}a \\
b c \\
b c \\
b c \\
b c \\
c \\
b\end{array}$ & $\begin{array}{l}\text { A } \\
C \\
A \\
A \\
A \\
B \\
A\end{array}$ & $\begin{array}{l}4,41 \\
4,22 \\
3,23 \\
2,65 \\
3,32 \\
2,58 \\
2,95\end{array}$ & $\begin{array}{l}a \\
a \\
b \\
b \\
b \\
b \\
b\end{array}$ & $\begin{array}{l}\text { A } \\
\text { B } \\
\text { A } \\
\text { A } \\
\text { A } \\
\text { B } \\
\text { A }\end{array}$ & $\begin{array}{l}5,04 \\
5,30 \\
3,73 \\
2,84 \\
2,53 \\
3,38 \\
2,11\end{array}$ & $\begin{array}{l}a \\
a \\
b \\
c d \\
\text { de } \\
b c \\
e\end{array}$ & $\begin{array}{l}\text { A } \\
\text { A } \\
\text { A } \\
\text { A } \\
\text { B } \\
\text { A } \\
\text { B }\end{array}$ \\
\hline Raizes & $\begin{array}{r}0 \\
15 \\
30 \\
45 \\
60 \\
75 \\
90\end{array}$ & $\begin{array}{l}0,06 \\
0,23 \\
0,44 \\
1,30 \\
1,00\end{array}$ & $\begin{array}{l}- \\
- \\
d \\
d \\
c \\
a \\
b\end{array}$ & $\begin{array}{l}\text { C } \\
B \\
B \\
A \\
B\end{array}$ & $\begin{array}{l}0,18 \\
0,23 \\
0,53 \\
1,16 \\
1,78\end{array}$ & $\begin{array}{l}d \\
d \\
c \\
b \\
a\end{array}$ & $\begin{array}{l}A \\
B \\
A B \\
A \\
A\end{array}$ & $\begin{array}{l}0,18 \\
0,40 \\
0,59 \\
1,13 \\
1,75\end{array}$ & $\begin{array}{l}\text { e } \\
\text { d } \\
\text { c } \\
b \\
a\end{array}$ & $\begin{array}{l}A \\
A \\
A \\
A \\
A\end{array}$ & $\begin{array}{r}- \\
- \\
0,12 \\
0,28 \\
0,51 \\
1,08 \\
0,85\end{array}$ & $\begin{array}{l}\text { e } \\
\text { d } \\
\text { c } \\
\text { a } \\
\text { b }\end{array}$ & $\begin{array}{l}B \\
B \\
A B \\
A \\
B\end{array}$ \\
\hline Total & $\begin{array}{r}0 \\
15 \\
30 \\
45 \\
60 \\
75 \\
90\end{array}$ & $\begin{array}{r}4,48 \\
4,32 \\
3,45 \\
4,15 \\
5,47 \\
11,87 \\
9,27\end{array}$ & $\begin{array}{l}\text { cd } \\
\text { cd } \\
d \\
\text { cd } \\
c \\
a \\
b\end{array}$ & $\begin{array}{l}\text { A } \\
B \\
A \\
A \\
C \\
A \\
B C\end{array}$ & $\begin{array}{r}4,69 \\
3,18 \\
3,46 \\
3,86 \\
6,13 \\
8,41 \\
11,98\end{array}$ & $\begin{array}{l}d \\
e \\
d e \\
d e \\
c \\
b \\
a\end{array}$ & $\begin{array}{l}\text { A } \\
\text { C } \\
\text { A } \\
\text { A } \\
\text { BC } \\
B \\
\text { A }\end{array}$ & $\begin{array}{r}4,41 \\
4,22 \\
4,05 \\
4,33 \\
6,84 \\
9,25 \\
11,17\end{array}$ & $\begin{array}{l}d \\
d \\
d \\
d \\
c \\
b \\
a\end{array}$ & $\begin{array}{l}A \\
B \\
A \\
A \\
A B \\
B \\
A B\end{array}$ & $\begin{array}{r}5,04 \\
5,30 \\
4,27 \\
4,63 \\
7,18 \\
11,39 \\
8,36\end{array}$ & $\begin{array}{l}c \\
c \\
c \\
c \\
b \\
a \\
b\end{array}$ & $\begin{array}{l}A \\
A \\
A \\
A \\
A \\
A \\
C\end{array}$ \\
\hline
\end{tabular}

(*) OBS: Letras maiúsculas diferentes em cada linha e letras minúsculas diferentes em cada coluna, indicam diferença significativa ao nível de $5 \%$ de probabilidade, entre clones e entre idades, respectivamente. 
Tabela 9. Equação de regressão para acúmulo de nitrogênio (mg planta $\left.{ }^{-1}\right)$, nas diversas partes da planta, nos clones de Eucalyptus estudados, em função da idade (dias).

Partes da planta Equação

R2 Prob.

C.V.

CLONE A7

Folhas

Caule

$y=-1,1733+0,0858^{*} X$

Raízes

$y=4,8053-0,0698^{\star} X+0,0005^{*} X^{2}$

0,79

$0,74<1 \% \quad 18,02$

$y=-0,2060+0,0142^{*} X$

$0,77<5 \% \quad 55,87$

Total

$y=2,8864+0,0735^{*} X$

0,55

$<1 \%$

33,17

CLONE C4

\begin{tabular}{llrrr} 
Folhas & $y=-1,2056+0,0770^{*} X$ & 0,87 & $<1 \%$ & 41,79 \\
Caule & $y=4,4451-0,0768^{*} X+0,0007^{*} X^{2}$ & 0,68 & $<1 \%$ & 15,47 \\
Raizes & $y=-0,2929+0,0190^{*} X$ & 0,83 & $<1 \%$ & 46,94 \\
\hline Total & $y=4,5105-0,1060^{*} X+0,0021^{*} X^{2}$ & 0,97 & $<1 \%$ & 9,16 \\
\hline
\end{tabular}

CLONE D19

\begin{tabular}{lllll} 
Folhas & $y=-1,0915+0,0783^{*} X$ & 0,90 & $<1 \%$ & 33,39 \\
Caule & $y=4,5354-0,0490^{*} X+0,0003^{*} X^{2}$ & 0,65 & $<1 \%$ & 14,08 \\
Raízes & $y=-0,2700+0,0189^{*} X$ & 0,88 & $<1 \%$ & 10,36 \\
\hline Total & $y=4,4169-0,0512^{*} X+0,0014^{*} X^{2}$ & 0,95 & $<1 \%$ & 10,36 \\
\hline CLONE F40 & & & & \\
Folhas & $y=-0,9915+0,0804^{*} X$ & 0,82 & $<5 \%$ & 44,82 \\
Caule & $y=5,3803-0,0598^{*} X+0,0003^{*} X^{2}$ & 0,78 & $<5 \%$ & 16,13 \\
Raízes & $y=-0,1380+0,0120^{*} X$ & 0,86 & $<5 \%$ & 37,54 \\
\hline Total & $y=3,9205+0,0591^{*} X$ & 0,55 & $<1 \%$ & 25,41 \\
\hline
\end{tabular}

Aos noventa dias, as quantidades de nitrogênio acumuladas nas folhas, pelos clones A7, C4, D19 e F40, representaram 65,16; 56,76; 58,01 e $64,59 \%$ do total. Para o caule, os valores obtidos responderam por 24,06; 28,$38 ; 26,41$ e $25,24 \%$ e as raizes 10,$79 ; 14,86 ; 15,67$ e $10,17 \%$, respectivamente. 


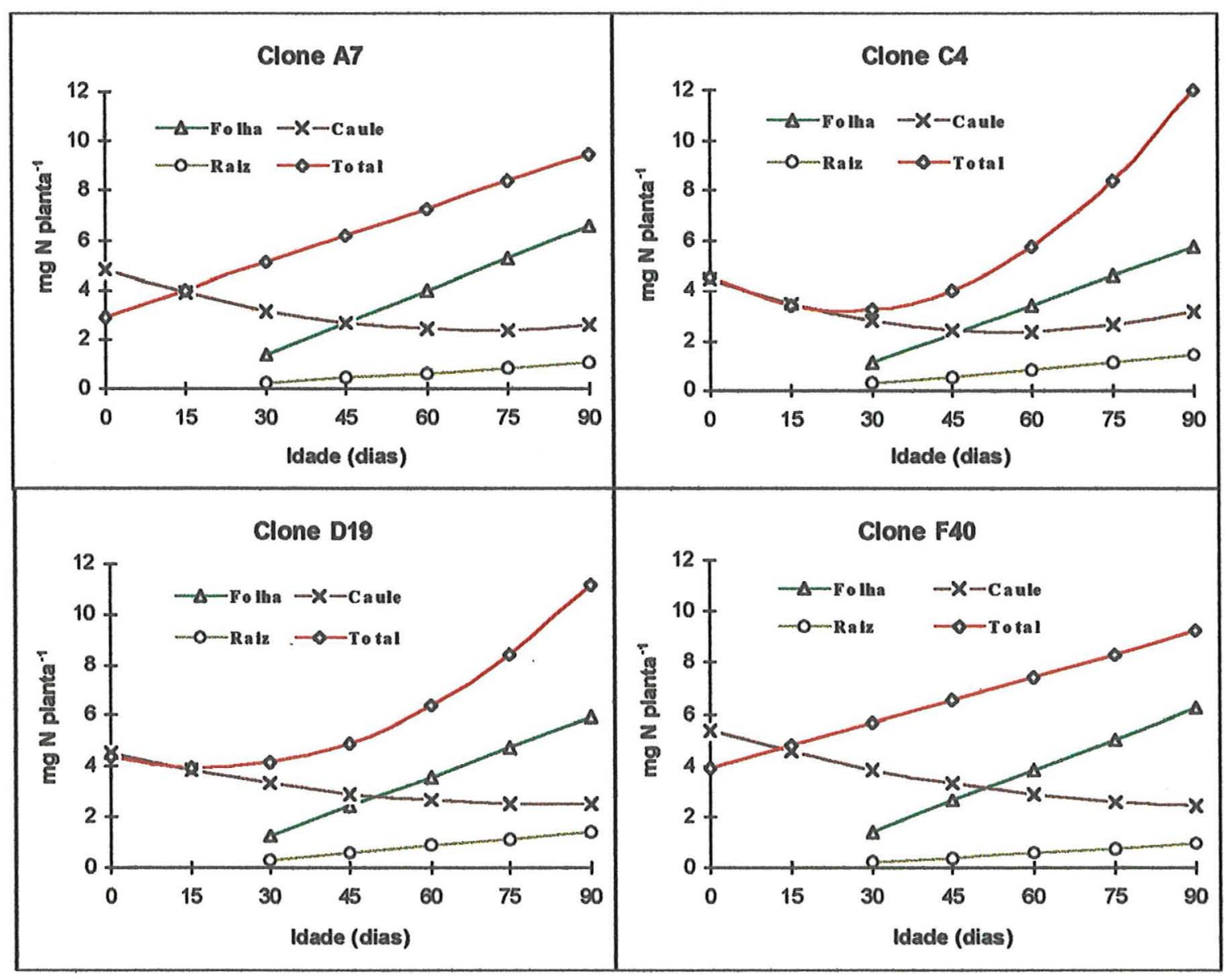

Figura 3 - Quantidades de nitrogênio ( $m$ g planta ${ }^{-1}$ ), nas diferentes partes e planta inteira, nos clones de Eucalyptus estudados, em função da idade (dias). 


\subsubsection{Fósforo}

\subsubsection{Concentração}

Diferenças significativas nos teores de fósforo, nas diversas partes da planta, em função das idades, foram observadas, conforme mostra a Tabela 10. As maiores concentrações de fósforo foram encontradas nas raízes, aos trinta dias e nas folhas, aos noventa dias de idade. Pode-se observar uma tendência de diminuição no teor de fósforo para as folhas e raízes, enquanto que o caule apresenta tendência de acréscimo de zero até 45 dias, diminuindo a partir desta data, para todos os clones testados.

Aos noventa dias de idade, as concentrações de fósforo nos clones estudados variaram de 1,9 a $2,5 \mathrm{~g} \mathrm{~kg}^{-1}$ nas folhas; 1,2 a $1,7 \mathrm{~g} \mathrm{~kg}^{-1}$ nos caules e de 0,4 a $1,0 \mathrm{~g} \mathrm{~kg}^{-1}$ nas raizes.

Os clones mostraram variações significativas para a concentração de fósforo para as folhas, entre os clones A7, e F40; para o caule, entre os clones D19 e F40, que diferiram dos clones A7 e C4. Nas raízes as diferenças ocorreram nos clones A7 e F40 em relação aos clones C4 e D19.

Em função da idade, o teor de fósforo nas diversas partes da planta de Eucalyptus tende a decrescer, como verificado por Silveira et al. (1995), na fase de produção de mudas e por Bellote (1976), em plantas adultas. As concentrações obtidas aos noventa dias de idade, nesse trabalho, está de acordo com os teores foliares considerado adequado por Dell et al. (1995), entre 1,5 a $2,2 \mathrm{~g} \mathrm{~kg}^{-1}$. 
Tabela 10. Concentração de fósforo, nas diversas partes da planta, nos clones de Eucalyptus estudados, em função da idade.

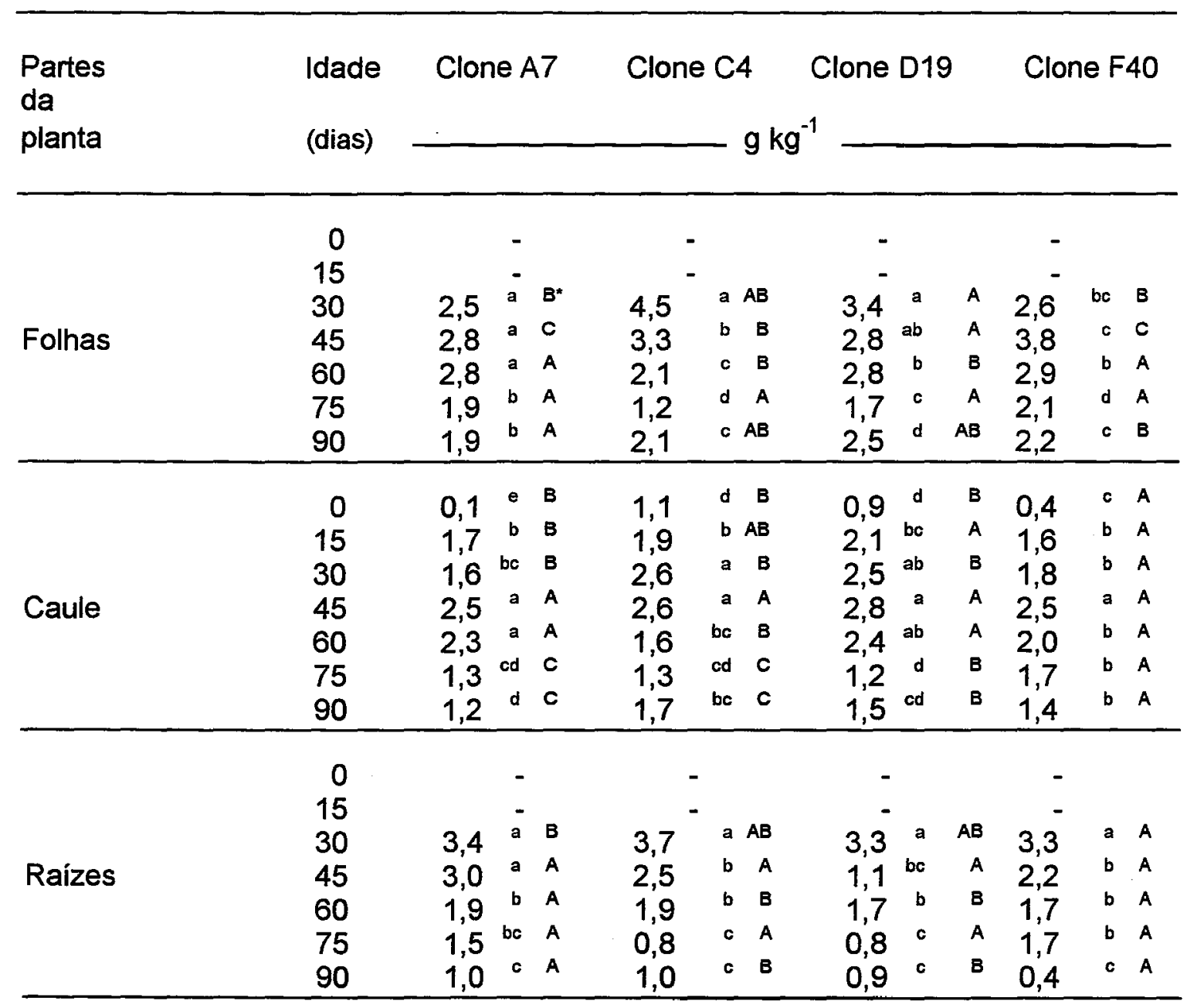

(*) OBS: Letras maiúsculas diferentes em cada linha e letras minúsculas diferentes em cada coluna, indicam diferença significativa ao nivel de $5 \%$ de probabilidade, entre clones e entre idades, respectivamente. 
A concentração de fósforo para as folhas e caule, para todos os clones estudados, ajustaram-se a equações do segundo grau, o mesmo acontecendo para as raízes nos clones C4 e D19. Para as raizes nos clones A7 e F40, ajustou-se equações do primeiro grau, conforme podemos observar na Tabela 11 e Figura 4.

Tabela 11. Equação de regressão para teor de fósforo $\left(\mathrm{g}^{\mathrm{kg}}{ }^{-1}\right)$, nas diversas partes da planta, para os clones de Eucalyptus estudados, em função da idade (dias).

\begin{tabular}{|c|c|c|c|c|c|}
\hline Clones & Partes da planta & Equação & $\mathrm{R}^{2}$ & Prob. & C.V. \\
\hline $\begin{array}{l}\text { A7 } \\
\text { C4 } \\
\text { D19 } \\
\text { F40 }\end{array}$ & $\begin{array}{l}\text { Folhas } \\
\text { Folhas } \\
\text { Folhas } \\
\text { Folhas }\end{array}$ & $\begin{array}{l}y=1,9150+0,0363^{*} X-0,0004^{*} X^{2} \\
y=-0,2260 X-0,0015^{\star} X^{2} \\
y=5,5600-0,0872^{*} X+0,0006^{*} X^{2} \\
y=1,6700+0,0613^{*} X-0,0006^{*} X^{2}\end{array}$ & $\begin{array}{l}0,66 \\
0,92 \\
0,56 \\
0,46\end{array}$ & $\begin{array}{l}<5 \% \\
<1 \% \\
<5 \% \\
<5 \%\end{array}$ & $\begin{array}{l}10,98 \\
13,98 \\
16,40 \\
17,76\end{array}$ \\
\hline $\begin{array}{l}\text { A7 } \\
\text { C4 } \\
\text { D19 } \\
\text { F40 }\end{array}$ & $\begin{array}{l}\text { Caule } \\
\text { Caule } \\
\text { Caule } \\
\text { Caule }\end{array}$ & $\begin{array}{l}y=0,3262+0,0771^{*} X-0,0008^{*} X^{2} \\
y=1,3512+0,0421^{*} X-0,0005^{*} X^{2} \\
y=1,1279+0,0656^{*} X-0,0007^{*} X^{2} \\
y=0,5714+0,0642^{*} X-0,0006^{*} X^{2}\end{array}$ & $\begin{array}{l}0,79 \\
0,46 \\
0,67 \\
0,83\end{array}$ & $\begin{array}{l}<1 \% \\
<1 \% \\
<1 \% \\
<1 \%\end{array}$ & $\begin{array}{l}22,97 \\
23,64 \\
22,16 \\
15,85\end{array}$ \\
\hline $\begin{array}{l}\text { A7 } \\
\text { C4 } \\
\text { D19 } \\
\text { F40 }\end{array}$ & $\begin{array}{l}\text { Raizes } \\
\text { Raízes } \\
\text { Raizes } \\
\text { Raízes }\end{array}$ & $\begin{array}{l}y=4,6950-0,0422^{\star} X \\
y=-0,1348^{*} X+0,0007^{*} X^{2} \\
y=6,7000-0,1501^{*} X+0,0010^{*} X^{2} \\
y=4,4100-0,0425^{*} X\end{array}$ & $\begin{array}{l}0,92 \\
0,89 \\
0,69 \\
0,80\end{array}$ & $\begin{array}{l}<1 \% \\
<1 \% \\
<5 \% \\
<1 \%\end{array}$ & $\begin{array}{l}12,90 \\
20,32 \\
37,52 \\
25,32\end{array}$ \\
\hline
\end{tabular}




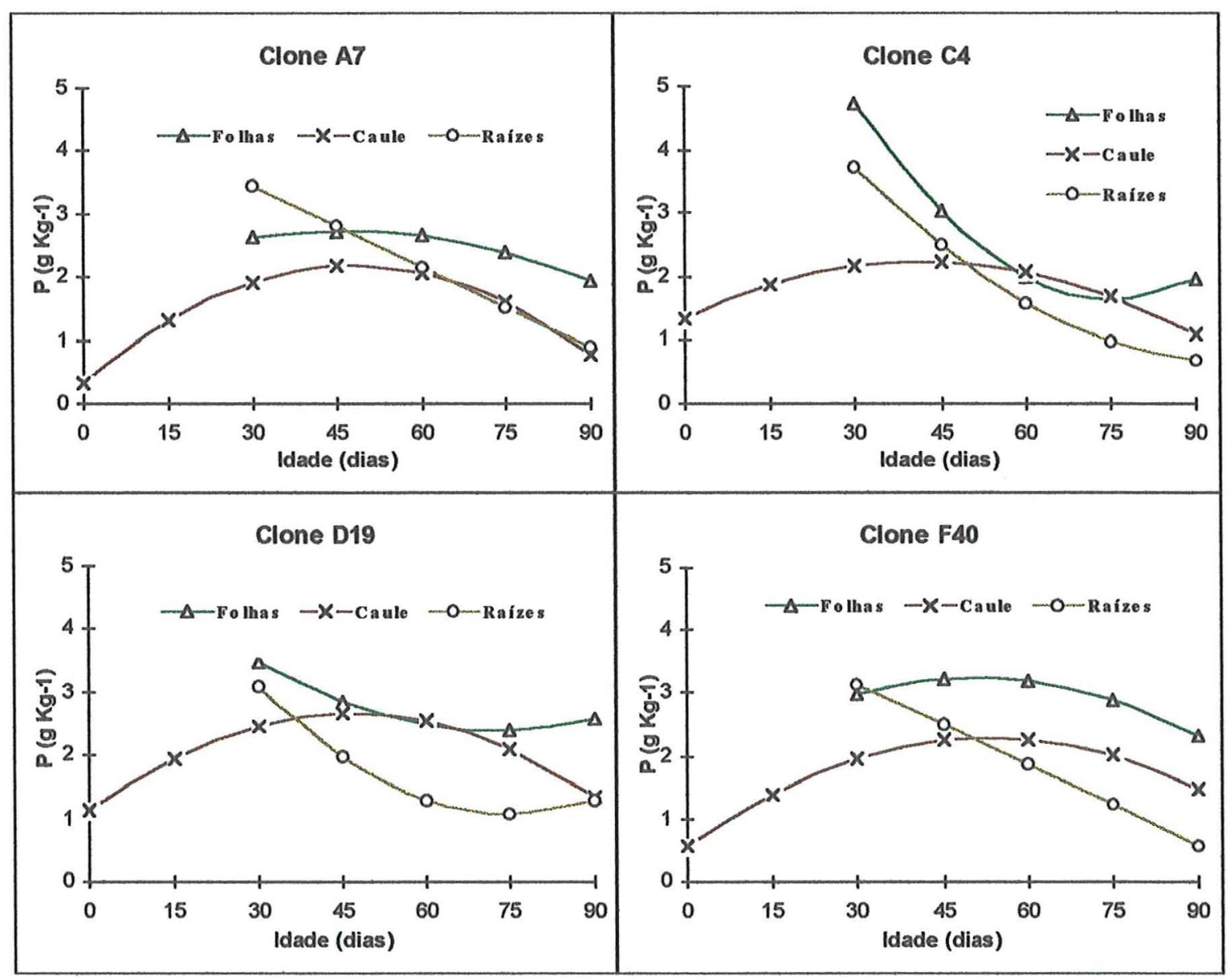

Figura 4 - Teores de fósforo $\left(\mathrm{g} \mathrm{kg}^{-1}\right)$ nas diferentes partes da planta, nos clones de Eucalyptus estudados, em função da idade (dias). 


\subsubsection{Acúmulo}

As quantidades de fósforo acumuladas nas diversas partes e na planta inteira, em função das idades e as variações entre os clones, estão apresentados na Tabela 12. O conteúdo de fósforo nas folhas, raízes e total mostraram acréscimos, enquanto que o caule apresentou variações no acúmulo de $P$ durante os tratamentos. $O$ fósforo total acumulado, aos noventa dias de idade, nos clones A7 e F40 diferiram significativamente, ao nivel de $5 \%$ de probabilidade, dos clones C4 e D19. Observou-se ainda, variações entre o clone D19 em relação aos demais para as folhas, entre o clone A7 em relação aos clones A7 e F40 para o caule, enquanto que nas raizes, apenas o clone $\mathrm{F} 40$ diferiu dos demais.

O acúmulo de fósforo aos noventa dias de idade, para os clones A7, C4, D19 e F40, nas folhas $\left(0,59 ; 0,67 ; 0,80\right.$ e $0,60 \mathrm{mg}$ planta $\left.^{-1}\right)$, caule $(0,55$; 0,$71 ; 0,60$ e $0,45 \mathrm{mg}$ planta $\left.^{-1}\right)$ e raizes $\left(0,12 ; 0,14 ; 0,12\right.$ e $\left.0,03 \mathrm{mg}_{\text {planta }}{ }^{-1}\right)$, são menores que os valores descritos por Silveira et al. (1995),em mudas de E. grandis com 97 dias de idade, para folhas, caule e raízes $(1,1 ; 1,2$ e 0,80 mg planta ${ }^{-1}$ ) respectivamente.

Para o caule, nos quatro clones estudados e para o caule, nos clones D19 e F40, ajustaram-se regressões de segundo grau, enquanto que as folhas, para todos os clones, raízes nos clones A7 e D19 e total, para os clones A7 e C4, foram representadas por equações de primeiro grau. $\mathrm{O}$ conteúdo de fósforo não foi significativo para as raízes, nos clones C4 e F40, conforme mostra a Tabela 13 e Figura 5. 
Tabela 12. Acúmulo de fósforo, nas diversas partes da planta, nos clones de Eucalyptus estudados, em função da idade.

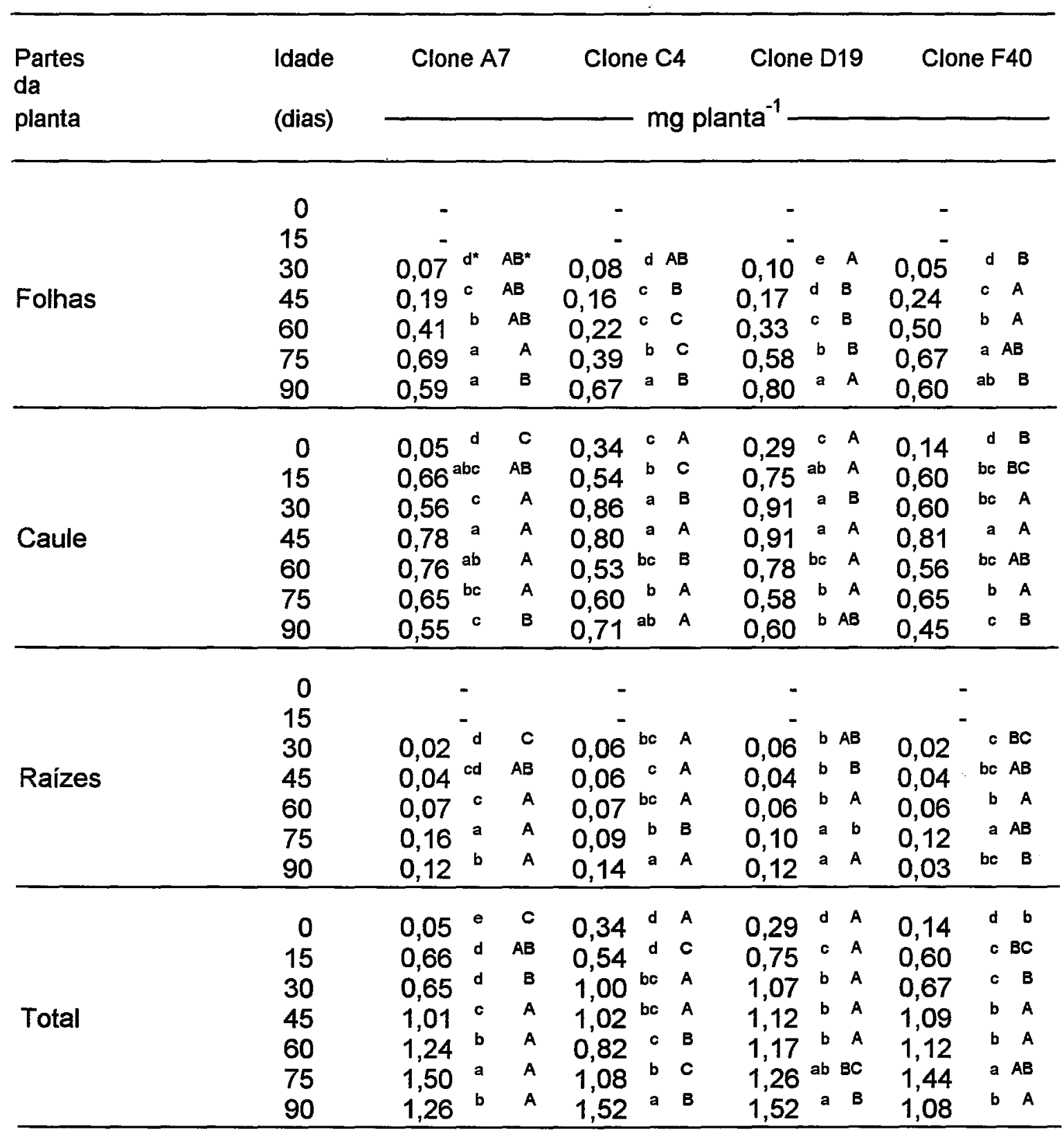

(*) OBS: Letras maiúsculas diferentes em cada linha e letras minúsculas diferentes em cada coluna, indicam diferença significativa ao nivel de $5 \%$ de probabilidade, entre clones e entre idades, respectivamente. 
As quantidades de fósforo acumuladas nas folhas, aos noventa dias de idade, pelos clones A7, C4, D19 e F40, representaram 46,82; 44,08; 52,63 e $55,55 \%$ do total. Para o caule e raízes, os valores obtidos corresponderam por 43,$65 ; 46,71 ; 39,47$ e $41,67 \%$ e 9,$52 ; 9,21 ; 7,89$ e $2,78 \%$, respectivamente.

Tabela 13. Equação de regressão para acúmulo de fósforo (mg planta $\left.{ }^{-1}\right)$ nas diversas partes da planta, nos clones de Eucalyptus estudados, em função da idade (dias).

Partes da planta

Equação

R2 Prob.

C.V.

CLONE A7

\begin{tabular}{lllll} 
Folhas & $y=-0,0967+0,0083^{*} X$ & 0,87 & $<1 \%$ & 35,69 \\
Caule & $y=0,1486+0,0236^{*} X-0,0002^{*} X^{2}$ & 0,78 & $<1 \%$ & 20,38 \\
Raízes & $y=-0,0187+0,0017^{*} X$ & 0,80 & $<1 \%$ & 44,85 \\
\hline Total & $y=0,2787+0,0141^{*} X$ & 0,83 & $<1 \%$ & 21,88 \\
\hline
\end{tabular}

CLONE C4

Folhas

Caule

Raízes

$$
y=-0,0972+, 00070^{*} x
$$

$0,87<1 \%$

39,36

$y=0,4070+0,0120^{*} X-0,0001 * X^{2}$

0,36

$<1 \%$

24,05

Total $y=$ não significativo

CLONE D19

\begin{tabular}{lllll} 
Folhas & $y=-0,1218+0,0090^{*} X$ & 0,91 & $<1 \%$ & 31,90 \\
Caule & $y=0,3885+0,0214^{*} X+0,0002^{*} X^{2}$ & 0,64 & $<1 \%$ & 20,59 \\
Raizes & $y=-0,0100+0,0014^{*} X$ & 0,88 & $<1 \%$ & 28,92 \\
\hline Total & $y=0,3825+0,0217^{*} X-0,0001^{*} X^{2}$ & 0,90 & $<1 \%$ & 35,73 \\
\hline CLONE F40 & & & & \\
Folhas & $y=-0,0918+0,0086^{*} X$ & 0,88 & $<1 \%$ & 34,06 \\
Caule & $y=0,2088+0,0213^{\star} X-0,0002^{*} X^{2}$ & 0,81 & $<1 \%$ & 16,72 \\
Raizes & $y=$ não significativo & & & \\
\hline Total & $y=0,1207+0,0303^{*} X-0,0002^{*} X^{2}$ & 0,90 & $<1 \%$ & 15,13 \\
\hline
\end{tabular}




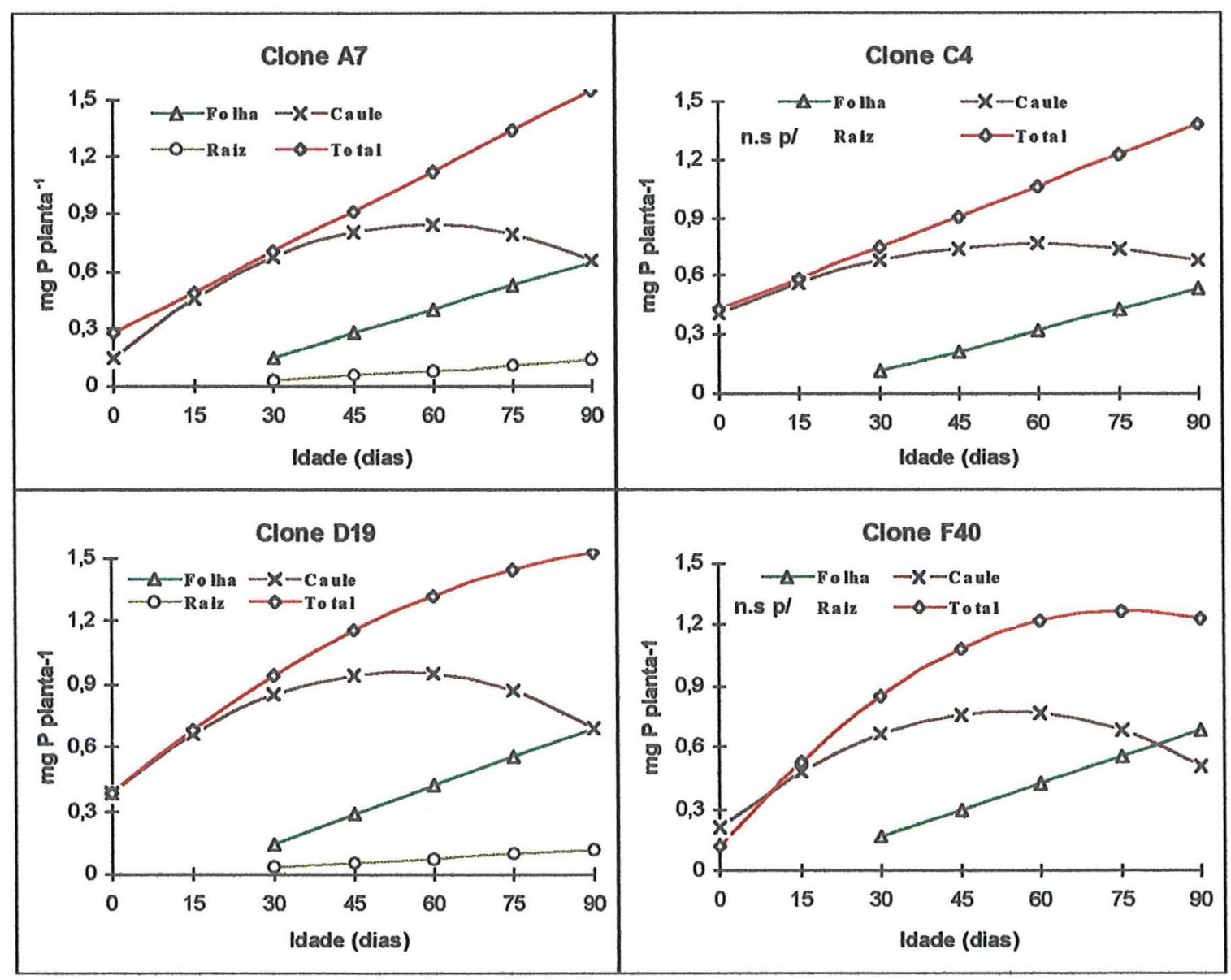

Figura 5 - Quantidades de fósforo (mg planta $\left.{ }^{-1}\right)$ nas diferentes partes e planta inteira, nos clones de Eucalyptus estudados, em função da idade (dias). 


\subsubsection{Potássio}

\subsubsection{Concentração}

Exceto para as folhas, nos clones A7 e D19, observa-se que houve diferenças na concentração de potássio, em função da idade, nas diversas partes das mudas, nos clones de Eucalyptus estudadas, conforme mostra a Tabela 14. Os teores de potássio diminuíram com a idade das plantas, para as raízes e caule, sendo esses os órgãos que apresentaram as maiores e menores concentrações do elemento, respectivamente. $O$ caule dos clones C4 e D19, aos noventa dias de idade, apresentaram variações no teor de potássio diferenciando-os do clone A7 e este do clone F40. Nas folhas, as variações ocorreram para o clone $A 7$ em relação aos demais. Nas raízes, $O$ clone A7 diferiu dos clones A7 e F40.

Aos noventa dias de idade os teores de potássio nos clones de Eucalyptus estudados variaram de 11,1 a $14,0 \mathrm{~g} \mathrm{~kg}^{-1}$ nas folhas; 10,3 a $12,3 \mathrm{~g}$ $\mathrm{kg}^{-1}$ nas raizes e de 6,8 a $10,2 \mathrm{~g} \mathrm{~kg}^{-1}$ nos caules. Essas concentrações de potássio observadas nas folhas dos clones de Eucalyptus, são semelhantes aos teores citado como adequado por Dell et al. (1995), de 12,0 a $14,0 \mathrm{~g} \mathrm{~kg}^{-1}$. Entretanto, os teores obtidos no presente trabalho são menores quando comparados com os obtidos por Silveira et al. (1995), cujos valores para folhas, caule e raízes foram de 13,$4 ; 14,9$ e $13,8 \mathrm{~g} \mathrm{~kg}^{-1}$, respectivamente e maiores, se comparados aos teores foliares encontrados por Kaul et al. (1968), de $8,0 \mathrm{~g} \mathrm{~kg}^{-1}$.

$\mathrm{Na}$ Tabela 15 são mostradas as equações de regressão. Para as raizes em todos os clones, para as folhas, clones C4 e F40 e o caule, clones C4 e D19, ajustaram-se equações do segundo grau. Para o caule, no clone A7 , D19 e F40 ajustou-se equações lineares, conforme podemos observar na Figura 6. 
Tabela 14. Concentração de potássio, nas diversas partes da planta, nos clones de Eucalyptus estudados, em função da idade.

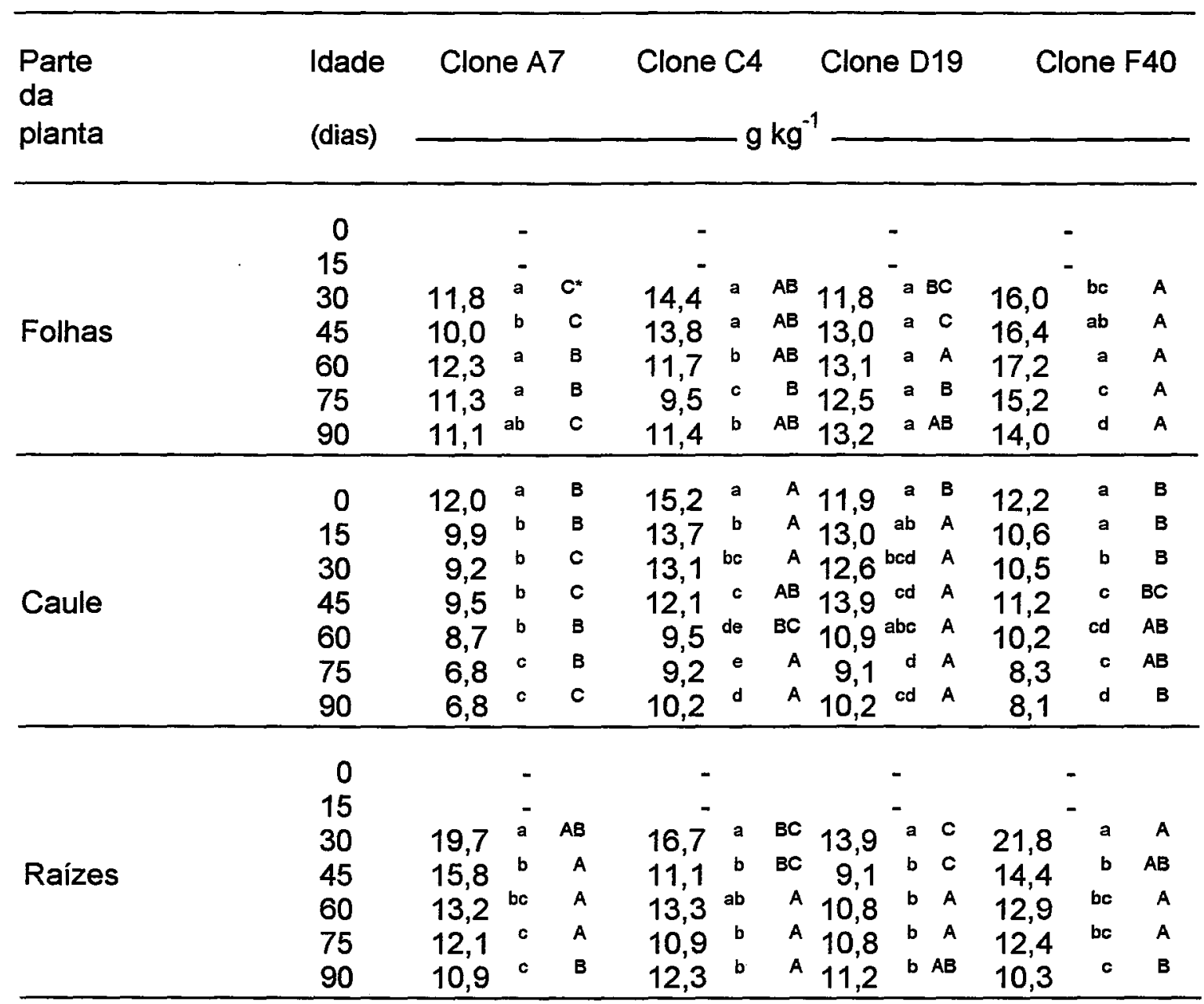

(*) OBS: Letras maiúsculas diferentes em cada linha e letras minúsculas diferentes em cada coluna, indicam diferença significativa ao nível de $5 \%$ de probabilidade, entre clones e entre idades, respectivamente. 
Tabela 15. Equação de regressão para teor de potássio $\left(\mathrm{g}^{\mathrm{kg}}{ }^{-1}\right)$, nas diversas partes da planta, nos clones de Eucalyptus estudados, em função da idade (dias).

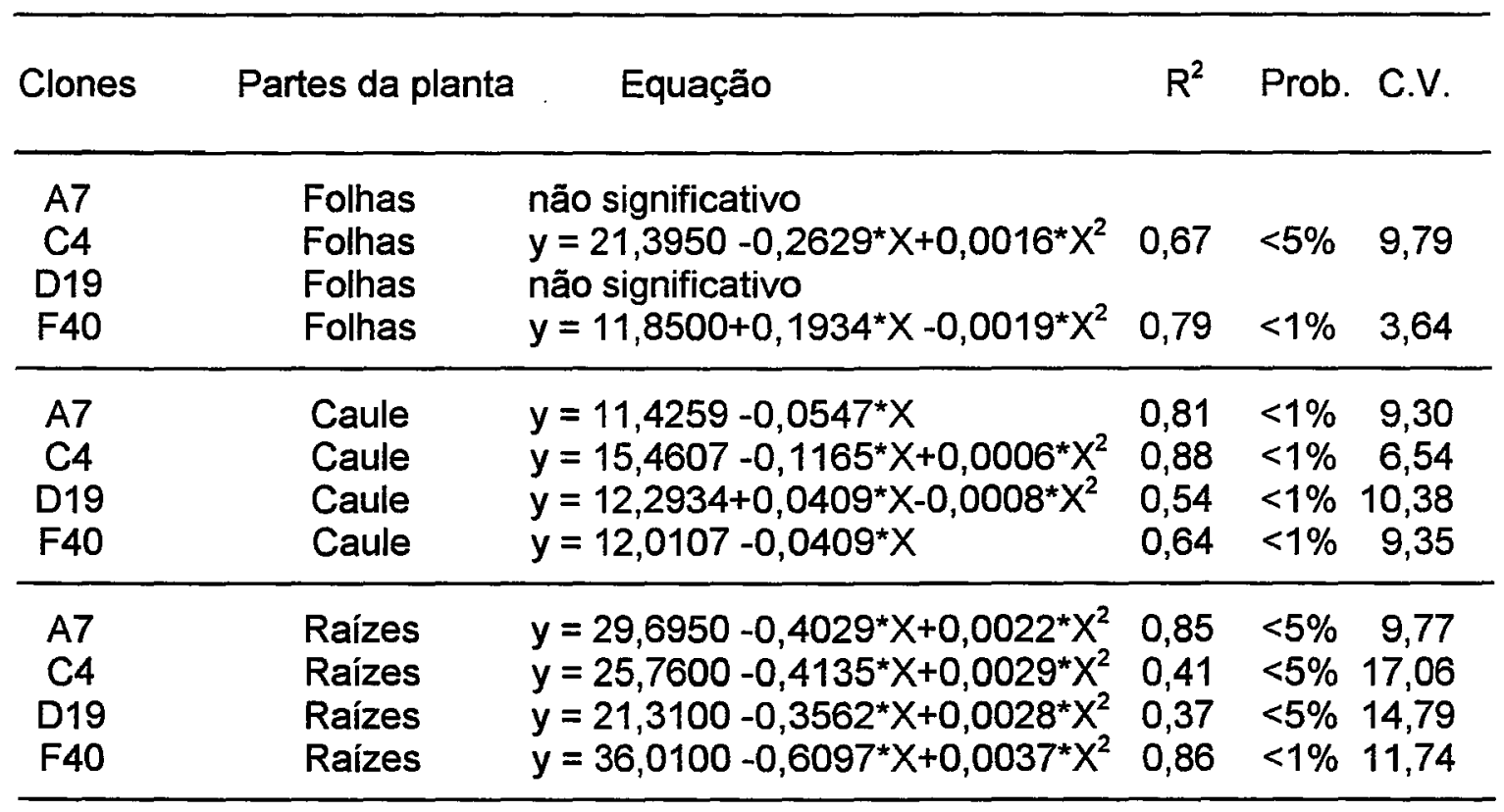




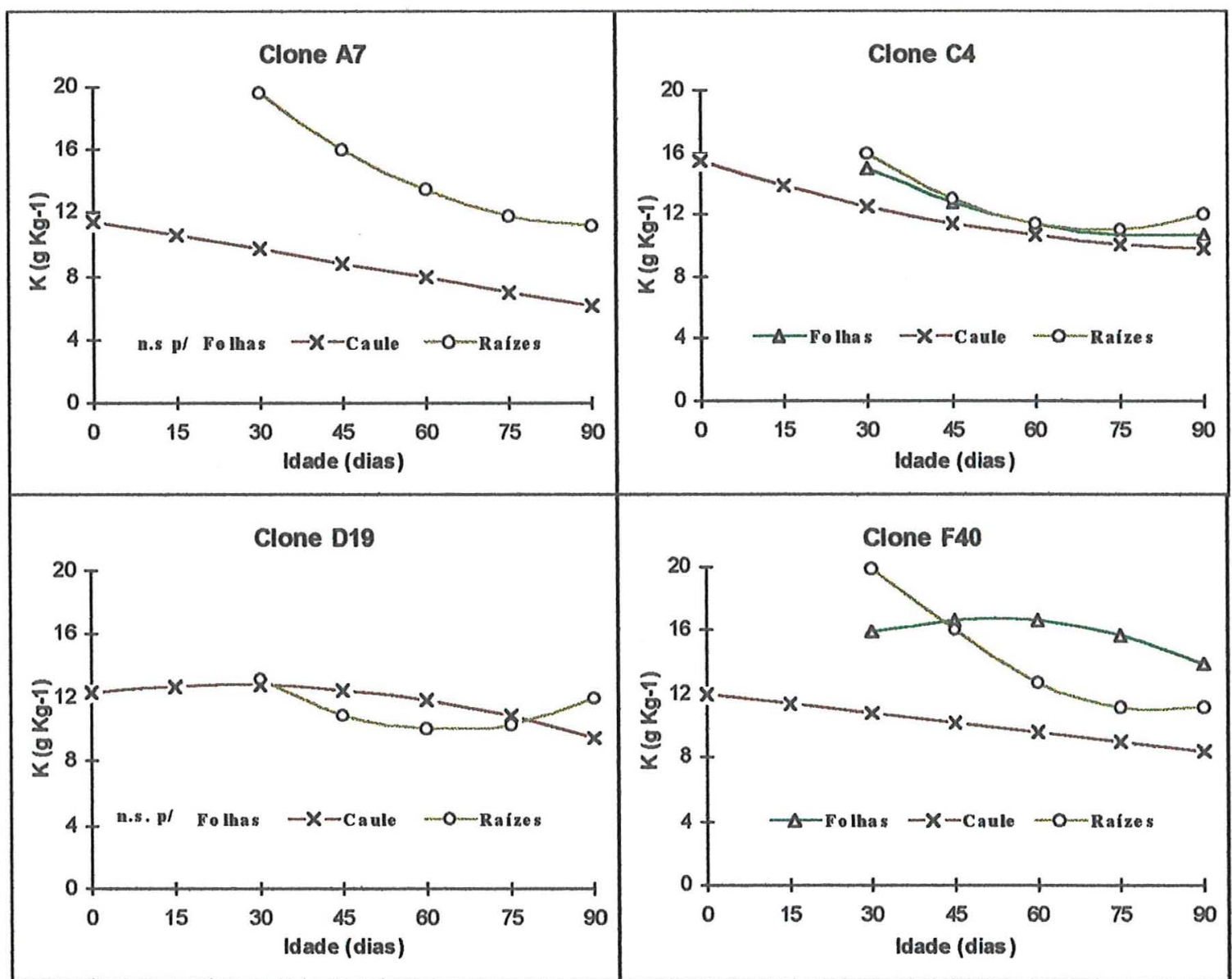

Figura 6 - Teores de potássio $\left(\mathrm{g} \mathrm{kg}^{-1}\right)$, nas diferentes partes da planta, nos clones de Eucalyptus estudados, em função da idade (dias). 


\subsubsection{Acúmulo}

A Tabela 16 mostra as quantidades de potássio acumuladas nas diferentes partes da planta, em função das idades. Observa-se aumento no conteúdo do elemento para as folhas e raizes, enquanto que apenas o caule, nos clones A7 e F40 apresentaram variações significativas, quando comparados os tratamentos zero e noventa dias de idade. No total de potássio acumulado, os clones não diferiram significativamente ao nível de $5 \%$ de probabilidade para as folhas. Diferiram apenas os clones A7 e F40 em relação aos clones C4 e D19 para o caule, raizes e total.

O acúmulo de potássio, aos noventa dias de idade, nos órgãos estudados, nos clones A7, C4, D19 e F40, foram : para as folhas $(3,45 ; 3,66$; 4,12 e $3,75 \mathrm{mg}$ planta $\left.{ }^{-1}\right)$, caule $\left(2,88 ; 4,30 ; 4,15\right.$ e $2,54 \mathrm{mg}$ planta $\left.{ }^{-1}\right)$, raízes $\left(1,25 ; 1,73 ; 1,62\right.$ e $0,87 \mathrm{mg}$ planta $\left.^{-1}\right)$ e total $(7,58 ; 9,69 ; 9,89$ e $7,16 \mathrm{mg}$ planta $^{-1}$ ) respectivamente. Essas quantidades de $K$ são menores se comparados aos valores para folhas $\left(7,02 \mathrm{mg}\right.$ planta $\left.{ }^{-1}\right)$, caule $\left(5,05 \mathrm{mg}\right.$ planta $\left.\mathrm{a}^{-1}\right) \mathrm{e}$ raízes (2,96 mg planta $\left.{ }^{-1}\right)$, descritos por Silveira et al. (1995), para mudas de E. grandis aos 97 dias de idade. $O$ acúmulo do elemento nas folhas, pelos clones A7, C4, D19 e F40, representaram 45,51; 37,77; 41,66 e 52,37\% do total, enquanto que o caule e as raízes acumularam: 37,$99 ; 44,37 ; 41,96$ e $35,47 \%$ e 16,$49 ; 17,85 ; 16,38$ e $12,15 \%$, respectivamente. 
Tabela 16. Acúmulo de potássio, nas diversas partes da planta, nos clones estudados, em função da idade.

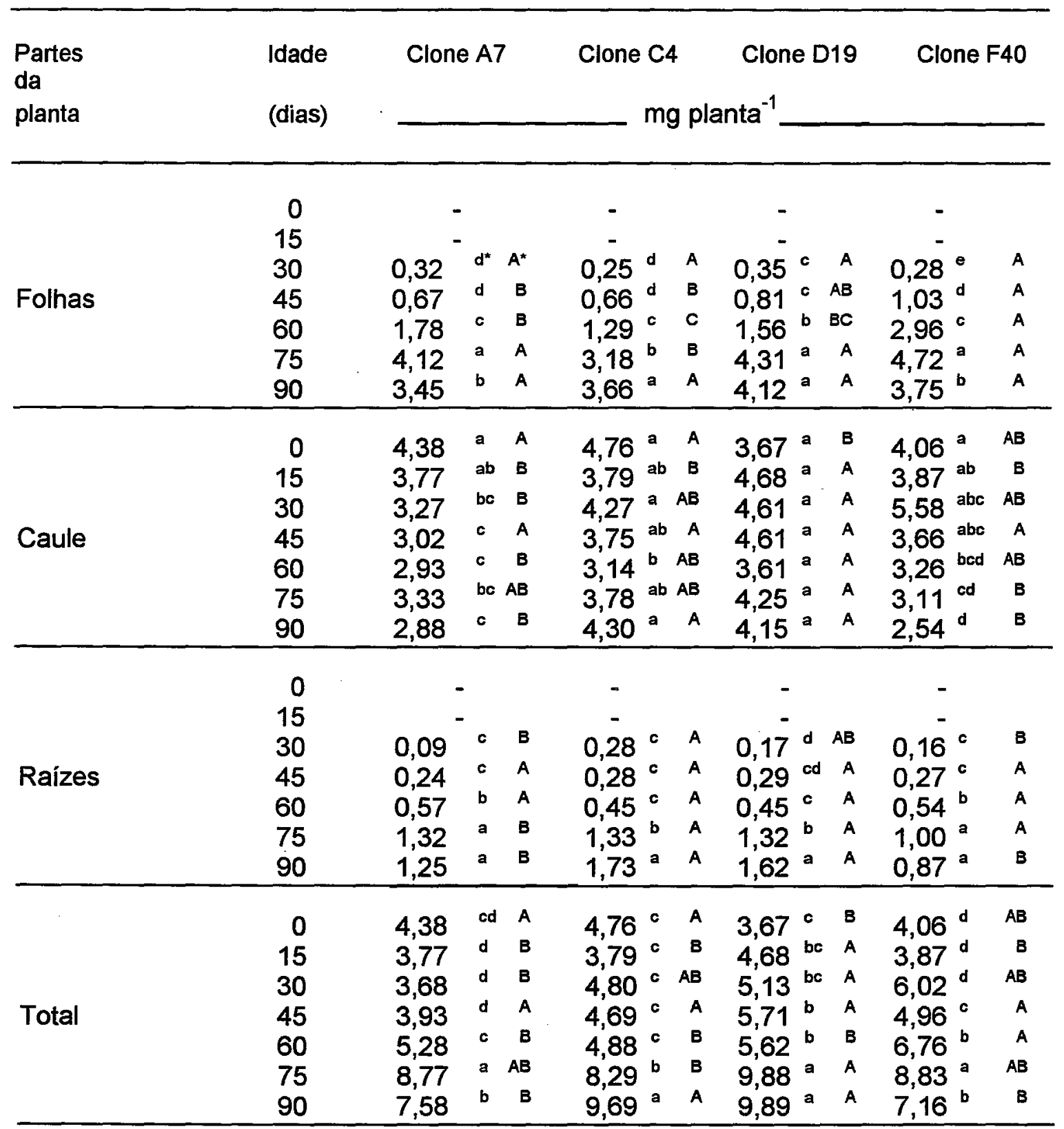

(*) OBS: Letras maiúsculas diferentes em cada linha e letras minúsculas diferentes em cada coluna, indicam diferença significativa ao nivel de $5 \%$ de probabilidade, entre clones e entre idades, respectivamente. 
Ajustaram-se equações de regressão de segundo grau para o caule, nos clones $\mathrm{A} 7$ e $\mathrm{C} 4$ e total, para o clone $\mathrm{C} 4$. Para as folhas e raízes, em todos os clones estudados, para o caule, no clone $F 40$, total, nos clones $A 7$, D19 e F40 ajustaram-se equações do primeiro grau, enquanto que o caule, no clone D19, não foi significativo, conforme podemos observar na Tabela 17 e Figura 7.

Tabela 17. Equação de regressão para acúmulo de potássio (mg planta ${ }^{-1}$ ), nas diversas partes da planta, nos clones de Eucalyptus estudados, em função da idade (dias).

\begin{tabular}{|c|c|c|c|c|}
\hline Partes da planta & Equação & $\mathrm{R} 2$ & Prob. & C.V. \\
\hline $\begin{array}{l}\text { CLONE A7 } \\
\text { Folhas } \\
\text { Caule } \\
\text { Raízes }\end{array}$ & $\begin{array}{l}y=-0,6684+0,0477^{\star} X \\
y=4,3171-0,0404^{\star} X+0,0003^{\star} x^{2} \\
y=-0,2413+0,0164^{\star} X\end{array}$ & $\begin{array}{l}0,82 \\
0,68 \\
0,83\end{array}$ & $\begin{array}{l}<1 \% \\
<1 \% \\
<1 \%\end{array}$ & $\begin{array}{l}47,75 \\
10,07 \\
46,16\end{array}$ \\
\hline Total & $y=3,0745+0,0504^{\star} x$ & 0,61 & $<1 \%$ & 23,28 \\
\hline $\begin{array}{l}\text { CLONE C4 } \\
\text { Folhas } \\
\text { Caule } \\
\text { Raizes }\end{array}$ & $\begin{array}{l}y=-0,6952+0,0449^{*} X \\
y=4,7223-0,0444^{*} X+0,0004^{*} x^{2} \\
y=-0,2889+0,0199^{*} X\end{array}$ & $\begin{array}{l}0,83 \\
0,37 \\
0,82\end{array}$ & $\begin{array}{l}<1 \% \\
<1 \% \\
<1 \%\end{array}$ & $\begin{array}{l}47,03 \\
13,02 \\
48,04\end{array}$ \\
\hline Total & $y=4,7093-0,0572^{*} X+0,0013^{*} x^{2}$ & 0,88 & $<1 \%$ & 13,67 \\
\hline $\begin{array}{l}\text { CLONE D19 } \\
\text { Folhas } \\
\text { Caule } \\
\text { Raízes }\end{array}$ & $\begin{array}{l}y=-0,7849+0,0529^{\star} X \\
\text { não significativo } \\
y=-0,2775+0,0185^{\star} X\end{array}$ & $\begin{array}{l}0,83 \\
0,83\end{array}$ & $\begin{array}{l}<1 \% \\
<1 \%\end{array}$ & $\begin{array}{l}46,93 \\
46,90\end{array}$ \\
\hline Total & $y=3,2081+0,0703^{*} x$ & 0,76 & $<1 \%$ & 19,20 \\
\hline $\begin{array}{l}\text { CLONE F40 } \\
\text { Folhas } \\
\text { Caule } \\
\text { Raízes }\end{array}$ & $\begin{array}{l}y=-0,6836+0,0556^{\star} X \\
y=4,1301-0,0153^{\star} X \\
y=-0,1323+0,0119^{\star} X\end{array}$ & $\begin{array}{l}0,84 \\
0,69 \\
0,88\end{array}$ & $\begin{array}{l}<1 \% \\
<1 \% \\
<1 \%\end{array}$ & $\begin{array}{r}41,83 \\
9,18 \\
34,43\end{array}$ \\
\hline Total & $y=3,3142+0,0523^{*} x$ & 0,74 & $<1 \%$ & 16,87 \\
\hline
\end{tabular}




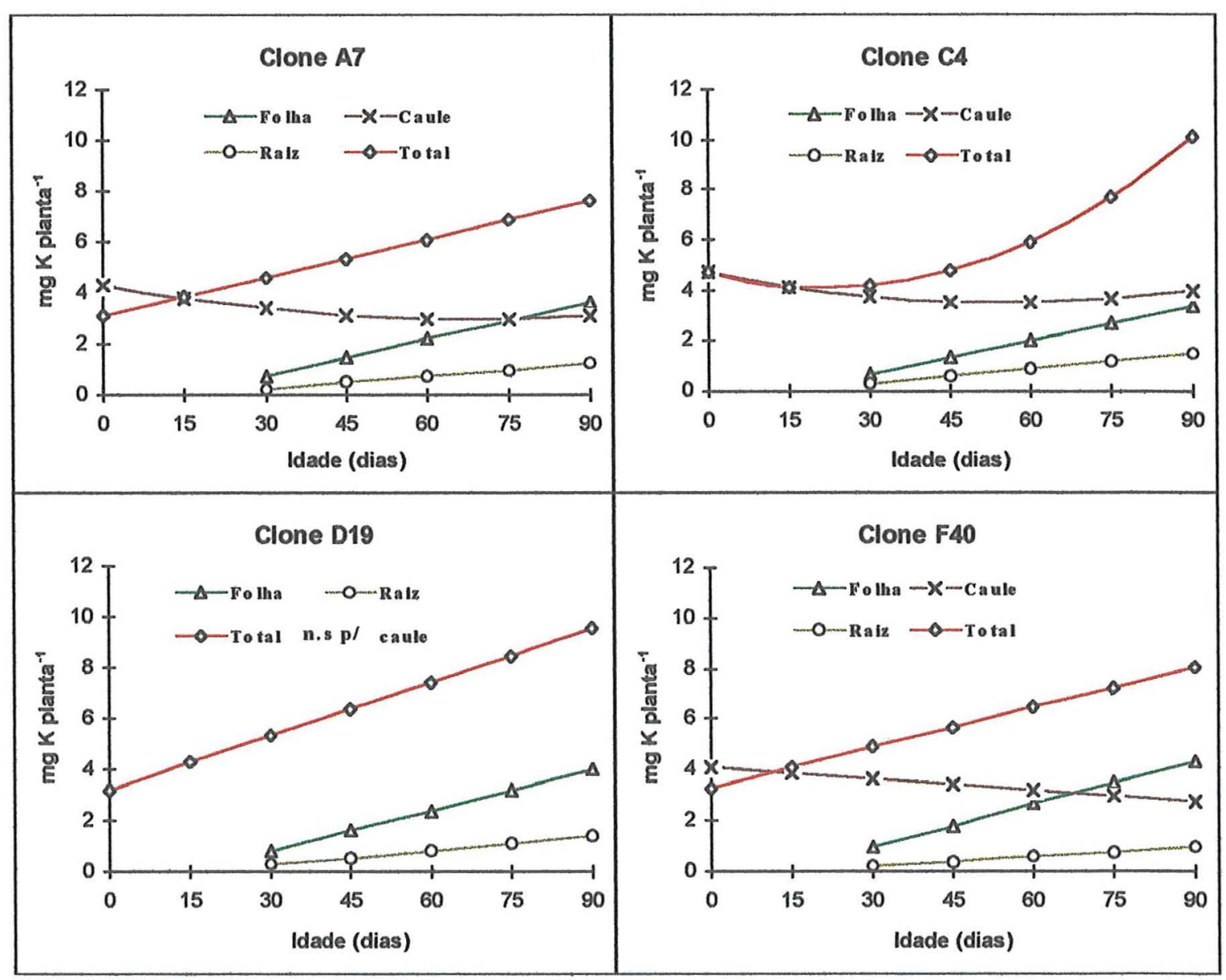

Figura 7 - Quantidades de potássio $\left(m g\right.$ planta $\left.{ }^{-1}\right)$ nas diferentes partes e planta inteira, nos clones de Eucalyptus estudados, em função da idlade (dias). 


\subsubsection{Cálcio}

\subsubsection{Concentração}

Diferenças significativas nos teores de cálcio foram observados nas folhas e no caule, nos quatro clones de Eucalyptus estudados, conforme mostra a Tabela 18. As maiores concentrações de cálcio, aos noventa dias de idade, foram observadas nas folhas e as menores nas raízes, enquanto que no caule os teores encontrados são semelhantes aos obtidos para as folhas (clones D19 e F40) e para as raizes (clones A7 e C4), de 6,8; 6,2 e 3,$9 ; 3,4 \mathrm{~g} \mathrm{~kg}^{-1}$, respectivamente. As folhas apresentaram tendência de aumento no teor de cálcio em função da idade, enquanto que o caule apresentou situação inversa e as raizes mostraram pouca ou nenhuma variação. Entre os clones, diferenças na concentração de cálcio nas folhas foram observadas em relação aos clones A7 e F40. No caule as diferenças foram entre os clones $\mathrm{A} 7$ e $\mathrm{C} 4$, em relação ao clone $\mathrm{D} 19$, que difere do clone F40 e os clones A7 e F40 em relação aos clones C4 e D19 para as raízes.

Os teores de cálcio observados aos noventa dias, no presente estudo de 6,2 a $6,9 \mathrm{~g} \mathrm{~kg}^{-1}$ para as folhas; 3,8 a $6.3 \mathrm{~g} \mathrm{~kg}^{-1}$ para os caules e de 3,3 a $3,9 \mathrm{~g} \mathrm{~kg}^{-1}$ para as raízes, são inferiores aos encontrados por Silveira et al.(1995), em estudo com E. grandis, realizado em mudas com 97 dias de idade, cujos teores obtidos para as folhas foram de $9,9 \mathrm{~g} \mathrm{~kg}^{-1}$ e para o caule de $12,2 \mathrm{~g} \mathrm{~kg}^{-1}$, ou em qualquer outra idade comparativa. Em outros trabalhos, Kaul et al. (1966), (1968) e (1970), obtiveram valores foliares de $14,8 \mathrm{~g} \mathrm{~kg}^{-1}$, $8,4 \mathrm{~g} \mathrm{~kg}^{-1}$ e $15,0 \mathrm{~g} \mathrm{~kg}^{-1}$ de Cálcio, para um eucalipto hibrido, $E$. grandis e $E$. globulus, respectivamente. 
Tabela 18. Concentração de cálcio nas diversas partes da planta, nos clones de Eucalyptus estudados, em função da idade.

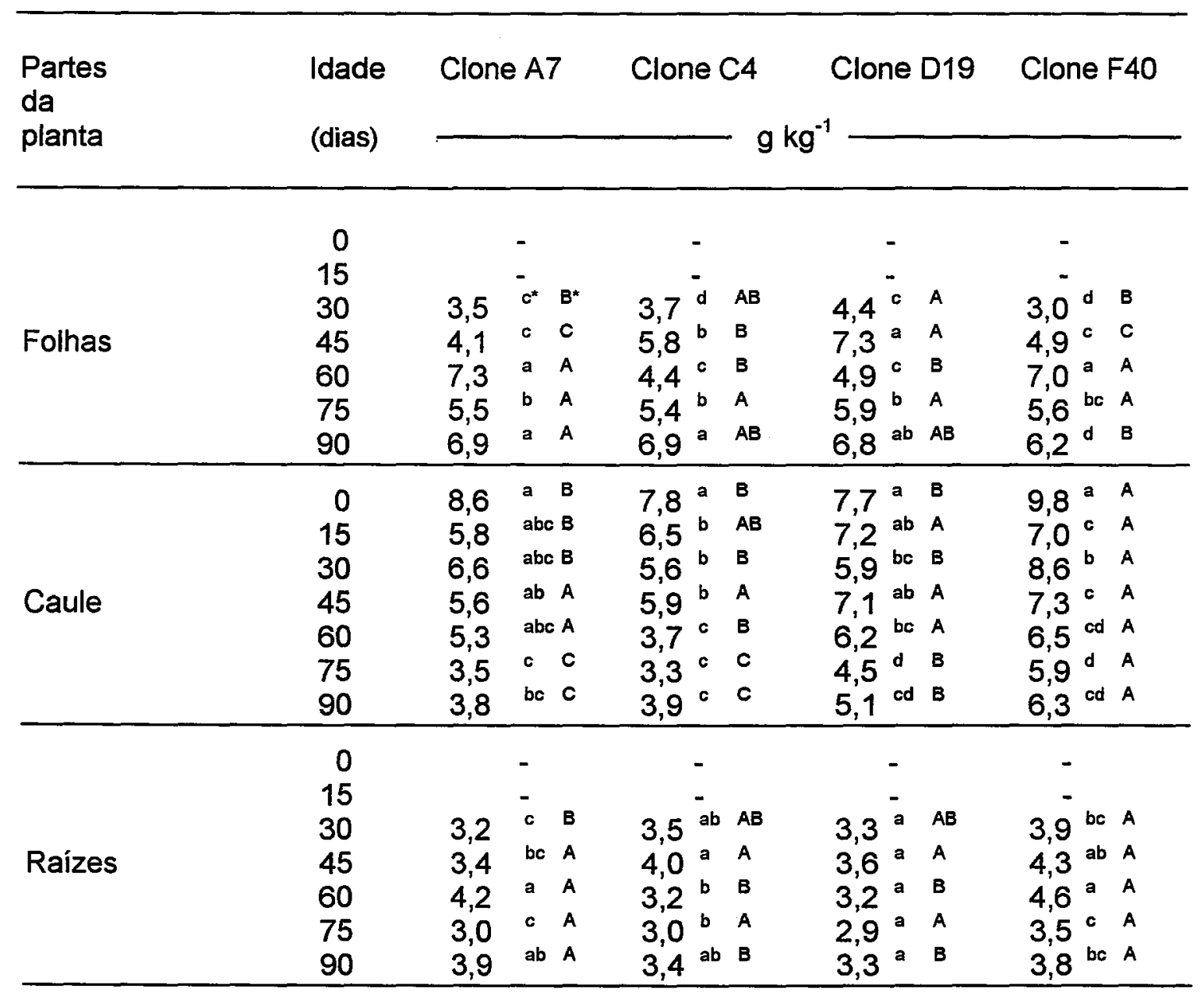

(*) OBS: Letras maiúsculas diferentes em cada linha e letras minúsculas diferentes em cada coluna, indicam diferença significativa ao nivel de $5 \%$ de probabilidade, entre clones e entre idades, respectivamente. 
As concentrações foliares de cálcio nas mudas dos clones de Eucalyptus observadas neste trabalho, são semelhantes à aquelas encontradas por Belloti (1979) em plantas adultas de eucalipto e por Rocha Filho et al. (1978) em mudas de $E$. urophylla cultivadas em solução nutritiva completa, cujos teores foram de $6,4 \mathrm{~g} \mathrm{~kg}^{-1}$ nas folhas superiores, $8,0 \mathrm{~g} \mathrm{~kg}^{-1}$, nas folhas medianas, $13,0 \mathrm{~g} \mathrm{~kg}^{-1}$ nas folhas inferiores, $9,4 \mathrm{~g} \mathrm{~kg}^{-1}$ no caule e de $16,4 \mathrm{~g} \mathrm{~kg}^{-1}$ nas raizes.

Contudo, o estudo apresenta valores superiores se comparados ao trabalho realizado por Haag et al. (1961) com mudas de E. alba cujos teores analisados foram de $3,0 \mathrm{~g} \mathrm{~kg}^{-1}$ nas folhas superiores, $3,4 \mathrm{~g} \mathrm{~kg}^{-1}$ nas folhas inferiores, $2,4 \mathrm{~g} \mathrm{~kg}^{-1}$ no caule e de $2,2 \mathrm{~g} \mathrm{~kg}^{-1}$ nas raízes. A concentração de $6,9 \mathrm{~g} \mathrm{~kg}^{-1}$ de cálcio encontrada nas folhas, estão dentro da faixa considerada como adequada por Dell et al. (1995), de 5,0 a $8,0 \mathrm{~g} \mathrm{~kg}^{-1}$ para mudas de $E$. grandis aos noventa dias de idade.

A concentração de cálcio para o caule e folhas dos clones C4 e F40, respectivamente, ajustaram-se a equações do segundo grau. Para as folhas, dos clones A7 e C4, para o caule nos clones A7, D19 e F40, ajustaram-se equações lineares, enquanto que para as raizes em todos os clones e folhas, no clone $\mathrm{D} 19$, não houve variação significativa, ao nível de $5 \%$ de probabilidade, conforme mostra a Tabela 19 e Figura 8. 
Tabela 19. Equação de regressão para teor de cálcio $\left(\mathrm{g}^{\mathrm{kg}}{ }^{-1}\right)$, nas diversas partes da planta, nos clones de Eucalyptus estudados, em função da idade (dias).

\begin{tabular}{|c|c|c|c|c|c|}
\hline Clones & Partes da planta & Equação & $\mathrm{R}^{2}$ & Prob. & C.V. \\
\hline $\begin{array}{l}\text { A7 } \\
\text { C4 } \\
\text { D19 } \\
\text { F40 }\end{array}$ & $\begin{array}{l}\text { Folhas } \\
\text { Folhas } \\
\text { Folhas } \\
\text { Folhas }\end{array}$ & $\begin{array}{l}y=2,2250+0,0545^{*} X \\
y=2,8550+0,0400^{*} X \\
\text { não significativo } \\
y=-3,5700+0,2789^{*} X-0,0019^{*} X^{2}\end{array}$ & $\begin{array}{l}0,58 \\
0,58 \\
0,78\end{array}$ & $\begin{array}{l}<1 \% \\
<1 \% \\
<1 \%\end{array}$ & $\begin{array}{l}19,37 \\
14,55 \\
13,16\end{array}$ \\
\hline $\begin{array}{l}\text { A7 } \\
\text { C4 } \\
\text { D19 } \\
\text { F40 }\end{array}$ & $\begin{array}{l}\text { Caule } \\
\text { Caule } \\
\text { Caule } \\
\text { Caule }\end{array}$ & $\begin{array}{l}y=7,7946-0,0482^{*} X \\
y=7,7798-0,0789^{*} X+0,0003^{*} X^{2} \\
y=7,6312-0,0303^{*} X \\
y=8,9196-0,0346^{*} X\end{array}$ & $\begin{array}{l}0,75 \\
0,83 \\
0,58 \\
0,62\end{array}$ & $\begin{array}{l}<1 \% \\
<5 \% \\
<1 \% \\
<1 \%\end{array}$ & $\begin{array}{l}15,59 \\
13,08 \\
12,74 \\
11,58\end{array}$ \\
\hline $\begin{array}{l}\text { A7 } \\
\text { C4 } \\
\text { D19 } \\
\text { F40 }\end{array}$ & $\begin{array}{l}\text { Raízes } \\
\text { Raízes } \\
\text { Raízes } \\
\text { Raízes }\end{array}$ & $\begin{array}{l}\text { não significativo } \\
\text { não significativo } \\
\text { não significativo } \\
\text { não significativo }\end{array}$ & & & \\
\hline
\end{tabular}




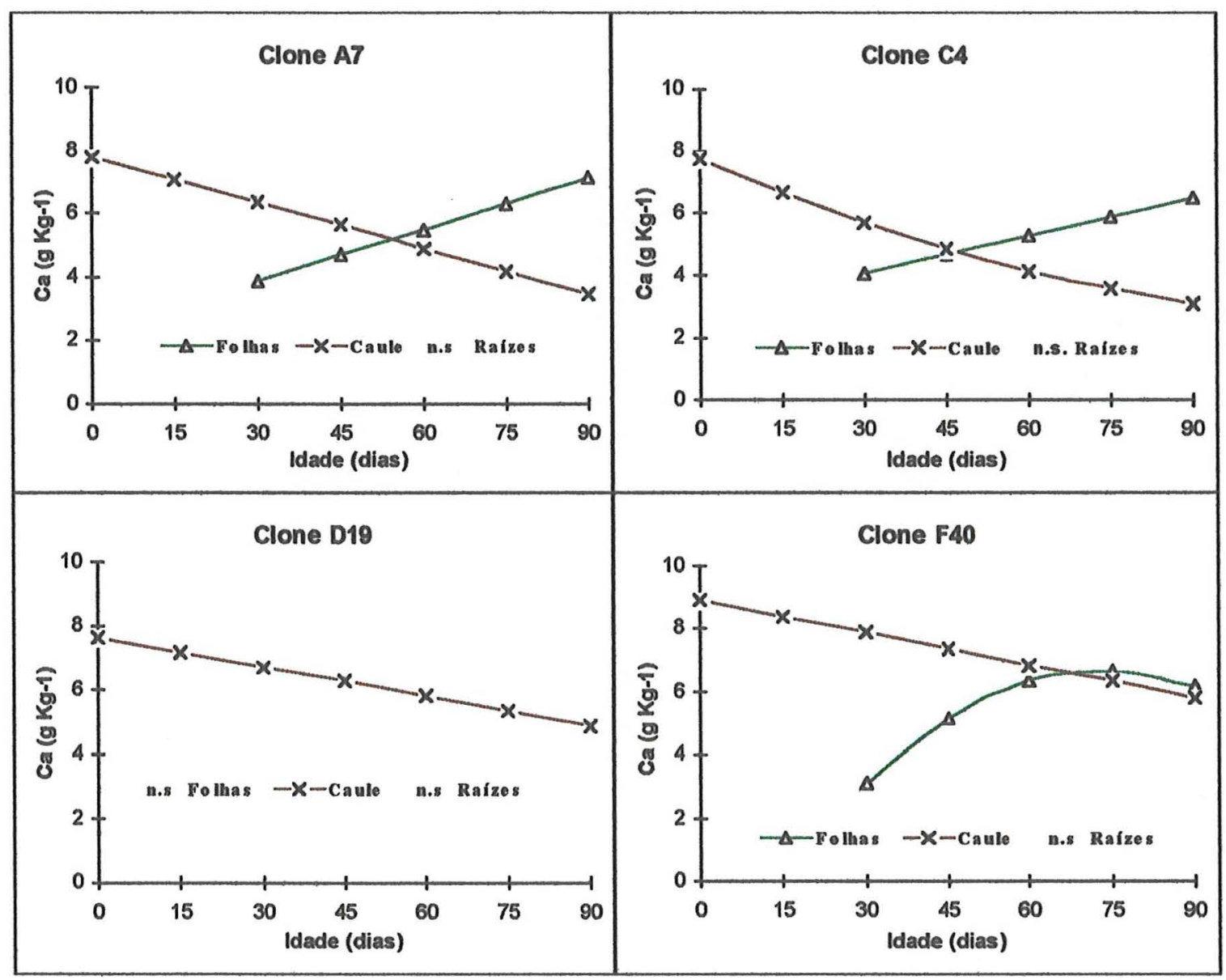

Figura 8 - Teores de cálcio $\left(\mathrm{g} \mathrm{kg}^{-1}\right)$, nas diferentes partes da planta, nos clones de Eucalyptus estudados, em função da idade (dias). 


\subsubsection{Acúmulo}

As quantidades de cálcio acumuladas, nas diversas partes da planta, nas diferentes idades, são mostradas na Tabela 20 . Verifica-se que houve diferenças na acumulação do elemento, sendo esse, um efeito crescente para as folhas, raízes e total e decrescente para o caule. Entre os clones estudados, observou-se variação significativa para as folhas e raízes no clone F40 em relação aos demais clones. No caule, o clone D19 diferiu dos clones A7 e C4. Para o acúmulo total de cálcio o clone D19 foi significativamente diferente apenas do clone F40.

O conteúdo de cálcio observado nos clones A7, C4, D19 e F40, nas folhas $\left(2,15 ; 2,20 ; 2,12\right.$ e 1,66 mg planta $\left.^{-1}\right)$, no caule $(1,69 ; 1,65 ; 2,09$ e 1,98 mg planta $\left.{ }^{-1}\right)$ e nas raizes $\left(0,45 ; 0,47 ; 0,48\right.$ e 0,32 mg planta $\left.^{-1}\right)$, são menores se comparados com os valores, obtidos por Silveira et al. (1995), de 5,20; 4,61 e $2,23 \mathrm{mg}$ planta ${ }^{-1}$, para folhas, caule e raizes, respectivamente.

$\mathrm{O}$ acúmulo de cálcio no caule e total, nos clones $\mathrm{A} 7$ e $\mathrm{C} 4$, ajustaramse a regressões do segundo grau, enquanto que para as folhas, raízes e para o caule e total, nos clones D19 e F40, foram representados por equações lineares, conforme podemos observar na Tabela 21 e Figura 9. 
Tabela 20. Acúmulo de cálcio, nas diversas partes da planta, nos clones de Eucalyptus estudados, em função da idade.

\begin{tabular}{|c|c|c|c|c|c|c|c|c|c|c|}
\hline \multirow{2}{*}{$\begin{array}{l}\text { Partes } \\
\text { da } \\
\text { planta }\end{array}$} & \multirow{2}{*}{$\begin{array}{c}\text { Idade } \\
\text { (dias) } \\
\\
0 \\
15 \\
30 \\
45 \\
60 \\
75 \\
90 \\
\end{array}$} & \multicolumn{3}{|c|}{ Clone A7 } & \multicolumn{2}{|c|}{ Clone C4 } & \multicolumn{2}{|c|}{ Clone D19 } & \multicolumn{2}{|c|}{ Clone F40 } \\
\hline & & $\begin{array}{l}0,10 \\
0,28 \\
1,07 \\
2,01 \\
2,15 \\
\end{array}$ & $\begin{array}{l}- \\
- \\
c^{*} \\
c \\
b \\
a \\
a\end{array}$ & $\begin{array}{l}A B^{*} \\
B \\
A \\
A \\
A\end{array}$ & $\begin{array}{l}0,06 \\
0,28 \\
0,49 \\
1,83 \\
2,20 \\
\end{array}$ & $\begin{array}{ll}- & \\
- & \\
d & B \\
\text { cd } & B \\
\text { C } & B \\
b & A \\
\text { a } & \text { A } \\
\end{array}$ & $\begin{array}{l}0,13 \\
0,46 \\
0,59 \\
2,04 \\
2,12 \\
\end{array}$ & $\begin{array}{ll}- & \\
- & \\
c & A \\
b & A \\
b & B \\
a & A \\
a & A \\
\end{array}$ & 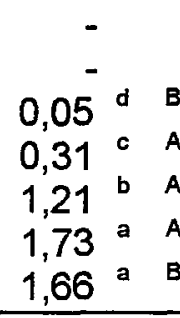 & $\begin{array}{l}B \\
A B \\
A \\
A \\
B\end{array}$ \\
\hline Caule & $\begin{array}{r}0 \\
15 \\
30 \\
45 \\
60 \\
75 \\
90 \\
\end{array}$ & $\begin{array}{l}3,15 \\
2,22 \\
2,35 \\
2,41 \\
1,78 \\
1,73 \\
1,69 \\
\end{array}$ & $\begin{array}{l}a \\
a b \\
a b \\
a b \\
b \\
b \\
b\end{array}$ & $\begin{array}{l}A \\
A B \\
A B \\
A \\
A \\
B C \\
B\end{array}$ & $\begin{array}{l}2,44 \\
1,80 \\
1,82 \\
1,84 \\
1,23 \\
1,46 \\
1,65 \\
\end{array}$ & $\begin{array}{ll}a & B \\
b & B \\
b & B \\
b & A \\
c & B \\
b c & C \\
b c & B \\
\end{array}$ & $\begin{array}{l}2,37 \\
2,59 \\
2,17 \\
2,26 \\
2,05 \\
2,13 \\
2,09 \\
\end{array}$ & $\begin{array}{ll}\text { a } & \text { B } \\
\text { a } & A \\
\text { a } & B \\
\text { a } & A \\
\text { a } & A \\
\text { a } & A B \\
\text { a } & A \\
\end{array}$ & $\begin{array}{l}3,25 \text { a } A \\
2,56 \text { be } A \\
2,93 \text { ab } A \\
2,39 \text { ad } A \\
2,08 \text { de } A \\
2,23 \text { cde } A \\
1,98\end{array}$ & $\begin{array}{l}\text { A } \\
A \\
A \\
A \\
A \\
A \\
A B\end{array}$ \\
\hline Raízes & $\begin{array}{r}0 \\
15 \\
30 \\
45 \\
60 \\
75 \\
90 \\
\end{array}$ & $\begin{array}{l}0,02 \\
0,06 \\
0,18 \\
0,33 \\
0,45 \\
\end{array}$ & $\begin{array}{l}- \\
- \\
d \\
d \\
c \\
b \\
a\end{array}$ & $\begin{array}{l}B \\
C \\
A B \\
A \\
A\end{array}$ & $\begin{array}{l}0,06 \\
0,10 \\
0,12 \\
0,31 \\
0,47\end{array}$ & $\begin{array}{ll}- & \\
- & \\
c & A \\
c & A B \\
c & C \\
b & A \\
a & A \\
\end{array}$ & $\begin{array}{l}0,05 \\
0,12 \\
0,13 \\
0,36 \\
0,48 \\
\end{array}$ & $\begin{array}{ll}- & \\
- & \\
\text { d } & A \\
\text { cd } & \text { A } \\
\text { c } & B C \\
\text { b } & \text { A } \\
\text { a } & \text { A } \\
\end{array}$ & $\begin{array}{c}- \\
- \\
0,03^{\text {d }} \\
0,08^{\circ} \\
0,19 \\
0,29 \\
0,32\end{array}$ & $\begin{array}{l}B \\
B C \\
A \\
A \\
B\end{array}$ \\
\hline Total & $\begin{array}{r}0 \\
15 \\
30 \\
45 \\
60 \\
75 \\
90\end{array}$ & $\begin{array}{l}3,15 \\
2,22 \\
2,47 \\
2,75 \\
3,03 \\
4,07 \\
4,29\end{array}$ & $\begin{array}{l}a b c \\
c \\
c \\
b c \\
a b c \\
a b \\
a\end{array}$ & $\begin{array}{l}A \\
A B \\
A B \\
A \\
=A B \\
A B \\
A B\end{array}$ & $\begin{array}{l}2,44 \\
1,80 \\
1,94 \\
2,22 \\
1,84 \\
3,60 \\
4,32\end{array}$ & $\begin{array}{ll}\text { C } & B \\
\text { d } & B \\
\text { cd } & B \\
\text { cd } & A \\
\text { d } & \text { C } \\
\text { b } & B \\
\text { a } & \text { AB }\end{array}$ & $\begin{array}{l}2,37 \\
2,59 \\
2,35 \\
2,84 \\
2,77 \\
4,53 \\
4,69\end{array}$ & $\begin{array}{ll}\mathbf{b} & \mathbf{B} \\
\mathbf{b} & \mathbf{A} \\
\mathbf{b} & \mathrm{AB} \\
\mathbf{b} & \mathbf{A} \\
\mathbf{b} & \mathrm{B} \\
\mathbf{a} & \mathbf{A} \\
\mathbf{a} & \mathrm{A}\end{array}$ & $\begin{array}{l}3,25 \text { bc } \\
2,56 \text { d } \\
3,01 \text { cd } \\
2,78 \text { d } \\
3,48 \\
4,25 \\
3,96\end{array}$ & $\begin{array}{l}\text { A } \\
\text { A } \\
\text { A } \\
\text { A } \\
\text { A } \\
\text { A } \\
\text { B }\end{array}$ \\
\hline
\end{tabular}

(*) OBS: Letras maiúsculas diferentes em cada linha e letras minúsculas diferentes em cada coluna, indicam diferença significativa ao nível de $5 \%$ de probabilidade, entre clones e entre idades, respectivamente. 
Aos noventa dias de idade, as quantidades de cálcio acumuladas nas folhas pelos clones A7, C4, D19 e F40, representaram 50,12; 50,93; 45,20 e $41,92 \%$ do total. Para o caule, os valores obtidos responderam por 39,39 ; 38,$19 ; 44,56$ e $50,00 \%$ e as raízes, 10,$49 ; 10,88 ; 10,23$ e $8,08 \%$, respectivamente.

Tabela 21. Equação de regressão para acúmulo de cálcio (mg planta-1), nas diversas partes da planta, nos clones de Eucalyptus estudados, em função da idade (dias).

\begin{tabular}{|c|c|c|c|c|}
\hline Partes da planta & Equação & R2 & Prob. & C.V. \\
\hline \multicolumn{5}{|l|}{ CLONE A7 } \\
\hline $\begin{array}{l}\text { Folhas } \\
\text { Caule } \\
\text { Raizes }\end{array}$ & $\begin{array}{l}y=-0,4250+0,0273^{*} X \\
y=3,0164-0,0365^{*} X+0,0002^{*} x^{2} \\
y=-0,0855+0,0051^{*} X\end{array}$ & $\begin{array}{l}0,85 \\
0,75 \\
0,83\end{array}$ & $\begin{array}{l}<1 \% \\
<1 \% \\
<1 \%\end{array}$ & $\begin{array}{l}44,82 \\
13,58 \\
49,77\end{array}$ \\
\hline Total & $y=2,9557-0,0400^{*} x+0,0006^{*} x^{2}$ & 0,77 & $<1 \%$ & 14,11 \\
\hline \multicolumn{5}{|l|}{ CLONE C4 } \\
\hline $\begin{array}{l}\text { Folhas } \\
\text { Caule } \\
\text { Raízes }\end{array}$ & $\begin{array}{l}y=-0,4500+0,0254^{*} X \\
y=2,3695-0,0272^{*} X+0,0002^{*} X^{2} \\
y=-0,0781+0,0053^{*} X\end{array}$ & $\begin{array}{l}0,79 \\
0,59 \\
0,82\end{array}$ & $\begin{array}{l}<1 \% \\
<1 \% \\
<1 \%\end{array}$ & $\begin{array}{l}59,45 \\
15,48 \\
48,06\end{array}$ \\
\hline Total & $y=2,4168-0,0426^{*} x+0,0007^{*} x^{2}$ & 0,84 & $<1 \%$ & 15,63 \\
\hline \multicolumn{5}{|l|}{ CLONE D19 } \\
\hline $\begin{array}{l}\text { Folhas } \\
\text { Caule } \\
\text { Raizes }\end{array}$ & $\begin{array}{l}y=-0,4027+0,0259^{*} X \\
y=2,4415-0,0045^{*} X \\
y=-0,0772+0,0053^{*} x\end{array}$ & $\begin{array}{l}0,82 \\
0,19 \\
0,84\end{array}$ & $\begin{array}{l}<1 \% \\
<5 \% \\
<1 \%\end{array}$ & $\begin{array}{l}50,07 \\
12,74 \\
44,23\end{array}$ \\
\hline Total & $y=1,9620+0,0267^{\star} x$ & 0,68 & $<1 \%$ & 17,98 \\
\hline \multicolumn{5}{|l|}{ CLONE F40 } \\
\hline $\begin{array}{l}\text { Folhas } \\
\text { Caule } \\
\text { Raizes }\end{array}$ & $\begin{array}{l}y=-0,3194+0,0229^{*} X \\
y=3,0620-0,0127^{*} x \\
y=-0,0530+0,0041^{*} x\end{array}$ & $\begin{array}{l}0,86 \\
0,71 \\
0,91\end{array}$ & $\begin{array}{l}<1 \% \\
<1 \% \\
<1 \%\end{array}$ & $\begin{array}{l}40,66 \\
10,24 \\
30,04\end{array}$ \\
\hline Total & $y=2,6883+0,0143^{*} x$ & 0,52 & $<1 \%$ & 12,87 \\
\hline
\end{tabular}




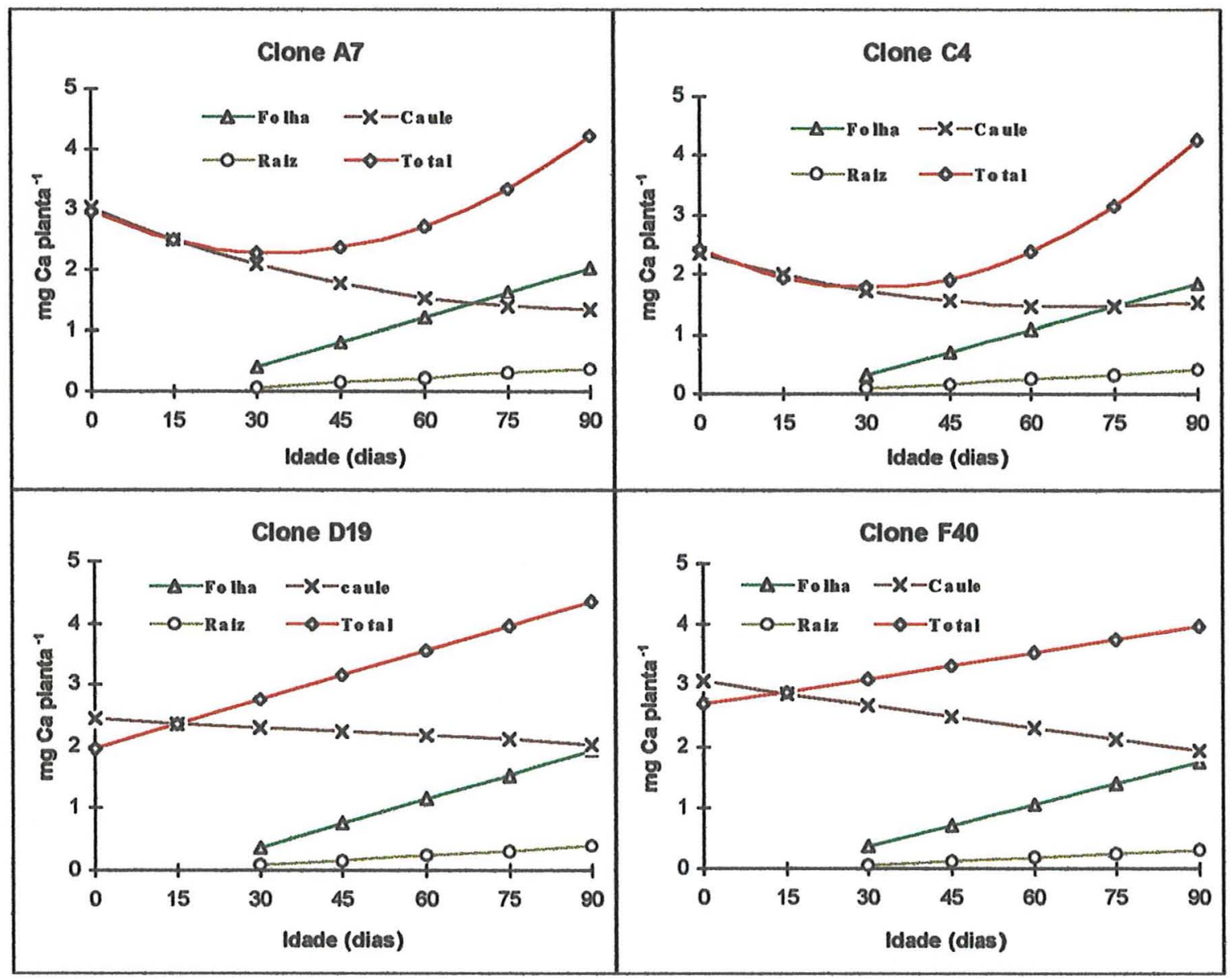

Figura 9 - Quantidades de cálcio ( $\left(\mathrm{mg}^{\mathrm{a}}\right.$ planta $\left.{ }^{-1}\right)$, nas diferentes partes e planta inteira, nos clones de Eucalyptus estudados, em função da idlade (dias). 


\subsubsection{Magnésio}

\subsubsection{Concentração}

$\mathrm{Na}$ Tabela 22 são apresentados os dados analíticos referentes às concentrações de magnésio, nas diferentes partes da planta, em função da idade. Os teores de magnésio aumentaram com as idades das plantas, para todos os órgãos, tendo as raízes apresentado os maiores valores, seguido das folhas e caules. Observa-se que as folhas apresentaram diferenças nas concentrações de magnésio enquanto que os caules e raízes não mostraram variações, de acordo com as idades.

Aos noventa dias de idade, ocorreu variação significativa para o teor de magnésio nas folhas, para o clone $\mathrm{C} 4$ em relação aos clones A7 e D19 e para o caule entre o clone F40 e clone D19, sendo que este diferiu dos demais. Nas raizes as variações ocorreram entre o clone F40 e os clones C4 e D19.

O último tratamento utilizado nesse estudo, mostrou que as concentrações de magnésio, nos clones estudados variaram de 5,7 a $6,5 \mathrm{~g}$ $\mathrm{kg}^{-1}$ para as folhas, 1,7 a $3,9 \mathrm{~g} \mathrm{~kg}^{-1}$ para os caules e de 13,9 a $21,3 \mathrm{~g} \mathrm{~kg}^{-1}$ nas raízes.

Segundo Dell et al. (1995), o teor adequado de magnésio para as folhas de $E$. grandis, na fase de viveiro, está entre 1,6 a $2,0 \mathrm{~g} \mathrm{~kg}^{-1}$ de matéria seca. Entretanto, são valores apenas encontrados nos caules dos clones A7 e C4 somente, sendo que as folhas e principalmente as raízes, nos quatro clones estudados apresentaram concentrações acima desse valor. 
Tabela 22. Concentração de magnésio, nas diversas partes da planta, nos clones de Eucalyptus estudados, em função da idade.

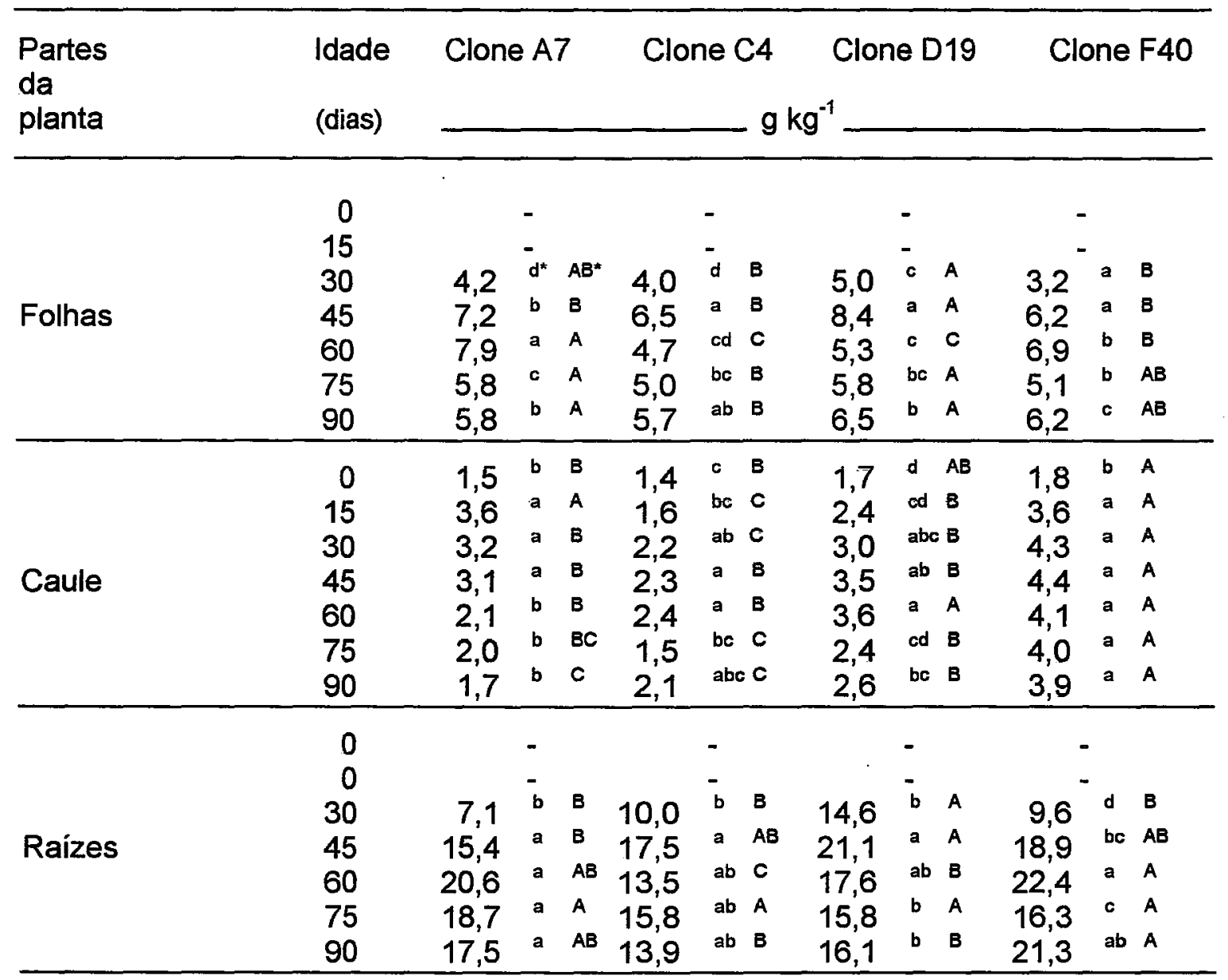

(*) OBS: Letras maiúsculas diferentes em cada linha e letras minúsculas diferentes em cada coluna, indicam diferença significativa ao nível de $5 \%$ de probabilidade, entre clones e entre idades, respectivamente. 
Kaul et al. (1966) e (1968), obtiveram valores foliares de $2,6 \mathrm{~g} \mathrm{~kg}^{-1} \mathrm{e}$ $2,9 \mathrm{~g} \mathrm{~kg}^{-1}$ de magnésio, para um eucalipto hibrido e $E$. grandis respectivamente. Rocha Filho et al. (1978) em mudas de E. urophylla cultivadas em solução nutritiva completa, apresentaram teores de magnésio para as folhas superiores de $1,7 \mathrm{~g} \mathrm{~kg}^{-1}$, folhas medianas de $1,3 \mathrm{~g} \mathrm{~kg}^{-1}$, folhas inferiores $1,9 \mathrm{~g} \mathrm{~kg}^{-1}$, para o caule de $1,1 \mathrm{~g} \mathrm{~kg}^{-1} \mathrm{e}$ raiz de $1,5 \mathrm{~g} \mathrm{~kg}^{-1}$. Enquanto que Silveira et al. (1995) encontraram teores foliares de $3,3 \mathrm{~g} \mathrm{~kg}^{-1}$, para o caule $1,7 \mathrm{~g} \mathrm{~kg}^{-1}$ e para as raízes $3,8 \mathrm{~g} \mathrm{~kg}^{-1}$.

O presente estudo apresenta valores superiores se comparados ao trabalho realizado a Haag et al. (1961) com mudas de $E$. alba cujos teores analisados foram de $5,2 \mathrm{~g} \mathrm{~kg}^{-1}$ nas folhas superiores, $5,1 \mathrm{~g} \mathrm{~kg}^{-1}$ nas folhas inferiores, $2,8 \mathrm{~g} \mathrm{~kg}^{-1}$ nas raízes e de $2,7 \mathrm{~g} \mathrm{~kg}^{-1}$ no caule. Entretanto, para a concentração de Ca no caule, apenas o clone F40 foi superior aos valores acima citados, sendo que nos demais clones estudados, os teores foram menores para o caule.

Como podemos observar, os teores de magnésio encontrados nas raizes, no presente trabalho, estão acima dos valores obtidos em outros trabalhos com eucalipto. A presença de vermiculita, mineral em grande quantidade e alto teor no substrato utilizado na produção das mudas, pode ter superestimado os valores encontrados (Tabela 2).

A concentração de magnésio para as folhas e raízes, nos clones $A 7$ e F40, ajustaram-se a equações de regressão do segundo grau, o mesmo acontecendo para o caule, nos clones C4, D19 e F40. O caule, no clone A7, as folhas e raizes, nos clones C4 e D19, não foram significativos, conforme mostra a Tabela 23 e Figura 10. 
Tabela 23. Equação de regressão para teor de magnésio $\left(\mathrm{g} \mathrm{kg}^{-1}\right)$, nas diversas partes da planta, nos clones de Eucalyptus estudados, em função da idade (dias).

\begin{tabular}{|c|c|c|c|c|}
\hline Clones & Partes da planta & Equação & $\mathrm{R}^{2}$ & Prob. C.V. \\
\hline $\begin{array}{l}\text { A7 } \\
\text { C4 } \\
\text { D19 } \\
\text { F40 }\end{array}$ & $\begin{array}{l}\text { Folhas } \\
\text { Folhas } \\
\text { Folhas } \\
\text { Folhas }\end{array}$ & $\begin{array}{l}y=-2,0600+0,2908^{*} X-0,0022^{*} X^{2} \\
\text { não significativo } \\
\text { não significativo } \\
y=-2,6650+0,2696^{*} X-0,0020^{*} X^{2}\end{array}$ & 0,56 & $\begin{array}{l}<1 \% \quad 14,78 \\
<1 \% \quad 17,87\end{array}$ \\
\hline $\begin{array}{l}\text { A7 } \\
\text { C4 } \\
\text { D19 } \\
\text { F40 }\end{array}$ & $\begin{array}{l}\text { Caule } \\
\text { Caule } \\
\text { Caule } \\
\text { Caule }\end{array}$ & $\begin{array}{l}y=2,1065+0,0506^{*} X-0,0007^{*} X^{2} \\
y=1,3881+0,0322^{*} X-0,0003^{*} X^{2} \\
y=1,6887+0,0648^{*} X-0,0006^{*} X^{2} \\
y=2,1946+0,0836^{*} X-0,0007^{*} X^{2}\end{array}$ & $\begin{array}{l}0,50 \\
0,38 \\
0,60 \\
0,69\end{array}$ & $\begin{array}{ll}<1 \% & 24,46 \\
<1 \% & 19,50 \\
<1 \% & 17,12 \\
<1 \% & 14,24\end{array}$ \\
\hline $\begin{array}{l}\text { A7 } \\
\text { C4 } \\
\text { D19 } \\
\text { F40 }\end{array}$ & $\begin{array}{l}\text { Raizes } \\
\text { Raizes } \\
\text { Raizes } \\
\text { Raizes }\end{array}$ & $\begin{array}{l}y=-19,7950+1,1527^{*} X-0,0083^{*} X^{2} \\
\text { não significativo } \\
\text { não significativo } \\
y=-8,9850+0,8385^{*} X-0,0058^{*} X^{2}\end{array}$ & 0,79 & $<1 \% \quad 16,31$ \\
\hline
\end{tabular}




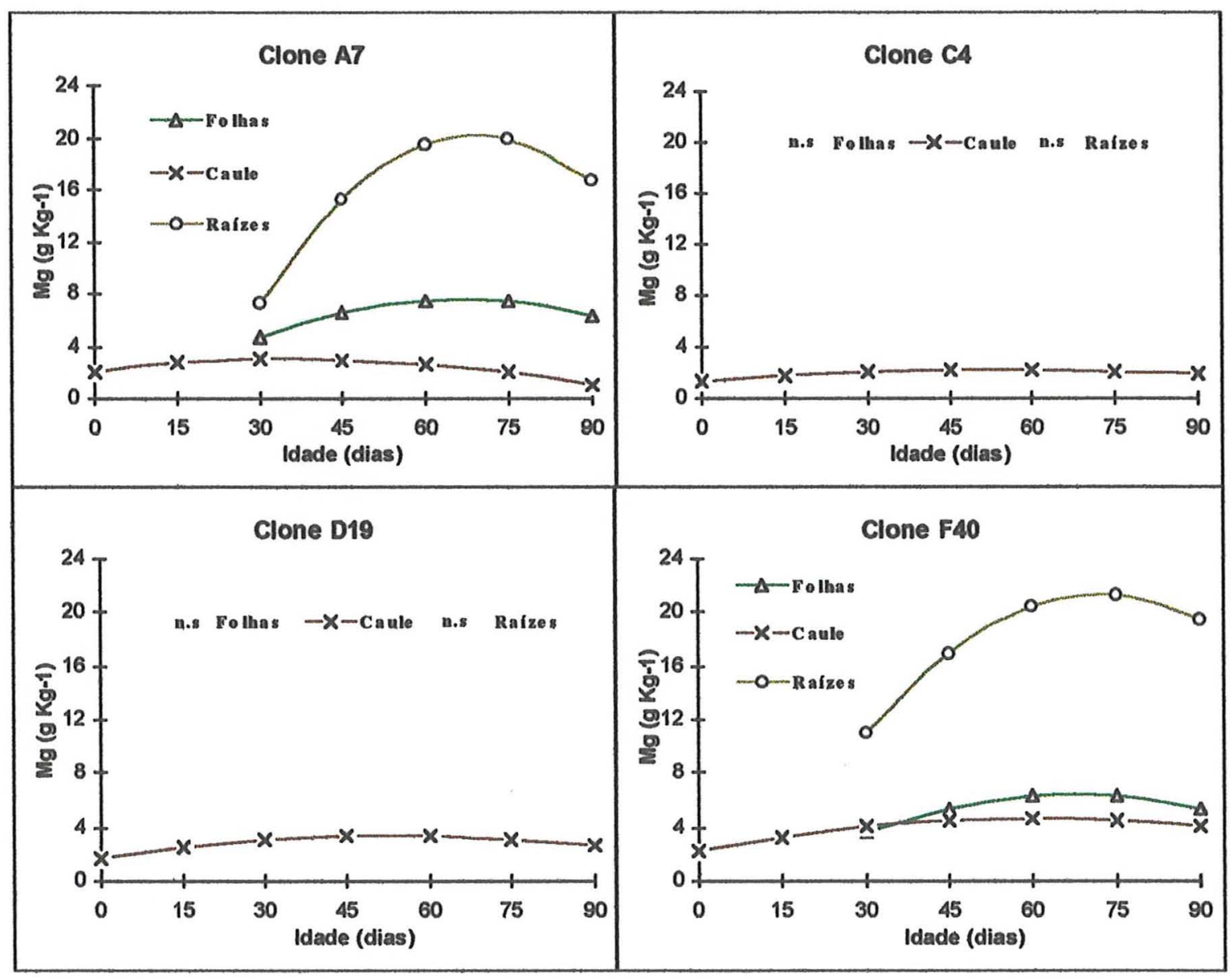

Figura 10 - Teores de magnésio (g $\left.\mathrm{kg}^{-1}\right)$, nas diferentes partes da planta, nos clones de Eucalyptus estudados, em função da idade (dias). 


\subsubsection{Acúmulo}

As quantidades de magnésio acumuladas pelas partes e planta inteira, em função das idades, encontram-se na Tabela 24. O conteúdo do elemento aumentou para folhas, raízes e na planta inteira, não havendo diferenças para o acúmulo de magnésio no caule dos clones estudados, Aos noventa dias de idade, o acúmulo de magnésio entre os clones não mostraram diferenças significativas para as folhas e total, entretanto, no caule, o clone A7 diferiu dos clones D19 e F40 e nas raízes a diferenciação ocorreu entre o clone A7 em relação aos clones C4 e D19.

O acúmulo de magnésio, nas mudas dos quatro clones de Eucalyptus. estudados, aos noventa dias de idade, são maiores em todos os órgãos, se comparados aos valores para folhas $\left(1,80 \mathrm{mg}\right.$ planta $\left.{ }^{-1}\right)$, caule $\left(0,43 \mathrm{mg}\right.$ planta $\left.^{-1}\right)$ e raízes $\left(1,37 \mathrm{mg} \mathrm{planta}^{-1}\right)$, descritos por Silveira et al. (1995).

Os clones A7, C4, D19 e F40 apresentavam, aos noventa dias, quantidades acumuladas de magnésio nas folhas, que correspondiam por 58,$31 ; 39,27 ; 37,43$ e $35,39 \%$ do total, enquanto que o caule e as raizes representaram 20,$84 ; 18,67 ; 19,63$ e $26,01 \%$ e 20,$84 ; 42,06 ; 42,93$ e $38,59 \%$, respectivamente.

Com exceção do clone $\mathrm{C} 4$, o acúmulo de magnésio no caule, foi ajustado por equações de regressão do segundo grau. Para as folhas e raízes, em todos os clones de Eucalyptus estudados e para o total, no clone F40, ajustaram-se equações lineares, sendo que o acúmulo de magnésio não foi significativo para os totais, nos clones A7, C4 e D19, conforme pode-se observar na Tabela 25 e Figura 11. 
Tabela 24. Acúmulo de magnésio nos clones de Eucalyptus estudados, nas diversas partes da planta, em função da idade.

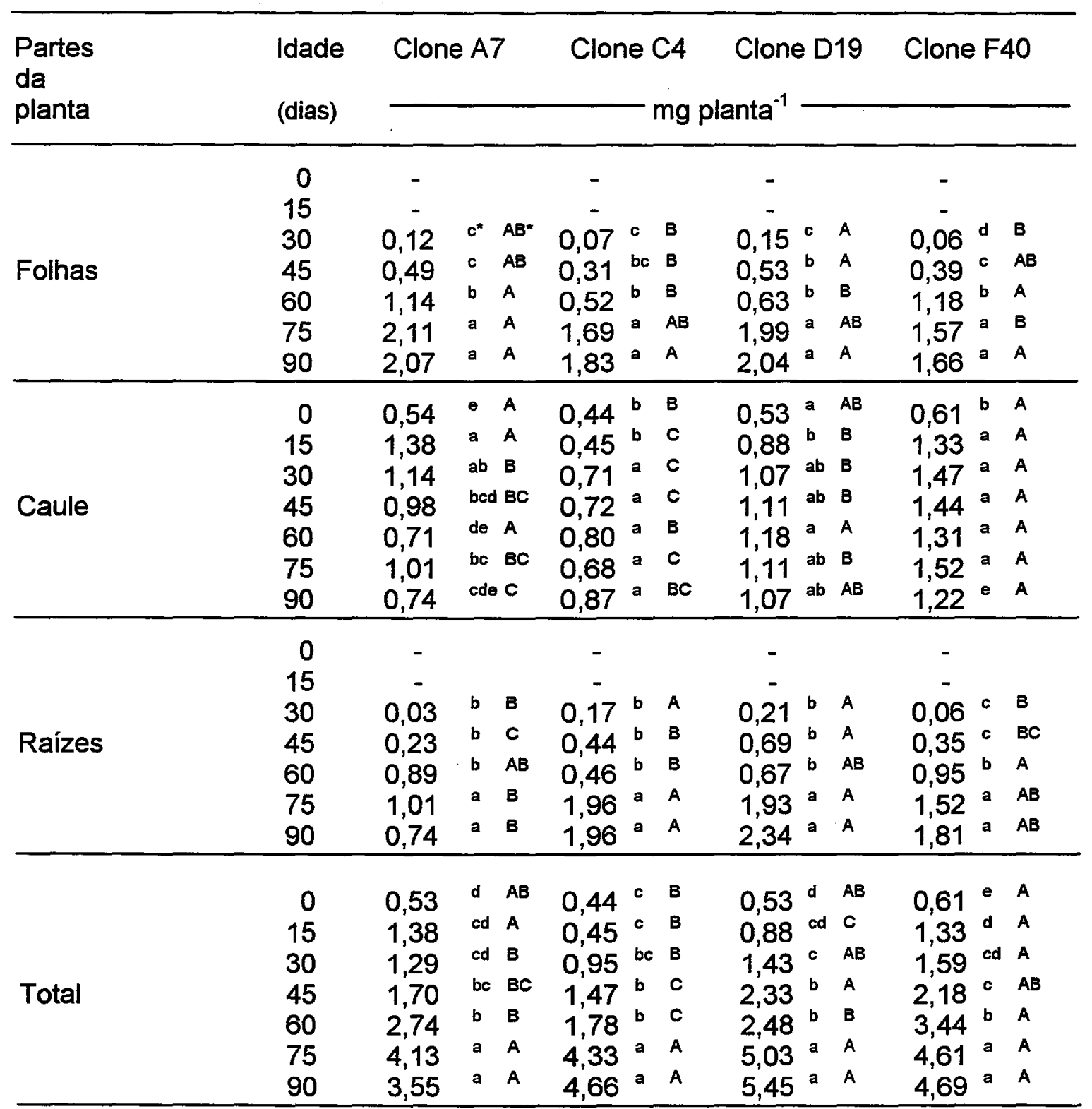

$\left({ }^{*}\right)$ OBS: Letras maiúsculas diferentes em cada linha e letras minúsculas diferentes em cada coluna, indicam diferença significativa ao nível de $5 \%$ de probabilidade, entre clones e entre idades, respectivamente. 
Tabela 25. Equação de regressão para acúmulo de magnésio (mg planta $^{-1}$ ), nas diversas partes da planta, para os clones de Eucalyptus estudados, em função da idade (dias).

\begin{tabular}{lllll}
\hline Partes da planta & \multicolumn{1}{c}{ Equação } & R2 & Prob. & C.V. \\
\hline CLONE A7 & & & & \\
Folhas & $y=-0,3810+0,0273^{*} X$ & 0,87 & $<1 \%$ & 38,79 \\
Caule & $y=0,8062+0,0132^{*} X-0,0002^{*} X^{2}$ & 0,22 & $<5 \%$ & 28,62 \\
Raízes & $y=-0,4350+0,0264^{*} X$ & 0,74 & $<5 \%$ & 64,90 \\
\hline Total & não significativo & & & \\
\hline CLONE C4 & & & & \\
Folhas & $y=-0,3656+0,0222^{*} X$ & 0,80 & $<1 \%$ & 54,84 \\
Caule & $y=0,4725+0,0044^{*} X$ & 0,57 & $<1 \%$ & 17,88 \\
Raízes & $y=-0,3677+0,0241^{*} X$ & 0,70 & $<5 \%$ & 68,34 \\
\hline Total & não significativo & & & \\
\hline CLONE D19 & & & & \\
Folhas & $y=-0,3696+0,0252^{*} X$ & 0,84 & $<1 \%$ & 45,51 \\
Caule & $y=0,5695+0,0203^{*} X-0,0002^{*} X^{2}$ & 0,81 & $<1 \%$ & 10,40 \\
Raízes & $y=-0,3787+0,0271^{*} X$ & 0,85 & $<1 \%$ & 42,38 \\
\hline Total & não significativo & & & \\
\hline CLONE F40 & & & & \\
Folhas & $y=-0,2960+0,0220^{*} X$ & 0,88 & $<1 \%$ & 35,87 \\
Caule & $y=0,7634+0,0283^{*} X-0,0003^{*} X^{2}$ & 0,65 & $<1 \%$ & 15,36 \\
Raízes & $y=-0,3313+0,0222^{*} X$ & 0,85 & $<1 \%$ & 43,93 \\
\hline Total & $y=0,4298+0,0491^{*} X$ & 0,68 & $<1 \%$ & 14,94 \\
\hline
\end{tabular}




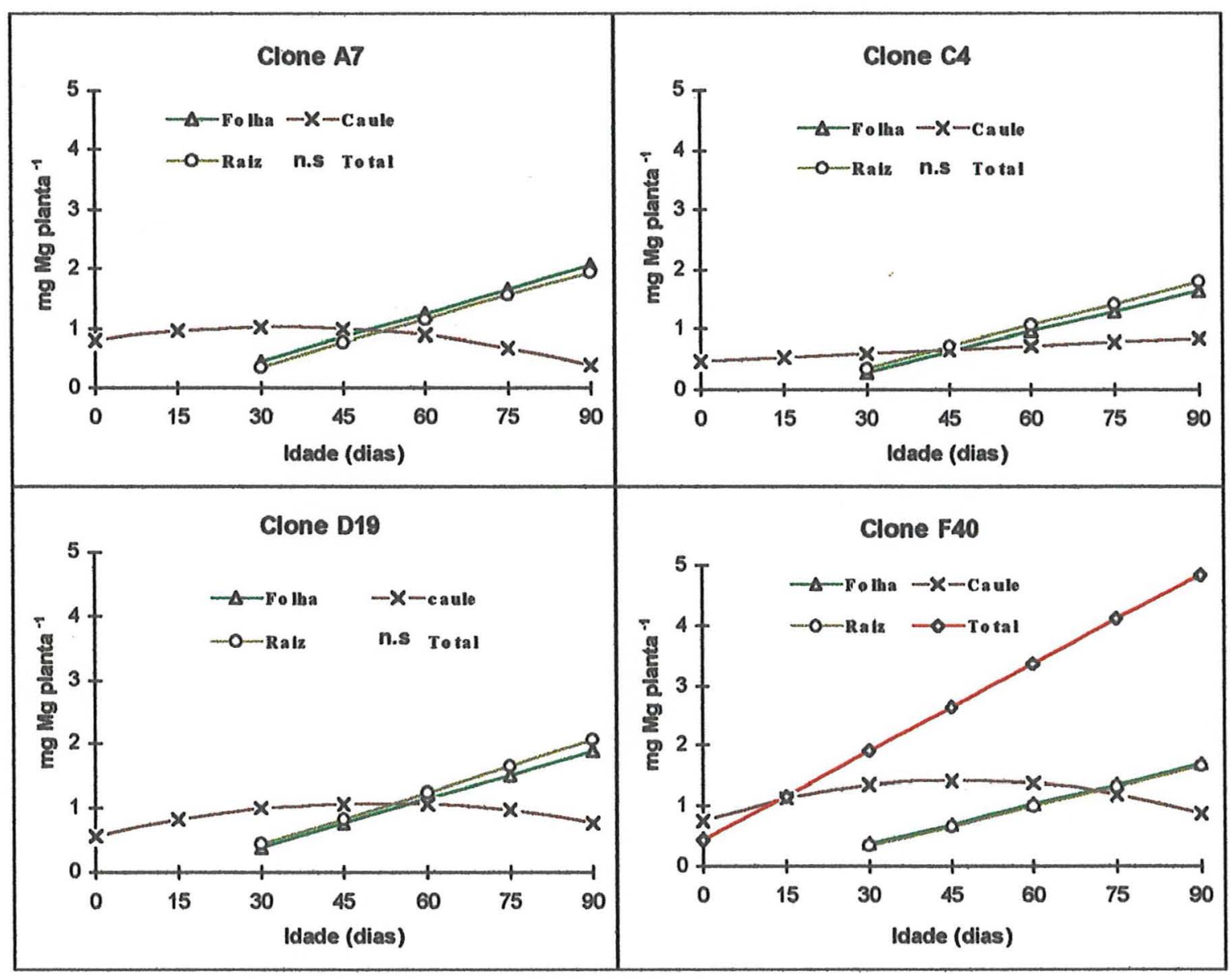

Figura 11 - Quantidades de magnésio (mg planta ${ }^{-1}$ ) nas diferentes partes e planta inteira, nos clones de Eucalyptus estudados, em função da idade (dias). 


\subsubsection{Enxofre}

\subsubsection{Concentração}

As concentrações de enxofre, nas diversas partes das plantas, em função da idade, são mostradas na Tabela 26. Podemos observar que os teores do elemento diminuiram com as idades, para todos os órgãos, sendo as diferenças nos teores, mais acentuadas quando se compara os tratamentos zero (plantio da estaca) e noventa dias de idade para o caule e entre 30 e 90 dias para as folhas e raízes. Durante o desenvolvimento das mudas, as maiores concentrações de enxofre foram encontradas nas raízes (clone F40) e as menores nos caules.

Observa-se que houve diferenças estatísticas entre os clones, aos noventa dias. Nas folhas, o clone A7 diferiu do clone F40, enquanto que para o caule houve diferenças entre os clones D19 e C4 e esses em relação aos demais. Nas raízes os clones A7 e F40 diferiram dos clones C4 e D19.

Os teores de enxofre nos quatro clones estudados, variaram aos 90 dias de idade, para as folhas de 1,2 a $1,6 \mathrm{~g} \mathrm{~kg}^{-1}$; no caule de 0,2 a $0,3 \mathrm{~g} \mathrm{~kg}^{-1}$ e nas raízes de 0,7 a $1,0 \mathrm{~g} \mathrm{~kg}^{-1}$.

A tendência de decréscimo no teor de enxofre com a idade das plantas, observado no presente trabalho, também foi verificado por Silveira et al. (1995), em mudas de E. grandis, que apresentaram valores para folhas de $1,0 \mathrm{~g} \mathrm{~kg}^{-1}$, para o caule $0,1 \mathrm{~g} \mathrm{~kg}^{-1}$ e para as raízes $1,1 \mathrm{~g} \mathrm{~kg}^{-1}$. Comparativamente os valores são inferiores aos encontrados no presente estudo, para as folhas e caule e semelhantes às raízes. Segundo Dell et al. (1995), o teor adequado para as folhas de $E$. grandis, aos noventa dias de idade, está entre 1,9 a $3,2 \mathrm{~g} \mathrm{~kg}^{-1}$. 
Tabela 26. Concentração de enxofre, nas diversas partes da planta, nos clones de Eucalyptus estudados, em função da idade.

\begin{tabular}{|c|c|c|c|c|c|c|c|c|c|c|c|c|c|}
\hline \multirow{2}{*}{$\begin{array}{l}\begin{array}{l}\text { Partes } \\
\text { da } \\
\text { planta }\end{array} \\
\text { Folhas }\end{array}$} & \multirow{2}{*}{$\begin{array}{l}\text { Idade } \\
\text { (dias) } \\
0 \\
15 \\
30 \\
45 \\
60 \\
75 \\
90 \\
\end{array}$} & \multicolumn{3}{|c|}{ Clone A7 } & \multicolumn{3}{|c|}{ Clone C4 } & \multicolumn{3}{|c|}{ Clone D19 } & \multicolumn{3}{|c|}{ Clone F40 } \\
\hline & & $\begin{array}{r}- \\
- \\
3,4 \\
2,7 \\
1,8 \\
1,7 \\
1,4 \\
\end{array}$ & $\begin{array}{l}a^{*} \\
b \\
c \\
c \\
c\end{array}$ & $\begin{array}{l}A^{*} \\
C \\
A \\
A \\
A\end{array}$ & $\begin{array}{r}- \\
- \\
3,2 \\
1,6 \\
1,6 \\
0,6 \\
1,6\end{array}$ & $\begin{array}{l}a \\
b \\
b \\
c \\
c \\
\end{array}$ & $\begin{array}{l}A B \\
B \\
B \\
A \\
A B\end{array}$ & $\begin{array}{c}- \\
- \\
2,5 \\
1,4 \\
1,7 \\
0,9 \\
1,4\end{array}$ & $\begin{array}{l}a \\
b \\
b \\
c \\
b\end{array}$ & $\begin{array}{l}\text { A } \\
A \\
B \\
A \\
A B\end{array}$ & $\begin{array}{c}- \\
- \\
3,2 \\
3,0 \\
1,8 \\
1,7 \\
1,2\end{array}$ & $\begin{array}{l}a \\
a \\
b \\
b \\
c\end{array}$ & $\begin{array}{l}\text { B } \\
\text { C } \\
\text { A } \\
\text { A } \\
\text { B }\end{array}$ \\
\hline Caule & $\begin{array}{r}0 \\
15 \\
30 \\
45 \\
60 \\
75 \\
90 \\
\end{array}$ & $\begin{array}{l}0,6 \\
1,8 \\
2,0 \\
1,9 \\
0,8 \\
0,7 \\
0,2 \\
\end{array}$ & $\begin{array}{l}c \\
a \\
a \\
a \\
b \\
b \\
c\end{array}$ & $\begin{array}{l}\text { B } \\
B \\
B \\
A \\
A \\
C \\
C\end{array}$ & $\begin{array}{l}1,4 \\
1,4 \\
1,3 \\
0,8 \\
0,7 \\
0,1 \\
0,3 \\
\end{array}$ & $\begin{array}{l}a \\
a \\
a \\
b \\
b \\
d \\
c \\
\end{array}$ & $\begin{array}{l}B \\
A B \\
B \\
A \\
B \\
C \\
C\end{array}$ & $\begin{array}{l}1,5 \\
1,5 \\
1,3 \\
0,8 \\
1,0 \\
0,3 \\
0,4 \\
\end{array}$ & $\begin{array}{l}a \\
a \\
a \\
b \\
b \\
c \\
c \\
\end{array}$ & $\begin{array}{l}\text { B } \\
A \\
B \\
A \\
A \\
B \\
B\end{array}$ & $\begin{array}{l}0,7 \\
1,9 \\
2,9 \\
2,2 \\
2,0 \\
0,9 \\
0,3 \\
\end{array}$ & $\begin{array}{l}c \\
b \\
a \\
a b \\
b \\
c \\
c \\
\end{array}$ & $\begin{array}{l}\text { A } \\
A \\
A \\
A \\
A \\
A \\
A\end{array}$ \\
\hline Raizes & $\begin{array}{r}0 \\
15 \\
30 \\
45 \\
60 \\
75 \\
90\end{array}$ & $\begin{array}{r}- \\
3,7 \\
2,9 \\
2,0 \\
1,8 \\
1,0\end{array}$ & $\begin{array}{l}a \\
b \\
c \\
c \\
d\end{array}$ & $\begin{array}{l}\text { B } \\
\text { A } \\
\text { A } \\
\text { A } \\
\text { A }\end{array}$ & $\begin{array}{r}- \\
- \\
2,2 \\
1,8 \\
1,8 \\
1,0 \\
1,0\end{array}$ & $\begin{array}{l}a \\
b \\
b \\
c \\
c\end{array}$ & $\begin{array}{l}A B \\
A \\
B \\
A \\
B\end{array}$ & $\begin{array}{c}- \\
- \\
2,6 \\
3,2 \\
1,4 \\
0,8 \\
1,0\end{array}$ & $\begin{array}{l}b \\
a \\
b \\
d \\
d\end{array}$ & $\begin{array}{l}\text { AB } \\
A \\
B \\
A \\
B\end{array}$ & $\begin{array}{c}- \\
- \\
4,5 \\
3,5 \\
1,6 \\
1,4 \\
0,7\end{array}$ & $\begin{array}{l}a \\
a \\
b \\
b \\
b\end{array}$ & $\begin{array}{l}A \\
A \\
A \\
A \\
A\end{array}$ \\
\hline
\end{tabular}

(*) OBS: Letras maiúsculas diferentes em cada linha e letras minúsculas diferentes em cada coluna, indicam diferença significativa ao nivel de $5 \%$ de probabilidade, entre clones e entre idades, respectivamente.

A concentração de enxofre, para as folhas, nos clones A7, B e D19 e caule e raízes, no clone $\mathrm{F40}$, ajustaram-se a equações de regressão do segundo grau. Para as folhas, no clone F40 e raízes, nos clones $A 7, \mathrm{C} 4$ e D19 e o para caule, nos clones C4 e D19, foram ajustadas equações de 
regressão do primeiro grau, conforme podemos observar na Tabela 27 e Figura 12.

Tabela 27. Equações de regressão para teor de enxofre $\left(\mathbf{g ~ k g}^{-1}\right)$, nas diversas partes da planta, nos clones de Eucalyptus estudados. em função da idade (dias).

\begin{tabular}{|c|c|c|c|c|c|}
\hline Clones & Partes da planta & Equação & $\mathrm{R}^{2}$ & Prob. & C.V. \\
\hline $\begin{array}{l}\text { A7 } \\
\text { C4 } \\
\text { D19 } \\
\text { F40 }\end{array}$ & $\begin{array}{l}\text { Folhas } \\
\text { Folhas } \\
\text { Folhas } \\
\text { Folhas }\end{array}$ & $\begin{array}{l}y=5,7750-0,0919^{*} X+0,0005^{\star} X^{2} \\
y=7,3650-0,1785^{\star} X+0,0012^{*} X^{2} \\
y=4,6050-0,0924^{*} X+0,0006^{\star} x^{2} \\
y=4,3100-0,0353^{*} X\end{array}$ & $\begin{array}{l}0,93 \\
0,86 \\
0,70 \\
0,88\end{array}$ & $\begin{array}{l}<1 \% \\
<1 \% \\
<1 \% \\
<1 \%\end{array}$ & $\begin{array}{l}10,16 \\
19,43 \\
19,13 \\
13,19\end{array}$ \\
\hline $\begin{array}{l}\text { A7 } \\
\text { C4 } \\
\text { D19 } \\
\text { F40 }\end{array}$ & $\begin{array}{l}\text { Caule } \\
\text { Caule } \\
\text { Caule } \\
\text { Caule }\end{array}$ & $\begin{array}{l}y=0,8922+0,0465^{*} X-0,0006^{*} X^{2} \\
y=1,5741-0,0155^{*} X \\
y=1,6098-0,0146^{*} X \\
y=0,8970+0,0785^{*} X-0,0010^{*} X^{2}\end{array}$ & $\begin{array}{l}0,73 \\
0,86 \\
0,83 \\
0,77\end{array}$ & $\begin{array}{l}<1 \% \\
<1 \% \\
<1 \% \\
<1 \%\end{array}$ & $\begin{array}{l}32,19 \\
21,84 \\
21,67 \\
29,54\end{array}$ \\
\hline $\begin{array}{l}\text { A7 } \\
\text { C4 } \\
\text { D19 } \\
\text { F40 }\end{array}$ & $\begin{array}{l}\text { Raízes } \\
\text { Raízes } \\
\text { Raízes } \\
\text { Raizes }\end{array}$ & $\begin{array}{l}y=4,8900-0,0435^{*} X \\
y=2,8150-0,0212^{*} X \\
y=4,1150-0,0383^{*} X \\
y=8,4850-0,1499^{*} X+0,0007^{*} X^{2}\end{array}$ & $\begin{array}{l}0,90 \\
0,87 \\
0,69 \\
0,88\end{array}$ & $\begin{array}{l}<1 \% \\
<1 \% \\
<1 \% \\
<5 \%\end{array}$ & $\begin{array}{l}13,95 \\
11,79 \\
31,33 \\
23,79\end{array}$ \\
\hline
\end{tabular}




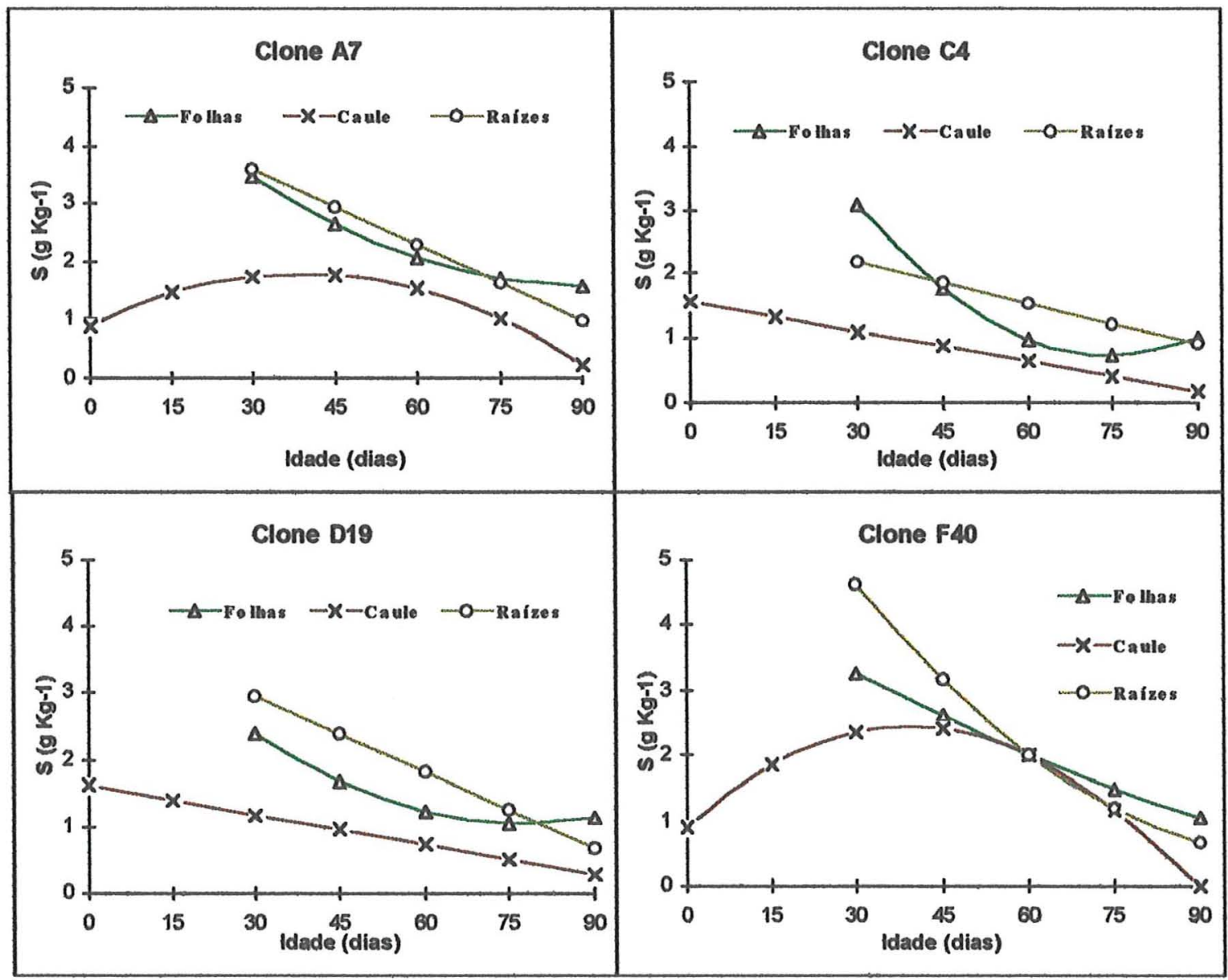

Figura 12 - Teores de Enxofre ( $\left.\mathrm{g} \mathrm{Kg}^{-1}\right)$, nas diferentes partes da planta, nos clones de Eucalyptus estudados, em função da idade (dias). 


\subsubsection{Acúmulo}

As quantidades de enxofre acumuladas, nas diversas partes da planta, nas diferentes idades, estão na Tabela 28. Verifica-se que houve diferenças na acumulação do elemento, sendo esse, um efeito crescente para as folhas, raízes e total e decrescente para o caule a partir de 45 dias de idade. Entre os clones estudados, observa-se variação significativa para as folhas no clone $\mathrm{C} 4$ em relação ao clone $\mathrm{F} 40$ e nas raízes, o clone $\mathrm{F} 40$, diferenciou dos demais. Para o acúmulo total de enxofre apenas o clone F40 é significativamente diferente em relação aos outros três, enquanto que para o caule, aos noventa dias, não houve diferenças entre os clones.

O conteúdo de enxofre observado nos clones A7, C4, D19 e F40, nas folhas $\left(0,44 ; 0,50,0,44\right.$ e $0,33 \mathrm{mg}$ planta $\left.^{-1}\right)$, no caule $(0,11 ; 0,15 ; 0,15$ e 0,11 $\left.\mathrm{mg}_{\text {planta }}{ }^{-1}\right)$ e nas raízes $\left(0,11 ; 0,14 ; 0,14\right.$ e $\left.0,06 \mathrm{mg} \mathrm{planta}^{-1}\right)$, são menores se comparados com os valores, obtidos por Silveira et al. (1995), que encontrou os valores de 0,$48 ; 0,19$ e $0,34 \mathrm{mg} \mathrm{planta}^{-1}$, para folhas, caule e raizes, respectivamente.

Aos noventa dias de idade, as quantidades de enxofre acumuladas nas folhas pelos clones A7, C4, D19 e F40, representaram 66,66; 63,29; 59,46 e $66,00 \%$ do total. Para o caule, os valores obtidos responderam por 16,$66 ; 18,98 ; 20,27$ e $22,00 \%$ e as raízes, 16,$66 ; 17,72 ; 18,92$ e $12,00 \%$, respectivamente. Observamos que o acúmulo de $S$ pelos caules e raízes, nos clones de Eucalyptus em estudados, apresentam valores próximos nos dois órgãos, diferenciando apenas o clone $\mathrm{F} 40$, em relação ao conteúdo de $\mathrm{S}$ nas raízes em relação ao total. 
Tabela 28. Acúmulo de enxofre, nas diversas partes da planta, nos clones de Eucalyptus estudados, em função da idade.

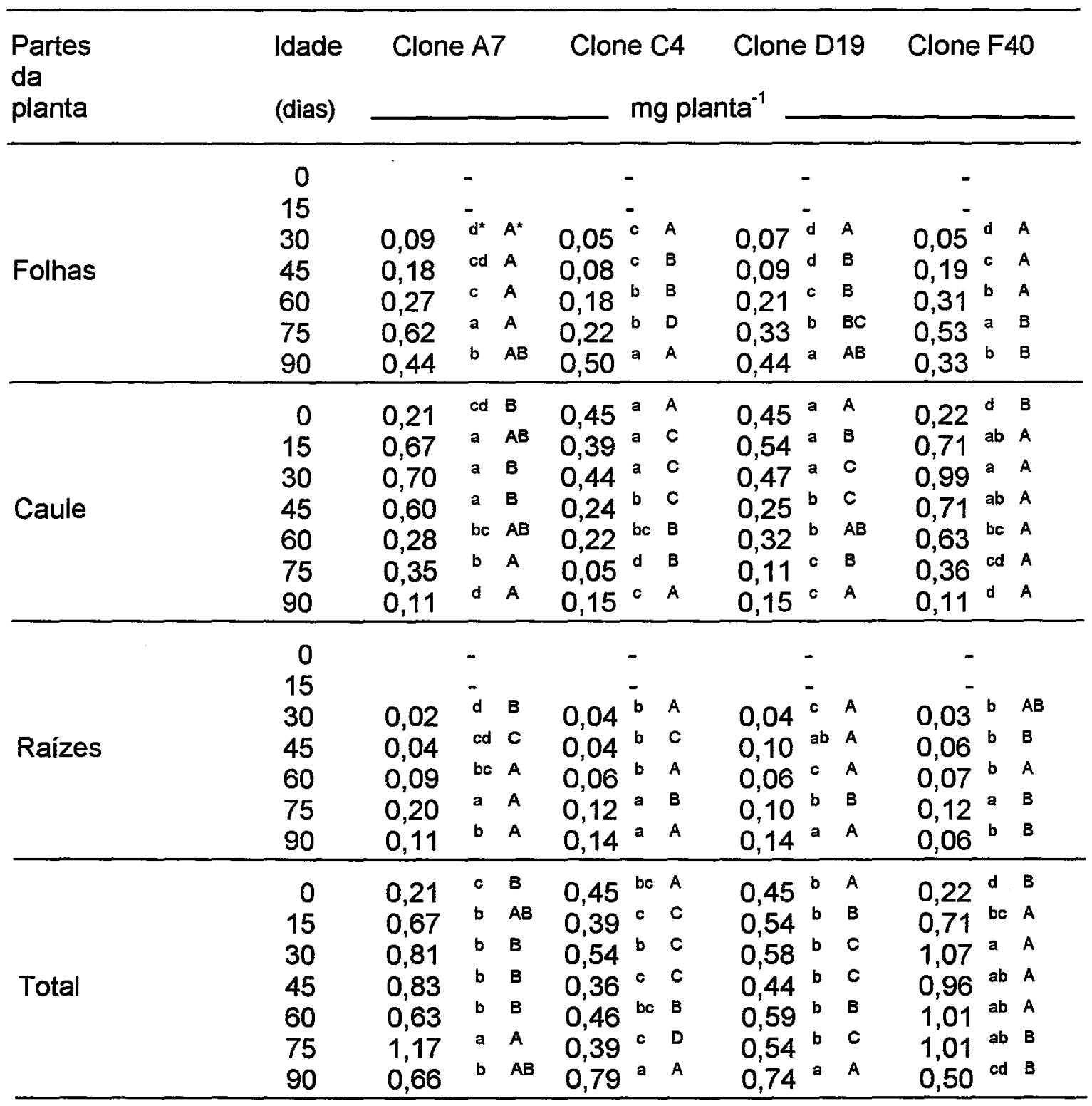

(*) OBS: Letras maiúsculas diferentes em cada linha e letras minúsculas diferentes em cada coluna, indicam diferença significativa ao nível de $5 \%$ de probabilidade, entre clones e entre idades, respectivamente. 
O acúmulo de enxofre no caule, para os clones A7 e F40 e total, para os clones A7, C4 e F40, ajustaram-se equações quadráticas. Para as folhas e caule, nos clones C4 e D19, para as raízes, no clone C4 e o total, no clone D19, ajustaram-se equações lineares. O acúmulo de enxofre, não foi significativo para as folhas, nos clones $A 7$ e $\mathrm{F} 40$ e para as raízes, nos clones A7, D19 e F40, conforme Tabela 29 e Figura 13.

Tabela 29. Equação de regressão para acúmulo de enxofre (mg planta $^{-1}$ ), nas diversas partes da planta, nos clones de Eucalyptus estudados, em função da idade (dias).

\begin{tabular}{|c|c|c|c|c|}
\hline Partes da planta & Equação & $\mathrm{R} 2$ & Prob. & C.V. \\
\hline \multicolumn{5}{|l|}{ CLONE A7 } \\
\hline $\begin{array}{l}\text { Folhas } \\
\text { caule } \\
\text { Raízes }\end{array}$ & $\begin{array}{l}\text { não significativo } \\
y=0,3439+0,0145^{*} X-0,0002^{*} X^{2} \\
\text { não significativo }\end{array}$ & 0,65 & $<1 \%$ & 34,05 \\
\hline Total & $y=0,2859+0,0209^{*} x-0,0002^{*} x^{2}$ & 0,55 & $<1 \%$ & 27,53 \\
\hline \multicolumn{5}{|l|}{ CLONE C4 } \\
\hline $\begin{array}{l}\text { Folhas } \\
\text { Caule } \\
\text { Raízes }\end{array}$ & $\begin{array}{l}y=-0,0738+0,0049^{*} x \\
y=0,4708-0,0043^{*} x \\
y=-0,0155+0,0016^{*} x\end{array}$ & $\begin{array}{l}0,80 \\
0,78 \\
0,89\end{array}$ & $\begin{array}{l}<1 \% \\
<1 \% \\
<5 \%\end{array}$ & $\begin{array}{l}51,45 \\
25,30 \\
30,02\end{array}$ \\
\hline Total & $y=0,4861-0,0061^{*} x+0,0001^{*} x^{2}$ & 0,50 & $<5 \%$ & 21,94 \\
\hline \multicolumn{5}{|l|}{ CLONE D19 } \\
\hline $\begin{array}{l}\text { Folhas } \\
\text { Caule } \\
\text { Raízes }\end{array}$ & $\begin{array}{l}y=-0,0646+0,0051^{*} X \\
y=0,5349-0,0045^{*} X \\
\text { não significativo }\end{array}$ & $\begin{array}{l}0,89 \\
0,75\end{array}$ & $\begin{array}{l}<1 \% \\
<1 \%\end{array}$ & $\begin{array}{l}33,67 \\
24,68\end{array}$ \\
\hline Total & $y=0,4646+0,0020^{*} x$ & 0,34 & $<1 \%$ & 15,95 \\
\hline \multicolumn{5}{|l|}{ CLONE F40 } \\
\hline $\begin{array}{l}\text { Folhas } \\
\text { Caule } \\
\text { Raízes }\end{array}$ & $\begin{array}{l}\text { não significativo } \\
y=0,3213+0,0258^{\star} X-0,0003^{\star} X^{2} \\
\text { não significativo }\end{array}$ & 0,77 & $<1 \%$ & 29,50 \\
\hline Total & $y=0,2483+0,0346^{*} X-0,0003^{*} x^{2}$ & 0,81 & $<1 \%$ & 18,83 \\
\hline
\end{tabular}




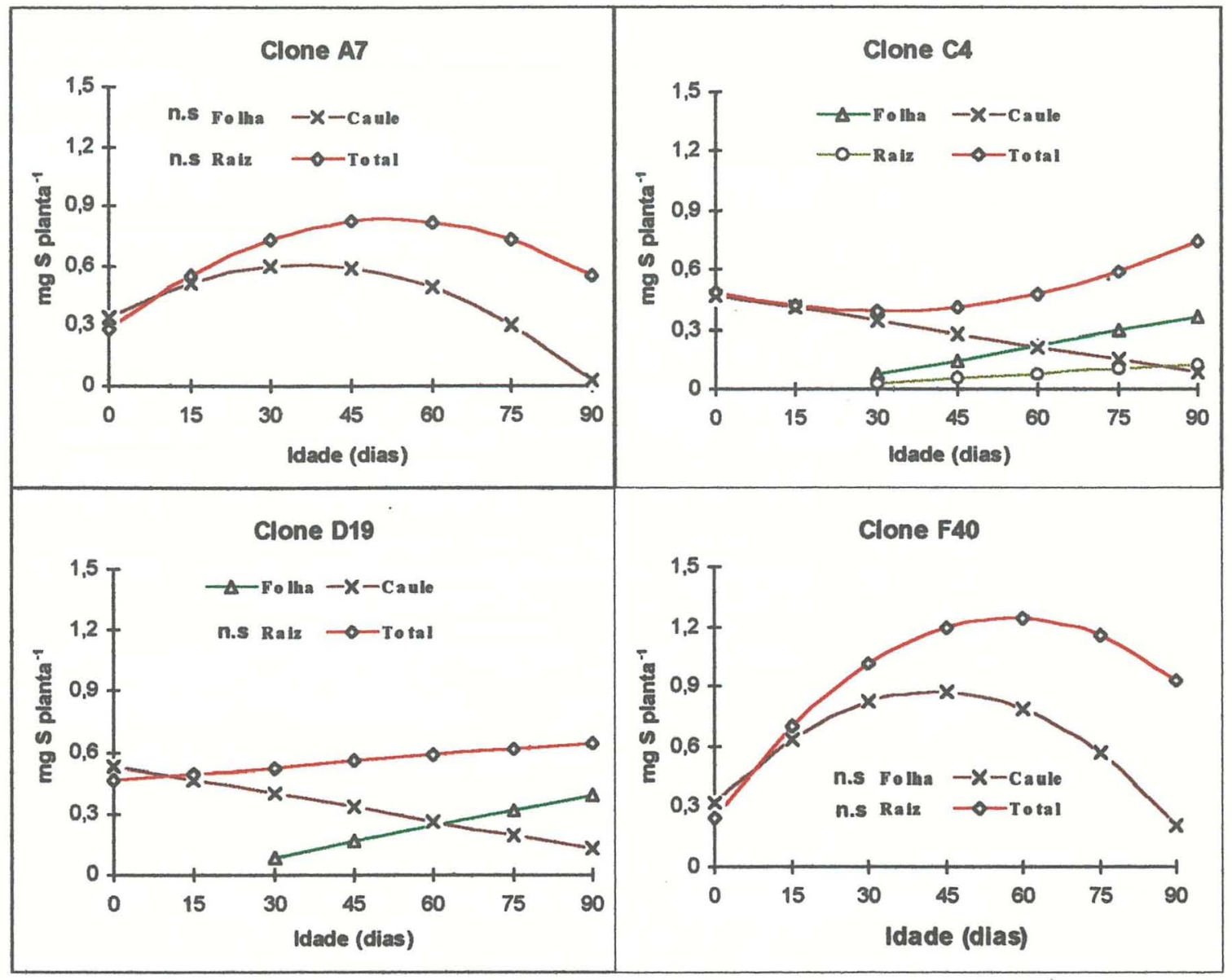

Figura 13 - Quantidades de enxofre (mg planta-1) nas diferentes partes das plantas, nos clones de Eucalyptus estudados, em função da idade (dias). 


\subsubsection{Considerações gerais}

A concentração foliar dos macronutrientes, aos noventa dias de idade, nos clones de Eucalyptus estudados, apresentou a seguinte ordem decrescente $: \mathrm{N}>\mathrm{K}>\mathrm{Ca}>\mathrm{Mg}>\mathrm{P}>\mathrm{S}$, para os clones A7, C4, e D19 e para o clone $\mathrm{F} 40$ a ordem foi : $\mathrm{N}>\mathrm{K}>\mathrm{Ca}=\mathrm{Mg}>\mathrm{P}>\mathrm{S}$. Para o caule, a seqüência foi : $\mathrm{K}>\mathrm{N}>\mathrm{Ca}>\mathrm{Mg}>\mathrm{P}>\mathrm{S}$, para todos os clones. As raízes apresentaram a seguinte seqüência de teores: $\mathrm{Mg}>\mathrm{K}>\mathrm{N}>\mathrm{Ca}>\mathrm{P}=\mathrm{S}$, para os clones $\mathrm{A} 7$ e C4 e para os clones D19 e F40 foram: $\mathrm{Mg}>\mathrm{N}>\mathrm{K}>\mathrm{Ca}>\mathrm{S}>\mathrm{P}$ e $\mathrm{Mg}>\mathrm{K}>$ $\mathrm{N}>\mathrm{Ca}>\mathrm{S}>\mathrm{P}$, respectivamente.

A seqüência dos teores de macronutrientes nos órgãos das mudas, aos 90 dias de idade, nos clones de Eucalyptus estudados foram : folha > raiz > caule, para o nitrogênio e enxofre, em tơdos os clones. Para o potássio, a mesma seqüência ocorreu nos clones A7, D19 e F40 e para o cálcio no clone A7. A ordem folha > caule > raiz foi observada para o fósforo em todos os clones estudados e para o cálcio nos clones C4 e D19. Em todos os clones o teor de magnésio foi maior nas raizes, seguido das folhas e caule, sendo que a mesma ordem foi observada para o potássio no clone F40. Apenas o cálcio no clone $\mathrm{F} 40$ apresentou teor maior no caule, em relação a folha e raiz.

O nitrogênio foi o elemento com a maior concentração nas folhas das mudas nos clones de Eucalyptus estudados, fato também observado por Barros et el., 1975, Brandi et al., 1977a, 1977b, Neves et al., 1990, Silveira et al., 1995 e em plantios de eucaliptos, como relatado por Belloti, 1979.

Nas Tabelas 29, 30 e 31, são apresentados os acréscimos ou decréscimos percentuais dos teores dos macronutrientes nas folhas, caule e raízes, respectivamente, em função da idade, considerando como valor 100 , os teores dos nutrientes aos 45 dias. Observamos que as concentrações que mais diminuiram nas folhas, com o desenvolvimento das mudas, na ordem 
foram : $\mathrm{P}$, seguido do $\mathrm{S}, \mathrm{Mg}, \mathrm{N}$ e $\mathrm{K}$, sendo que o cálcio apresentou acréscimos. Para o caule a raízes a seqüência dos elementos que mais diminuíram foram : $\mathrm{S}, \mathrm{P}, \mathrm{Ca}, \mathrm{K}, \mathrm{Mg}$ e $\mathrm{N}$ e $\mathrm{S}, \mathrm{P}, \mathrm{N}, \mathrm{K}, \mathrm{Ca}$ e $\mathrm{Mg}$, respectivamente.

O acúmulo dos macronutrientes nas folhas e caule, aos 90 dias de idade, nos quatro clones de Eucalyptus estudados, apresentaram a mesma ordem acima mostrada para os teores. $O$ conteúdo dos elementos nas raízes porém, apresentaram a seguinte ordem decrescente: $\mathrm{K}>\mathrm{N}>\mathrm{Mg}>\mathrm{Ca}>\mathrm{P}>$ $\mathrm{S}$, para o clone $\mathrm{A} 7 ; \mathrm{N}>\mathrm{K}>\mathrm{Mg}>\mathrm{Ca}>\mathrm{P}=\mathrm{S}$, para o clone $\mathrm{C} 4 ; \mathrm{Mg}>\mathrm{N}>\mathrm{K}>$ $\mathrm{Ca}>\mathrm{S}>\mathrm{P}$, para o clone $\mathrm{D} 19$ e $\mathrm{Mg}>\mathrm{K}>\mathrm{N}>\mathrm{Ca}>\mathrm{S}>\mathrm{P}$, para o clone F40. Silveira et al. (1995) encontraram a seguinte seqüência para o conteúdo de macronutrientes, aos 97 dias de idade $: \mathrm{K}>\mathrm{N}>\mathrm{Ca}>\mathrm{Mg}>\mathrm{P}>\mathrm{S}$, para as folhas; $\mathrm{K}>\mathrm{Ca}>\mathrm{N}>\mathrm{P}>\mathrm{Mg}>\mathrm{S}$, para o caule e de $\mathrm{K}>\mathrm{Ca}>\mathrm{N}>\mathrm{Mg}=\mathrm{P}>\mathrm{S}$, para as raizes. A menor quantidade de nitrogênio quando comparada a de potássio e cálcio, em relação ao atual estudo, pode ser explicada pelo manejo adotado para a rustificação das mudas, onde o corte das adubações, associada a maiores intervalos de irrigação, tendo como resultado um estresse nutricional, principalmente para o $\mathrm{N}$, a fim de que a muda tenha maiores condições para sua adaptação no campo, não foi executado no presente trabalho. 
Tabela 29. Percentuais dos teores foliares dos nutrientes, nos clones de Eucalyptus estudados, em função da idade (dias).

\begin{tabular}{|c|c|c|c|c|c|}
\hline \multirow[b]{2}{*}{ Nutrientes } & \multirow[b]{2}{*}{ Clones } & \multicolumn{4}{|c|}{ Idades (dias) } \\
\hline & & 45 & 60 & 75 & 90 \\
\hline $\mathrm{N}$ & $\begin{array}{l}\text { A7 } \\
\text { C4 } \\
\text { D19 } \\
\text { F40 } \\
\end{array}$ & $\begin{array}{l}100 \\
100 \\
100 \\
100 \\
\end{array}$ & $\begin{array}{r}94,89 \\
98,27 \\
119,51 \\
98,76 \\
\end{array}$ & $\begin{array}{l}99,07 \\
63,36 \\
78,05 \\
92,18 \\
\end{array}$ & $\begin{array}{r}90,70 \\
91,20 \\
100,97 \\
89,71 \\
\end{array}$ \\
\hline Média & & 100 & 102,86 & 83,16 & 93,14 \\
\hline$P$ & $\begin{array}{l}\text { A7 } \\
\text { C4 } \\
\text { D19 } \\
\text { F40 }\end{array}$ & $\begin{array}{l}100 \\
100 \\
100 \\
100\end{array}$ & $\begin{array}{r}100,00 \\
63,64 \\
100,00 \\
76,31 \\
\end{array}$ & $\begin{array}{l}67,86 \\
36,36 \\
60,71 \\
55,26\end{array}$ & $\begin{array}{l}67,86 \\
63,34 \\
89,28 \\
57,89 \\
\end{array}$ \\
\hline Média & & 100 & 84,99 & 55,05 & 69,67 \\
\hline $\mathrm{K}$ & $\begin{array}{l}\text { A7 } \\
\text { C4 } \\
\text { D19 } \\
\text { F40 } \\
\end{array}$ & $\begin{array}{l}100 \\
100 \\
100 \\
100 \\
\end{array}$ & $\begin{array}{r}123,00 \\
84,78 \\
100,77 \\
104,88 \\
\end{array}$ & $\begin{array}{r}113,00 \\
68,84 \\
96,15 \\
92,68 \\
\end{array}$ & $\begin{array}{r}111,00 \\
82,61 \\
101,54 \\
85,36 \\
\end{array}$ \\
\hline Média & & 100 & 103,36 & 92,62 & 95,13 \\
\hline $\mathrm{Ca}$ & $\begin{array}{l}\text { A7 } \\
\text { C4 } \\
\text { D19 } \\
\text { F40 } \\
\end{array}$ & $\begin{array}{l}100 \\
100 \\
100 \\
100 \\
\end{array}$ & $\begin{array}{r}178,05 \\
75,86 \\
67,12 \\
142,86 \\
\end{array}$ & $\begin{array}{r}134,15 \\
93,10 \\
80,82 \\
114,28 \\
\end{array}$ & $\begin{array}{r}168,29 \\
118,96 \\
93,15 \\
126,53 \\
\end{array}$ \\
\hline Média & & 100 & 115,97 & 105,59 & 126,73 \\
\hline $\mathrm{Mg}$ & $\begin{array}{l}\text { A7 } \\
\text { C4 } \\
\text { D19 } \\
\text { F40 } \\
\end{array}$ & $\begin{array}{l}100 \\
100 \\
100 \\
100 \\
\end{array}$ & $\begin{array}{r}109,72 \\
72,31 \\
63,09 \\
111,29 \\
\end{array}$ & $\begin{array}{l}80,56 \\
76,92 \\
69,05 \\
82,26 \\
\end{array}$ & $\begin{array}{r}80,56 \\
87,69 \\
77,38 \\
100,00 \\
\end{array}$ \\
\hline Média & & 100 & 89,10 & 77,20 & 86,41 \\
\hline$S$ & $\begin{array}{l}\text { A7 } \\
\text { C4 } \\
\text { D19 } \\
\text { F40 } \\
\end{array}$ & $\begin{array}{l}100 \\
100 \\
100 \\
100 \\
\end{array}$ & $\begin{array}{r}66,67 \\
100,00 \\
121,43 \\
60,00 \\
\end{array}$ & $\begin{array}{l}62,96 \\
37,50 \\
64,29 \\
56,67 \\
\end{array}$ & $\begin{array}{r}51,85 \\
100,00 \\
100,00 \\
40,00 \\
\end{array}$ \\
\hline Média & & 100 & 87,02 & 55,35 & 72,96 \\
\hline
\end{tabular}


Tabela 30. Percentuais dos teores dos nutrientes no caule, nos clones de Eucalyptus estudados, em função da idade (dias).

\begin{tabular}{|c|c|c|c|c|c|}
\hline \multirow[b]{2}{*}{ Nutrientes } & \multirow[b]{2}{*}{ Clones } & \multicolumn{4}{|c|}{ Idades (dias) } \\
\hline & & 45 & 60 & 75 & 90 \\
\hline$N$ & $\begin{array}{l}\text { A7 } \\
\text { C4 } \\
\text { D19 } \\
\text { F40 } \\
\end{array}$ & $\begin{array}{l}100 \\
100 \\
100 \\
100 \\
\end{array}$ & $\begin{array}{r}80,52 \\
116,05 \\
122,89 \\
91,86 \\
\end{array}$ & $\begin{array}{r}74,02 \\
64,20 \\
66,26 \\
104,65 \\
\end{array}$ & $\begin{array}{r}66,23 \\
100,00 \\
86,75 \\
79,07 \\
\end{array}$ \\
\hline Média & & 100 & 102,83 & 61,39 & 83,01 \\
\hline$P$ & $\begin{array}{l}\text { A7 } \\
\text { C4 } \\
\text { D19 } \\
\text { F40 } \\
\end{array}$ & $\begin{array}{l}100 \\
100 \\
100 \\
100 \\
\end{array}$ & $\begin{array}{l}92,00 \\
61,54 \\
85,71 \\
80,00\end{array}$ & $\begin{array}{l}52,00 \\
50,00 \\
42,86 \\
68,00 \\
\end{array}$ & $\begin{array}{l}.48,00 \\
65,38 \\
53,57 \\
56,00 \\
\end{array}$ \\
\hline Média & & 100 & 79,81 & 53,21 & 55,74 \\
\hline $\mathrm{K}$ & $\begin{array}{l}\text { A7 } \\
\text { C4 } \\
\text { D19 } \\
\text { F40 } \\
\end{array}$ & $\begin{array}{l}100 \\
100 \\
100 \\
100 \\
\end{array}$ & $\begin{array}{l}91,58 \\
78,51 \\
78,42 \\
91,07\end{array}$ & $\begin{array}{l}71,58 \\
76,03 \\
65,47 \\
74,11 \\
\end{array}$ & $\begin{array}{l}71,58 \\
84,30 \\
73,38 \\
72,32 \\
\end{array}$ \\
\hline Média & & 100 & 84,89 & 71,80 & 75,39 \\
\hline $\mathrm{Ca}$ & $\begin{array}{l}\text { A7 } \\
\text { C4 } \\
\text { D19 } \\
\text { F40 } \\
\end{array}$ & $\begin{array}{l}100 \\
100 \\
100 \\
100 \\
\end{array}$ & $\begin{array}{l}94,64 \\
62,71 \\
87,32 \\
89,04 \\
\end{array}$ & $\begin{array}{l}62,50 \\
55,93 \\
63,38 \\
80,82 \\
\end{array}$ & $\begin{array}{l}67,86 \\
66,10 \\
71,83 \\
86,30 \\
\end{array}$ \\
\hline Média & & 100 & 83,43 & 65,66 & 73,02 \\
\hline $\mathrm{Mg}$ & $\begin{array}{l}\text { A7 } \\
\text { C4 } \\
\text { D19 } \\
\text { F40 } \\
\end{array}$ & $\begin{array}{l}100 \\
100 \\
100 \\
100 \\
\end{array}$ & $\begin{array}{r}67,74 \\
104,35 \\
102,86 \\
93,18 \\
\end{array}$ & $\begin{array}{l}64,52 \\
65,22 \\
68,57 \\
90,91 \\
\end{array}$ & $\begin{array}{l}54,84 \\
91,30 \\
74,28 \\
88,64 \\
\end{array}$ \\
\hline$\overline{\text { Média }}$ & & 100 & 92,03 & 72,30 & 77,26 \\
\hline$S$ & $\begin{array}{l}\text { A7 } \\
\text { C4 } \\
\text { D19 } \\
\text { F40 } \\
\end{array}$ & $\begin{array}{l}100 \\
100 \\
100 \\
100 \\
\end{array}$ & $\begin{array}{r}42,10 \\
87,50 \\
125,00 \\
90,91 \\
\end{array}$ & $\begin{array}{l}36,84 \\
12,50 \\
37,50 \\
40,91 \\
\end{array}$ & $\begin{array}{l}10,53 \\
37,50 \\
50,00 \\
13,64 \\
\end{array}$ \\
\hline Média & & 100 & 86,38 & 31,94 & 27,92 \\
\hline
\end{tabular}


Tabela 31. Percentuais dos teores dos nutrientes nas raízes, nos clones de Eucalyptus estudados, em função da idade (dias).

\begin{tabular}{|c|c|c|c|c|c|}
\hline \multirow[b]{2}{*}{ Nutrientes } & \multirow[b]{2}{*}{ Clones } & \multicolumn{4}{|c|}{ Idades (dias) } \\
\hline & & 45 & 60 & 75 & 90 \\
\hline$N$ & $\begin{array}{l}\text { A7 } \\
\text { C4 } \\
\text { D19 } \\
\text { F40 } \\
\end{array}$ & $\begin{array}{l}100 \\
100 \\
100 \\
100 \\
\end{array}$ & $\begin{array}{r}66,45 \\
122,31 \\
115,45 \\
82,12 \\
\end{array}$ & $\begin{array}{l}78,29 \\
77,68 \\
74,80 \\
86,09 \\
\end{array}$ & $\begin{array}{r}57,24 \\
104,13 \\
98,37 \\
66,22\end{array}$ \\
\hline$\overline{\text { Média }}$ & & 100 & 96,58 & 79,21 & 81,49 \\
\hline$P$ & $\begin{array}{l}\text { A7 } \\
\text { C4 } \\
\text { D19 } \\
\text { F40 }\end{array}$ & $\begin{array}{l}100 \\
100 \\
100 \\
100\end{array}$ & $\begin{array}{r}63,33 \\
76,00 \\
154,54 \\
77,27 \\
\end{array}$ & $\begin{array}{l}50,00 \\
32,00 \\
72,73 \\
77,27\end{array}$ & $\begin{array}{l}33,33 \\
40,00 \\
81,82 \\
18,18\end{array}$ \\
\hline Média & & 100 & 92,78 & 58,00 & 43,33 \\
\hline $\mathrm{K}$ & $\begin{array}{l}\text { A7 } \\
\text { C4 } \\
\text { D19 } \\
\text { F40 } \\
\end{array}$ & $\begin{array}{l}100 \\
100 \\
100 \\
100 \\
\end{array}$ & $\begin{array}{r}83,54 \\
119,82 \\
118,68 \\
89,58 \\
\end{array}$ & $\begin{array}{r}76,58 \\
98,20 \\
118,68 \\
86,11 \\
\end{array}$ & $\begin{array}{r}68,99 \\
110,81 \\
123,08 \\
71,53 \\
\end{array}$ \\
\hline Média & & 100 & 102,90 & 94,89 & 93,60 \\
\hline $\mathrm{Ca}$ & $\begin{array}{l}\text { A7 } \\
\text { C4 } \\
\text { D19 } \\
\text { F40 } \\
\end{array}$ & $\begin{array}{l}100 \\
100 \\
100 \\
100 \\
\end{array}$ & $\begin{array}{r}123,53 \\
80,00 \\
88,89 \\
106,97 \\
\end{array}$ & $\begin{array}{l}88,23 \\
75,00 \\
80,56 \\
81,39 \\
\end{array}$ & $\begin{array}{r}114,71 \\
85,00 \\
91,67 \\
88,37 \\
\end{array}$ \\
\hline Média & & 100 & 99,85 & 81,29 & 94,94 \\
\hline $\mathrm{Mg}$ & $\begin{array}{l}\text { A7 } \\
\text { C4 } \\
\text { D19 } \\
\text { F40 }\end{array}$ & $\begin{array}{l}100 \\
100 \\
100 \\
100\end{array}$ & $\begin{array}{r}133,77 \\
77,14 \\
83,41 \\
118,52\end{array}$ & $\begin{array}{r}121,43 \\
90,28 \\
74,88 \\
86,24\end{array}$ & $\begin{array}{r}113,64 \\
79,43 \\
76,30 \\
112,70\end{array}$ \\
\hline Média & & 100 & 103,21 & 93,21 & 95,52 \\
\hline$S$ & $\begin{array}{l}\text { A7 } \\
\text { C4 } \\
\text { D19 } \\
\text { F40 } \\
\end{array}$ & $\begin{array}{l}100 \\
100 \\
100 \\
100 \\
\end{array}$ & $\begin{array}{r}68,96 \\
100,00 \\
43,75 \\
45,71 \\
\end{array}$ & $\begin{array}{l}62,07 \\
55,56 \\
25,00 \\
40,00 \\
\end{array}$ & $\begin{array}{l}34,48 \\
55,56 \\
31,25 \\
20,00 \\
\end{array}$ \\
\hline Média & & 100 & 64,60 & 45,66 & 35,32 \\
\hline
\end{tabular}


A seqüência do conteúdo dos macronutrientes nos órgãos das mudas, nos quatro clones de Eucalyptus estudados, aos noventa dias de idade foram : folha > caule > raiz, para o nitrogênio, em todos os clones, e para o fósforo, nos clones A7, D19 e F40, para o potássio, nos clones A7 e F40, para o cálcio nos clones A7, C4 e D19 e para o enxofre nos clones C4, D19 e F40. O acúmulo de nutrientes nas folhas foi maior em relação ao caule, porém este não diferiu do conteúdo nas raízes no clone $A 7$, tanto para o elemento magnésio e enxofre. O caule apresentou maior acúmulo que as folhas e raizes, para o fósforo no clone $\mathrm{C} 4$, para o potássio nos clones $\mathrm{C} 4 \mathrm{e}$ D19 e para cálcio no clone F40. O magnésio, nos clones C4, D19 e F40, acumulou mais nas raízes em relação as folhas e estas em relação ao caule.

$\mathrm{Na}$ Tabela 32 são mostradas as quantidades de nutrientes exportados pelas folhas, caule e raízes e planta inteira, nos quatro clones de Eucalyptus estudados, aos 90 dias de idade. Observa-se que para 0 nitrogênio e o enxofre, a seqüência na exportação apresentou a seguinte ordem decrescente: clone $\mathrm{C} 4>$ clone $\mathrm{D} 19>$ clone A7 > clone F40. Com relação aos outros elementos, a ordem foi a seguinte; clone C4 = clone D19 $>$ clone A7 > clone F40 para o fósforo; clone D19 > clone C4 > clone A7 > clone F40, para o potássio e o cálcio e clone D19 > clone F40 > clone C4 > clone A7 para o magnésio. 
Tabela 32. Exportação de nutrientes $\left(\mathrm{mg} \mathrm{planta}^{-1}\right)$ pelas diversas partes e planta inteira, nos clones de Eucalyptus estudados, aos 90 dias de idade (dias).

\begin{tabular}{|c|c|c|c|c|c|c|c|c|}
\hline \multirow[b]{3}{*}{ Nutrientes } & \multicolumn{4}{|c|}{ Folhas } & \multicolumn{4}{|c|}{ Caule } \\
\hline & \multicolumn{4}{|c|}{ Clones } & \multicolumn{4}{|c|}{ Clones } \\
\hline & $A 7$ & $\mathrm{C} 4$ & D19 & $\mathrm{F} 40$ & $\mathrm{~A} 7$ & $\mathrm{C} 4$ & D19 & F40 \\
\hline$N$ & 6,04 & 6,80 & 6,98 & 5,40 & 2,23 & 3,40 & 2,95 & 2,11 \\
\hline$P$ & 0,59 & 0,67 & 0,80 & 0,60 & 0,55 & 0,71 & 0,60 & 0,45 \\
\hline K & 3,45 & 3,66 & 4,12 & 3,75 & 2,88 & 4,30 & 4,15 & 2,54 \\
\hline $\mathrm{Ca}$ & 2,15 & 2,20 & 2,12 & 1,66 & 1,69 & 1,65 & 2,09 & 1,98 \\
\hline $\mathrm{Mg}$ & 2,07 & 1,83 & 2,04 & 1,66 & 0,74 & 0,87 & 1,07 & 1,22 \\
\hline \multirow[t]{3}{*}{$S$} & 0,44 & 0,50 & 0,44 & 0,33 & 0,11 & 0,15 & 0,15 & 0,11 \\
\hline & \multicolumn{4}{|c|}{ Raízes } & \multicolumn{4}{|c|}{ Total } \\
\hline & \multicolumn{4}{|c|}{ Clones } & \multicolumn{4}{|c|}{ Clones } \\
\hline Nutrientes & $\mathrm{A} 7$ & $\mathrm{C} 4$ & D19 & $\mathrm{F} 40$ & $\mathrm{~A} 7$ & $\mathrm{C} 4$ & D19 & F40 \\
\hline$N$ & 1,00 & 1,78 & 1,75 & 0,85 & 9,27 & 11,98 & 11,68 & 8,36 \\
\hline$P$ & 0,12 & 0,14 & 0,12 & 0,03 & 1,26 & 1,52 & 1,52 & 1,08 \\
\hline $\mathrm{K}$ & 1,25 & 1,73 & 1,62 & 0,87 & 7,58 & 9,69 & 9,89 & 7,16 \\
\hline $\mathrm{Ca}$ & 0,45 & 0,47 & 0,48 & 0,32 & 4,29 & 4,32 & 4,69 & 3,96 \\
\hline $\mathrm{Mg}$ & 0,74 & 1,96 & 2,34 & 1,81 & 3,55 & 4,66 & 5,45 & 4,69 \\
\hline$S$ & 0,11 & 0,14 & 0,14 & 0,06 & 0,66 & 0,79 & 0,73 & 0,50 \\
\hline
\end{tabular}




\section{CONCLUSÃO}

Nas condições em que foi desenvolvido o presente trabalho, os resultados obtidos permitem as seguintes conclusões:

1 - Aos 90 dias, idade de maior produção de matéria seca total, apenas o clone F40 diferiu dos demais. A distribuição da matéria seca total obedeceu a seguinte ordem decrescente: caule > folhas > raizes, para os quatros clones de Eucalyptus estudados;

2 - As maiores concentrações de nutrientes ocorreram nas folhas, exceto para o magnésio, que apresentou teores elevados nas raízes;

3 - Todas as concentrações de nutrientes avaliados, decresceram com as idades das plantas;

4 - As concentrações foliares dos nutrientes, aos 90 dias de idade, apresentou a seguinte ordem decrescente: $\mathrm{N}>\mathrm{K}>\mathrm{Ca}>\mathrm{Mg}>\mathrm{P}>\mathrm{S}$, para os clones A7, C4, D19 e N > K > Ca $=\mathrm{Mg}>\mathrm{P}>\mathrm{S}$, para o clone F40. Para o caule a ordem foi: $: \mathrm{K}>\mathrm{N}>\mathrm{Ca}>\mathrm{Mg}>\mathrm{P}>\mathrm{S}$, para todos os clones. As raízes apresentaram a seguinte ordem: $\mathrm{Mg}>\mathrm{K}>\mathrm{N}>\mathrm{Ca}>\mathrm{P}=\mathrm{S}$, para os clones A7 e $\mathrm{C} 4, \mathrm{Mg}>\mathrm{N}>\mathrm{K}>\mathrm{Ca}>\mathrm{S}>\mathrm{P}$ e $\mathrm{Mg}>\mathrm{K}>\mathrm{N}>\mathrm{Ca}>\mathrm{S}>\mathrm{P}$ para os clones D19 e F40, respectivamente.

5 - De acordo com o acúmulo total dos nutrientes, nos quatros clones de Eucalyptus estudados, as exigências nutricionais se intensificaram a partir do quadragésimo quinto dia; 
6 - Considerando a idade de maior acúmulo (90 dias de idade), o $\mathrm{N}$ foi o nutriente mais extraído, seguido em ordem decrescente pelo $\mathrm{K}, \mathrm{Mg}$, $\mathrm{Ca}, \mathrm{P}$ e S, com exceção do clone $\mathrm{A} 7$, cuja seqüência foi a seguinte: $\mathrm{N}, \mathrm{K}, \mathrm{Ca}$, $\mathrm{Mg}, \mathrm{P}$ e S. 


\section{REFERÊNCIAS BIBLIOGRÁFICAS}

ARAÚJO, S.S. Crescimento de mudas de Eucalyptus grandis e Eucalyptus urophylla em resposta a adição de NPK e gesso. Viçosa, 1994. 45 p. Dissertação (M.S.) - Universidade Federal de Viçosa.

BALLONI, E.A. Efeitos da fertilização mineral sobre o desenvolvimento do Pinus caribaea var.bahamensis (Griseb) Barret et Golfari em solo de cerrado do Estado de São Paulo. Piracicaba. 1984. 121p. Dissertação (Mestrado) - Escola Superior de Agricultura "Luiz de Queiroz", Universidade de São Paulo.

BARROS, N.F.; BRANDI, R.M.; ALFENAS, A.C. Aplicação de fertilizantes na produção de mudas de Eucalyptus saligna sm. Brasil Florestal, v.6, n.22, p. 25-29, abr./jun. 1975.

BARROS, N.F.; BRAGA, J.M.; BRANDI,R.M.; DEFELIPO, B.V. Produção de eucalipto em solos de cerrados em resposta à aplicação de NPK e de B e Zn. Revista Árvore, v.5, n.1, p. 90-103, jan./jun. 1981 a. 
BARROS, N.F; GOMES,J.M.; NOVAIS, R.F.; NEVES, J.C.R. Níveis críticos de Ca e K no solo para o crescimento de mudas de Eucalyptus grandis. In: CONGRESSO BRASILEIRO DE CIÊNCIA DO SOLO, 18., Salvador, 1981. Programas e resumos. Salvador: SBCS, 1981b. p.92

BARROS, N.F.; NOVAIS, R.F.; NEVES, J.C.L.; GOMES, J.M. Interpretação de análises químicas de solo para o crescimento de Eucalyptus spp. Revista Árvore, v.6, n.1, p 38-44, jan./jun. 1982.

BELLOTTI, A.F.J. Concentração, acumulação e exportação de nutrientes pelo Eucalyptus grandis (Hill ex Maiden) em função da idade. Piracicaba, 1979. 129p. Dissertação (Mestrado) - Escola Superior de Agricultura "Luiz de Queiroz", Universidade de São Paulo.

BRANDI, R.M.; BARROS, N.F.; VALE, A.B. Ensaio de adubação de Eucalyptus spp. Revista Ceres, v.18, n.96, p 151-158, mar./abr. 1971.

BRANDI, R.M.; CÂNDIDO, J.F. ; BARROS, N.F. ; OLIVEIRA, L.M. Efeito de adubação NPK no "amadurecimento" de mudas de Eucalyptus citriodora Hook para estabelecimento no campo, sob condições adversas de umidade de solo. Revista Ceres, v.24, n.136, p. 608-616, nov./dez. $1977 a$.

BRANDI, R.M.; CÂNDIDO, J.F. ; BRAGA, J.M.; BARROS, N.F. Efeito de adubação NPK no Desenvolvimento inicial de mudas de Eucalyptus citriodora Hook . Revista Ceres, v.24, n.134, p. 405-411, jul./ago. 1977b. 
BRASIL, U.M. ; SIMÕES, J.W. Determinação da dosagem de fertilizantes minerais para formação de mudas de eucalipto. IPEF, n.6, p. 79-95, dez. 1973.

CAMPINHOS JÚNIOR., E. ; IKEMORI, Y.K. Nova técnica para a produção de mudas de essências florestais. IPEF, n.23, p. 47-52, abr. 1983.

CAMPINHOS JÚNIOR, E.; IKEMORI, Y.K.; MARTINS, F.C.G. Determinação do meio de crescimento mais adequado à formação de mudas de Eucalyptus spp (estaca e sementes) e Pinus spp (sementes) em recipientes plásticos rígidos. In: SIMPÓSIO INTERNACIONAL: MÉTODOS DE PRODUÇÃO E CONTROLE DE QUALIDADE DE SEMENTES E MUDAS FLORESTAIS, Curitiba, 1984. Curitiba: UFPR, 1984. p.350-365.

CURLIN, J.W. Nutrient cycling as a factor in site productivity and forest fertilization. In: YOUNGBERG, C.T.; DAVEY, C.B. (Ed.) Tree growth and forest soils. Oregon: Oregon State University Press, 1970. p.313-326.

DANTAS, C.E.S. Crescimento e composição mineral de mudas de eucaliptos produzidas em composto orgânico em função de aplicação de fertilizantes minerais. Viçosa, 1992. 61p. Dissertação (M.S.) - Universidade Federal de Viçosa.

DELL, B.; MALAJEZUK, N.; GROVE, T.S. Nutrient disorders in plantation Eucalypts. Camberra: The Australian Centre for International Agricultural Research, 1995. 110p. 
FERREIRA, M.G.R. Crescimento de mudas de Eucalyptus grandis W.Hill ex Maiden, em resposta a tamanhos de embalagem, substratos e fertilização NPK. Viçosa, 1984. 44p. Dissertação (M.S.) - Universidade Federal de Viçosa.

GOMES, J.M.; SOUZA, A.L.; NETO, F.P.; REZENDE, G.C. Influência do tamanho da embalagem plástica na formação de mudas de Eucalyptus grandis W.Hill ex maiden. In: CONGRESSO FLORESTAL BRASILEIRO, 3., Manaus, 1978. Anais. Manaus, IBDF, 1978. p.387-388.

GOMES, J.M. ; COUTO, L.. Produção de mudas de Eucalyptus grandis spp no Estado de Minas Gerais - evolução e tendências. In: SIMPÓSIO INTERNACIONAL: MÉTODOS DE PRODUÇÃO E CONTROLE DE QUALIDADE DE SEMENTES E MUDAS FLORESTAIS, Curitiba, 1984. Curitiba : UFPR, 1984. p.440-458.

GOMES, J.M.; COUTO, L.; BORGES, R.C.G.; FONSECA, E.P. Efeitos de diferentes substratos na produção de mudas de Eucalyptus grandis W.Hill ex Maiden, em "Win strip". Revista Árvore, v.15, n.1, p.35-42, jan./abr. 1991.

HAAG, H.P.; MELLO, F.A.F. de; BRASIL SOBRINHO, M.O.C.; ACCORSI, W.R.; MALAVOLTA, E.; ARZOLLA, S. Estudos sobre a alimentação mineral do eucalipto; sintomas das deficiências dos macronutrientes e composição mineral. In: CONFERÊNCIA MUNDIAL DO EUCALIPTO, 2., São Paulo: Ed. Cia Paulista Estrada de Ferro, 1961a. v.2, p.926-932. 
HAAG, H.P.; MELLO, H.A.; MELLO, F.A.F. de; BRASIL SOBRINHO, M.O.C.; VEIGA, A.A.. Composição química de Eucalyptus alba Reinw e Eucalyptus grandis (Hill) Maiden: resultados preliminares. In: CONFERÊNCIA MUNDIAL DO EUCALIPTO, 2., São Paulo: Ed. Cia Paulista Estrada de Ferro, 1961b. v2, p.1329-1334.

HAAG, H.P.; SARRUGE, J.R.; OLIVEIRA, G.D. de; POGGIANI, F.; FERREIRA, C.A. Análise foliar em cinco espécies de Eucalyptus. IPEF, n.13, p. 99-116, dez. 1976.

HAAG, H.P.; SIMÕES, J.W.; OLIVEIRA, G.D. de; SARRUGE, J.R.; POGGIANI, F. Distúrbios nutricionais em Eucalyptus citriodora. IPEF, n.14, p. 59-68, jul. 1977.

JACOB, A..; UEXKULL, J. VON. Fertilización: nutrición y abonado de los cultivos tropicales y subtropicales. Amsterdam: Int. Handelmatschappiy. Meststoffen, 1961.625p.

KAUL, O.N.; SRIVASTAVA, P.B.L.; BORA, N.K.S. Nutrition studies on Eucalyptus I. Diagnosis of mineral deficiencies in Eucalyptus Hybrid seedlings. Indian Forest, v.92, n.4, p. 264-268, Apr. 1966.

KAUL, O.N.; SRIVASTAVA, P.B.L.; TANDON, V.N. Nutrition studies on Eucalyptus III. Diagnosis of mineral deficiencies in Eucalyptus grandis seedlings. Indian Forest, v.94, n.11, p. 831-834, Nov. 1968. 
KAUL, O.N.; SRIVASTAVA, P.B.L.; TANDON, V.N. Nutrition studies on Eucalyptus IV. Diagnosis of mineral deficiencies in Eucalyptus globulus seedlings. Indian Forest, v.96, n.6, p. 453-456, June 1970.

KARSCHON, R. Soil evolution affected by Eucalyptus. In: CONFERÊNCIA MUNDIAL DO EUCALIPTO, 2., São Paulo, 1961. Resumos e documentos. São Paulo, Ed. Cia Paulista Estrada de Ferro, 1961. v.2, p. 897910.

KIEHL, E.J. Fertilizantes orgânicos, Piracicaba: Ed. Agrônomica "Ceres" Ltda., 1985. 492p.: il.

KRAMER, P.J. ; KOSLOWSKI, T.T. Mineral nutrition and salt absorption Physiology of trees. New York: McGraw-Hill Book, 1960. 642p.

LOCATELLI, M. Efeito de formas, fontes e doses de Nitrogênio sobre o crescimento e composições mineral de mudas de Eucalyptus grandis $\mathrm{W}$. Hill (ex Maiden) Viçosa, 1984. 64p. Dissertação (M.S.) - Universidade Federal de Viçosa.

LOCATELLI, M., BARROS, N.F.; BRANDI, R.M.; NEVES, J.C.L. ; GOMES, J.M. Efeito de fontes e doses de nitrogênio no crescimento de mudas de eucaliptos. Revista Árvore, v.8, n.1, p.39-52, jan./jun. 1984a.

LOCATELLI, M., BARROS, N.F.; NEVES, J.C.L.. ; NOVAIS, R.F. Efeito de formas de nitrogênio sobre o crescimento e composição mineral de mudas de eucaliptos. Revista Árvore, v.8, n.1, p. 53-69, jan./jun. 1984b. 
MACHADO, J.O.; AGUIAR, I.B.; BANZATTO, D.A.; VALERI, S.V.; MIRANDA, R.; SILVA, E.F. Efeito de inócuos de fungos endomicorrizicos sobre o desenvolvimento de mudas de Eucalyptus citriodora Hook em diferentes substratos. Brasil Florestal, v.15, n.63, p. 25-32, jan./mar. 1988.

MELLO, F.A.F.; BRASIL SOBRINHO, M.O.C.; MELLO, H.A.; VEIGA, A.A. ; ARZOLLA, S. Efeitos da adubação nitrogenada fosfatada e potássica sobre o "stand" em eucaliptos (Eucalyptus alba Reinw). In: CONFERÊNCIA MUNDIAL DO EUCALIPTO, 2, São Paulo, 1961. Resumos e documentos. São Paulo: Ed. Cia Paulista Estrada de Ferro, 1961. v.2, p. 933-937.

MORAIS, E.J.; BARROS, N.F.; NOVAIS, R.F.; BRANDI, R.M. Biomassa e eficiência nutricional de espécies de eucalipto em duas regiões bioclimáticas de Minas Gerais. Revista Brasileira de Ciência do Solo, v. 14, n.3, p.353-362, set./dez., 1990

NEVES, J.C.L. Aspectos nutricionais em mudas de Eucalyptus spp. tolerância o Alumínio e níveis críticos de fósforo no solo. Viçosa, 1983. 87p. Dissertação (M.S.) - Universidade Federal de Viçosa.

NEVES, J.C.L. ; BARROS, N.F.; NOVAIS, R.F. ; ANJOS, J.L. dos. Efeito do alumínio em amostras de dois latossolos sob cerrado sobre o crescimento e absorção de nutrientes de mudas de Eucalyptus spp. Revista Árvore, v.6, n.1, p. 17-28, jan./jun. 1982. 
NEVES, J.C.L.; GOMES, J.M. ; NOVAIS, R.F. Fertilização mineral de mudas de eucalipto. In: BARROS, N.F. ; NOVAIS, R.F. (Ed.) Relação soloeucalipto. Viçosa: Ed. Folha de Viçosa, 1990. p. 99-126.

NOVAIS, R.F.; ROCHA, D.; BORGES, E.E.L.. Calagem e adubação mineral na produção de mudas de eucalipto (Eucalyptus grandis W.Hill ex Maiden). I. Efeito da calagem e dos nutrientes N.P. e K. Revista Árvore, v.3, n.2, p. 121-134, jul./dez. 1979.

NOVAIS, R.F.; REGO, A.K. ; GOMES,J.M. Nível crítico de potássio no solo e na planta para o crescimento de mudas de Eucalyptus grandis W.Hill ex Maiden e de Eucalyptus cloeziana F. Muell. Revista Árvore, v.4, n.1, p.14-23, jan./jun. 1980.

PEREIRA, A. R.; BARROS, F.; ANDRADE, D. C.; CAMPOS, P.T.A. Concentração e distribuição de nutrientes em Eucalyptus grandis em função da idade, cultivado na região do cerrado. Brasil Florestal, v.14, n.59, p. 27-37, jul./set. 1984.

PEREIRA, A.R. Biomassa e ciclagem de nutrientes minerais em povoamentos jovens de Eucalyptus grandis W.Hill (ex Maiden) e Eucalyptus urophylla, em região de cerrado. Viçosa, 1990. 167p. Dissertação (M.S.) - Universidade Federal de Viçosa. 
POGGIANI, F.; COUTO, H. T. Z. Biomass and nutrients estimates in short rotation intensively cultured plantation of Eucalyptus grandis. IPEF, n. 23, p.37-42, abr. 1983.

POGGIAN,I F.; COUTO, H. T. Z.; CORRADINI, L.; FAZZIO, E.C.M. Exportação de biomassa e nutrientes através da explotação dos troncos e das copas de um povoamento de Eucalyptus grandis. IPEF, n. 25, p.37-39, dez. 1983.

PREZOTTI, L.C. Nível crítico de potássio no solo para a produção de mudas de eucalipto. Viçosa, 1985. 45p. Dissertação (M.S.) - Universidade Federal de Viçosa.

REIS, M. G. F.; BARROS, N. F.; KIMMINS, J. P. Acúmulo de biomassa numa seqüência de idades de Eucalyptus grandis W. Hill (ex Maiden) plantado no cerrado, em duas áreas com diferentes produtividades, em Minas Gerais. Revista Árvore, v.9, n.2, p.149-162, jul./dez. 1985.

REIS, M. G. F.; BARROS, N. F.; KIMMINS, J. P. Acúmulo de nutrientes numa seqüência de idades de Eucalyptus grandis W. Hill (ex Maiden) plantado no cerrado, em duas áreas com diferentes produtividades, em Minas Gerais. Revista Árvore, v.11, n.1, p.1-15, jan.jun. 1987.

REIS, M. G. F.; BARROS, N. F. Ciclagem de nutrientes em plantios de eucalipto. In: BARROS, N. F.; NOVAIS, R. F. (Ed.) Relação soloeucalipto. Viçosa, Ed. Folha de Viçosa, 1990. p.265-301. 
ROCHA FILHO, J.V.C.; HAAG, H.P.; OLIVEIRA, G.D. Deficiência de macronutrientes, boro e ferro em Eucalyptus urophylla. Anais da Escola Superior de Agricultura "Luiz de Queiroz", v.35, p.19-34, 1978.

SANTANA, R.L. Crescimento e eficiência nutricional de procedências de Eucalyptus grandis e Eucalyptus saligna em sítios do Estado de São Paulo, Viçosa, 1994. 73p. Dissertação (M.S.) - Universidade Federal de Viçosa.

SARRUGE, J.R. ; HAAG, H.P. Análise química em plantas, Piracicaba: ESALQ, 1974. 55p.

SILVA, H.D. da Biomassa e aspectos nutricionais de cinco espécies do gênero Eucalyptus, plantadas em solo de baixa fertilidade. Piracicaba. 1983. 91p. Tese (Mestrado) - Escola Superior de Agricultura "Luiz de Queiroz", Universidade de São Paulo.

SILVEIRA, R.L.V.A.; LUCA, E.F. ; SHIBATA, F. Absorção de macronutrientes pelas mudas de Eucalyptus grandis em condição de viveiro. In: : CONGRESSO BRASILEIRO DE CIÊNCIA DO SOLO, 25, Viçosa, 1995. Resumos expandidos. Viçosa, SBCS; UFV, 1995. p. 839-41.

SIMÕES, J.W. Métodos de produção de mudas de eucalipto. IPEF, n.1, p.101-116, dez. 1970.

TABATABAI, M.A. ; BREMNER, J.M.A. Simple turbimetria method of determining total sulfur in plant materials. Agronomy Journal, v.62, n.5, p. 805 - 806, Sept/Oct. 1970. 
TEIXEIRA, R.C. ; BARROS, N.F.; COSTA, L.M. ; CAMPOS, J.C.C.; LEAL, P.G.L.. Biomassa e conteúdo de nutrientes de duas espécies de eucalipto em diferentes ambientes do médio Rio Doce, M.G. Revista Árvore, v.13, n.1, p.34-50, jan./jun., 1989.

WILL, G.M. Some notes on nutrient deficiency Eucalyptus spp. In: CONFERENCIA MUNDIAL DO EUCALIPTO, 2., São Paulo: Ed. Cia Paulista Estrada de Ferro, 1961. v.2, p.938-941. 
APÊNDICE 
Tabela 1A. Coeficiente de variação (CV) e diferença média significativa (DMS) para acúmulo de nitrogênio, nas diversas partes da planta, nos clones estudados, em função da idade (dias).

\begin{tabular}{lcccccccc}
\hline $\begin{array}{l}\text { Partes da } \\
\text { Planta }\end{array}$ & \multicolumn{2}{c}{ Clone A7 } & \multicolumn{2}{c}{ Clone C4 } & Clone D19 & \multicolumn{2}{c}{ Clone F40 } \\
\cline { 2 - 9 } & CV & DMS & CV & DMS & CV & DMS & CV & DMS \\
\hline Folhas & 14,05 & 1,15 & 10,99 & 0,76 & 7,94 & 0,58 & 16,48 & 1,32 \\
Caule & 12,26 & 0,85 & 13,35 & 0,97 & 11,70 & 0,90 & 6,74 & 0,55 \\
Raizes & 14,89 & 0,20 & 16,63 & 0,28 & 9,32 & 0,16 & 10,15 & 0,13 \\
\hline Total & 10,53 & 1,49 & 10,36 & 1,42 & 8,06 & 1,17 & 7,90 & 1,20 \\
\hline
\end{tabular}

Tabela 2A. Coeficiente de variação (CV) e diferença média significativa (DMS) para acúmulo de fósforo, nas diversas partes da planta, nos clones estudados, em função da idade (dias).

\begin{tabular}{lrccccccc}
\hline $\begin{array}{l}\text { Partes da } \\
\text { Planta }\end{array}$ & \multicolumn{2}{c}{ Clone A7 } & \multicolumn{2}{c}{ Clone C4 } & \multicolumn{2}{c}{ Clone D19 } & \multicolumn{2}{c}{ Clone F40 } \\
\cline { 2 - 9 } & CV & DMS & CV & DMS & CV & DMS & CV & DMS \\
\hline Folhas & 12,07 & 0,10 & 10,49 & 0,07 & 8,05 & 0,07 & 13,60 & 0,12 \\
Caule & 9,60 & 0,13 & 12,70 & 0,18 & 15,82 & 0,25 & 12,33 & 0,15 \\
Raízes & 23,24 & 0,04 & 17,30 & 0,03 & 22,53 & 0,04 & 32,06 & 0,04 \\
\hline Total & 9,09 & 0,19 & 11,04 & 0,23 & 12,69 & 0,30 & 7,96 & 0,16
\end{tabular}


Tabela 3A. Coeficiente de variação (CV) e diferença média significativa (DMS) para acúmulo de potássio, nas diversas partes da planta, nos clones estudados, em função da idade (dias).

\begin{tabular}{llllllllll}
$\begin{array}{l}\text { Partes da } \\
\text { Planta }\end{array}$ & \multicolumn{2}{c}{ Clone A7 } & \multicolumn{2}{c}{ Clone C4 } & \multicolumn{2}{c}{ Clone D19 } & \multicolumn{2}{c}{ Clone F40 } \\
\cline { 2 - 9 } & CV & DMS & CV & DMS & CV & DMS & CV & DMS \\
\hline Folhas & 13,50 & 0,61 & 11,16 & 0,44 & 11,04 & 0,54 & 9,45 & 0,53 \\
Caule & 9,31 & 0,72 & 11,28 & 1,03 & 17,70 & 1,72 & 9,18 & 0,73 \\
Raízes & 16,61 & 0,25 & 19,89 & 0,35 & 13,39 & 0,23 & 12,14 & 0,15 \\
\hline Total & 9,12 & 1,12 & 8,99 & 1,21 & 12,95 & 1,90 & 6,42 & 0,84
\end{tabular}

Tabela 4A. Coeficiente de variação (CV) e diferença média significativa (DMS) para acúmulo de cálcio, nas diversas partes da planta, nos clones estudados, em função da idade (dias).

\begin{tabular}{lcccccccc}
\hline $\begin{array}{l}\text { Partes da } \\
\text { Planta }\end{array}$ & \multicolumn{2}{c}{ Clone A7 } & \multicolumn{2}{c}{ Clone C4 } & Clone D19 & \multicolumn{2}{c}{ Clone F40 } \\
\cline { 2 - 9 } & CV & DMS & CV & DMS & CV & DMS & CV & DMS \\
\hline Folhas & 15,59 & 0,38 & 12,36 & 0,26 & 9,85 & 0,23 & 9,94 & 0,22 \\
Caule & 26,53 & 1,33 & 12,65 & 0,51 & 12,90 & 0,66 & 6,90 & 0,39 \\
Raízes & 22,82 & 0,10 & 12,92 & 0,06 & 17,39 & 0,09 & 10,70 & 0,04 \\
\hline Total & 19,23 & 1,39 & 9,88 & 0,59 & 10,35 & 0,75 & 5,83 & 0,45 \\
\hline
\end{tabular}


Tabela 5A. Coeficiente de variação (CV) e diferença média significativa (DMS) para acúmulo de magnésio, nas diversas partes da planta, nos clones estudados, em função da idade (dias).

\begin{tabular}{lcccccccc}
\hline $\begin{array}{l}\text { Partes da } \\
\text { Planta }\end{array}$ & \multicolumn{2}{c}{ Clone A7 } & \multicolumn{2}{c}{ Clone C4 } & \multicolumn{2}{c}{ Clone D19 } & \multicolumn{2}{c}{ Clone F40 } \\
\cline { 2 - 9 } & CV & DMS & CV & DMS & CV & DMS & CV & DMS \\
\hline Folhas & 14,68 & 0,38 & 18,85 & 0,36 & 9,87 & 0,23 & 12,40 & 0,26 \\
Caule & 13,07 & 0,28 & 14,85 & 0,23 & 10,57 & 0,24 & 11,07 & 0,32 \\
Raízes & 40,50 & 0,94 & 42,36 & 0,92 & 19,88 & 0,51 & 25,92 & 0,53 \\
\hline Total & 10,94 & 1,11 & 19,50 & 0,90 & 10,23 & 0,61 & 10,03 & 0,61
\end{tabular}

Tabela 6A. Coeficiente de variação (CV) e diferença média significativa (DMS) para acúmulo de enxofre, nas diversas partes da planta, nos clones estudados, em função da idade (dias).

\begin{tabular}{lcccccccc}
\hline $\begin{array}{l}\text { Partes da } \\
\text { Planta }\end{array}$ & \multicolumn{2}{c}{ Clone A7 } & \multicolumn{2}{c}{ Clone C4 } & \multicolumn{2}{c}{ Clone D19 } & \multicolumn{2}{c}{ Clone F40 } \\
\cline { 2 - 9 } & CV & DMS & CV & DMS & CV & DMS & CV & DMS \\
\hline Folhas & 15,42 & 0,11 & 8,73 & 0,04 & 16,10 & 0,08 & 14,40 & 0,09 \\
Caule & 14,53 & 0,14 & 13,87 & 0,09 & 13,17 & 0,10 & 25,28 & 0,31 \\
Raízes & 22,05 & 0,04 & 18,25 & 0,03 & 18,90 & 0,04 & 30,88 & 0,05 \\
\hline Total & 12,43 & 0,20 & 9,73 & 0,11 & 11,03 & 0,14 & 17,46 & 0,31 \\
\hline
\end{tabular}

